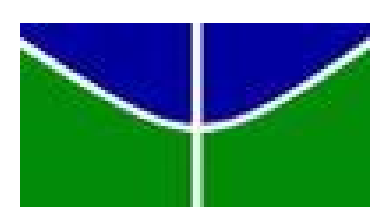

UNIVERSIDADE DE BRASÍLIA - UnB

FACULDADE DE ECONOMIA, ADMINISTRAÇÃO, CONTABILIDADE E GESTÃO DE POLÍTICAS PÚBLICAS - FACE

PROGRAMA DE PÓS-GRADUAÇÃO EM ADMINISTRAÇÃO - PPGA

MESTRADO PROFISSIONAL EM ADMINISTRAÇÃO

ALEXANDRE POZZA URNAU SILVA

IMPLEMENTAÇÃO DE UM SISTEMA DE INFORMAÇÃO NO ATENDIMENTO DE DETERMINAÇÃO JUDICIAL PARA FORNECIMENTO DE MEDICAMENTOS NA UNIÃO: BARREIRAS, FACILITADORES E RESULTADOS INICIAIS.

BRASÍLIA

2016 

NA UNIÃO: BARREIRAS, FACILITADORES E RESULTADOS INICIAIS.

Dissertação apresentada ao Programa de PósGraduação em Administração da Universidade de Brasília, como requisito parcial para a obtenção do grau de Mestre em Administração.

Orientadora: Profa. Dra. Tatiane Paschoal.

BRASÍLIA 
ALEXANDRE POZZA URNAU SILVA

\section{IMPLEMENTAÇÃO DE UM SISTEMA DE INFORMAÇÃO NO ATENDIMENTO DE DETERMINAÇÃO JUDICIAL PARA FORNECIMENTO DE MEDICAMENTOS NA UNIÃO: BARREIRAS, FACILITADORES E RESULTADOS INICIAIS}

Dissertação apresentada ao Programa de Pós-Graduação em Administração da Faculdade de Economia, Administração, Contabilidade e Gestão Pública da Universidade de Brasília (PPGA/FACE/UnB) como requisito parcial à obtenção do grau de Mestre em Administração Pública. Aprovada em de de 2016. Banca examinadora constituída por:

Profa. Dra. Tatiane Paschoal - Orientadora

MPA/PPGA/FACE/UnB

Profa. Dr. Francisco Antonio Coelho Junior - Membro Interno MPA/PPGA/FACE/UnB

Profa. Dra. Darcy Mitiko Mori Hanashiro - Membro Externo UPM

Prof. Dr. Solange Alfinito - Suplente MPA/PPGA/FACE/UnB 


\section{AGRADECIMENTOS}

À Deus por guiar o meu caminho, ter me concedido força e por ter me proporcionado momentos que me desafiaram e me fizeram crescer como gestor público e cidadão.

À minha esposa, Laiana da Silva Dias, pelo carinho e compreensão pelos momentos de ausência e por estar ao meu lado em todos os momentos do mestrado, acreditando em meu potencial e me apoiando.

Aos meus pais, Ana Helena Pozza Urnau Silva e José Roberto Cunha Silva, que sempre acreditaram em minha capacidade e por toda orientação e apoio que recebi e recebo ao longo de minha vida.

Ao meu irmão, Julio Roberto Pozza Urnau Silva, por ajudar em todos os momentos de dificuldades.

À minha orientadora, Dra. Tatiane Paschoal, pelos ensinamentos, por toda a sua disposição, boa vontade, compreensão e pelo apoio inestimável.

Aos professores Dr. Francisco Antonio Coelho Junior e Dra. Darcy Mitiko Mori Hanashiro, pelas valiosas contribuições e ensinamentos.

Ao meu amigo, Israel Silva de Moraes, que sempre esteve ao meu lado me auxiliando e ensinando.

Aos demais professores e colaboradores do PPGA, obrigada pelo esforço na formação de mestres e doutores capacitados.

Aos colegas do PPGA, sou grato pelos momentos de aprendizado, de dificuldades, de dúvidas, de anseios e também de diversão que compartilhei com vocês. 


\section{RESUMO}

A presente dissertação teve como objetivo geral analisar a implementação do sistema PECJUDICIAL no atendimento das determinações judiciais em que a União é obrigada a fornecer insumos para a saúde. Os objetivos específicos foram descrever barreiras e facilitadores para a implementação do PECJUDICIAL na organização; realizar a análise comparativa dos resultados preliminares dos custos por atividade envolvidos no atendimento da determinação judicial pré e pós adoção do PECJUDICIAL; e realizar a avalição dos resultados preliminares da utilização do sistema PECJUDICIAL na perspectiva dos usuários internos. Para alcance desses objetivos, foram realizados o levantamento e a categorização das barreiras e dos facilitadores que impactaram na implementação do Sistema, a realização da análise de custos por atividade através da metodologia Active Based Cost e a avaliação do Sistema na perspectiva do usuário através das normas estabelecidos pela ISO/IEC 25000 Software Quality Requirements and Evaluation (SQuaRE). Os resultados encontrados por meio das entrevistas sugerem que as barreiras políticas e os facilitadores políticos e de recursos impactaram de forma mais relevante na implementação do Sistema. Do ponto de vista de custos, o levantamento realizado sugere que a implementação do Sistema trouxe a economia de $12 \%$ nos custos totais no cumprimento da determinação judicial. Na perspectiva dos usuários internos, todas as características propostas pelas normas estabelecidas pela ISSO/IEC 25000 foram avaliadas positivamente, apontando que a característica usabilidade deve ser a prioridade imediata do gestor na implementação das melhorias ao sistema. As implicações teóricas e práticas e as limitações do estudo são apresentadas, bem como uma agenda de pesquisa.

Palavra-chave: Avaliação de sistema. Active Based Cost. Ferramenta de Gestão. Políticas Públicas. Tecnologia da Informação e Comunicação. 


\begin{abstract}
The present study had as general objective to analyze the implementation of PECJUDICIAL system in the fulfillment of court determinations in which Union is obliged to provide inputs for health. The specific objectives were to describe barriers and facilitators for the implementation of PECJUDICIAL in the organization; to carry out the comparative analysis of the initial results of the costs per activity involved in the fulfillment of the court determination before and after adoption of PECJUDICIAL; and to evaluate the initial results of the use of PECJUDICIAL system from the perspective of internal users. In order to achieve these objectives, the survey and the categorization of the barriers and facilitators that impacted the implementation of the System, the analysis of costs per activity through the Active Based Cost methodology and the evaluation of the System from the perspective of the user through the norms established by ISO / IEC 25000 - Software Quality Requirements and Evaluation (SQuaRE) were carried out. The results found through the interviews suggest that political barriers and political/resource facilitators had a more relevant impact on the implementation of the System. From the point of view of costs, the survey suggests that the implementation of the System brought the economy of $12 \%$ in the total costs in the implementation of the court determinations. From the perspective of the internal users, all the characteristics proposed by the norms established by ISSO / IEC 25000 were evaluated positively, pointing out that the characteristic usability should be the immediate priority of the manager in the implementation of the improvements to the system. The theoretical and practical implications and limitations of the study as well as a research agenda are presented.
\end{abstract}

Keyword: System evaluation. Active Based Cost. Management Tool. Public policy. Technology of Information and Communication. 


\section{LISTA DE FIGURAS}

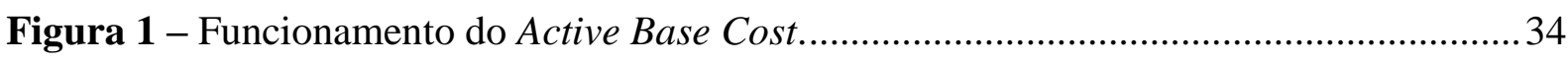

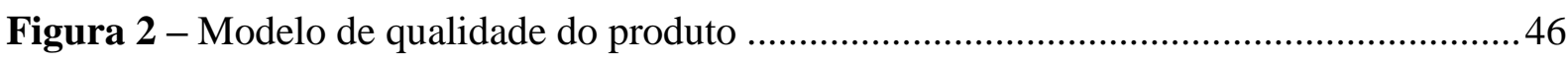

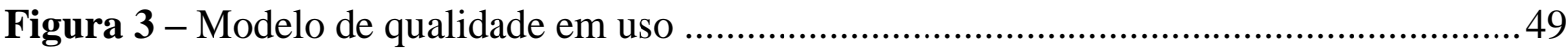

Figura 4 - Modelo de referência para as barreiras à implantação de TI nas organizações ......53

Figura 5 - Avaliação das características: adequação funcional, confiabilidade, usabilidade, eficiência de desempenho, compatibilidade e segurança do PECJUDICIAL ..........................77 Figura 6 - Estratificação dos itens em desacordo das características de qualidade do

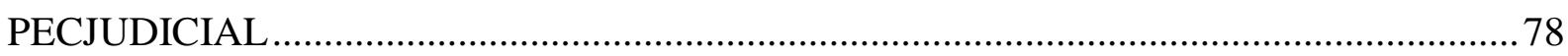




\section{LISTA DE QUADROS}

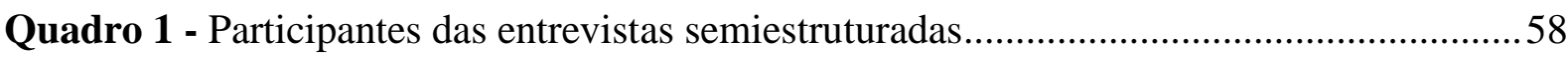

Quadro 2 - Respondentes do questionário para avaliação do PECJUDICIAL ......................62

Quadro 3 - Técnicas adotadas para alcance dos objetivos da pesquisa.................................63

Quadro 4 - Principais barreiras à implementação do sistema................................................ 67

Quadro 5 - Atividades relevantes identificadas por setor/equipe antes do PECJUDICIAL .. 79

Quadro 6 - Principais atividades após a adoção do PECJUDICIAL .......................................96 


\section{LISTA DE TABELAS}

Tabela 1 - Fatores que influenciaram a implementação do sistema ....................................66

Tabela 2 - Principais barreiras facilitadoras à implementação do sistema .............................6 68

Tabela 3 - Distribuição das respostas relativas à Adequação Funcional do PECJUDICIAL.. 69

Tabela 4 - Distribuição das respostas relativas à Confiabilidade do PECJUDICIAL ..............71

Tabela 5 - Distribuição das respostas relativas à Usabilidade do PECJUDICIAL.................. 72

Tabela 6 - Distribuição das respostas relativas à Eficiência do Desempenho do PECJUDICIAL

Tabela 7 - Distribuição das respostas relativas à Compatibilidade PECJUDICAL ................ 75

Tabela 8 - Distribuição das respostas relativas à Segurança do PECJUDICIAL .....................76

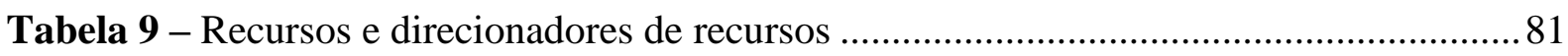

Tabela 10 - Percentual de tempo gasto por atividades - Coordenação e ECAP ..................... 83

Tabela 11 - Percentual de tempo gasto por atividades - ECOMP ........................................ 84

Tabela 12- Percentual de tempo gasto por atividades - ECODE ........................................ 84

Tabela 13 - Percentual de tempo gasto por atividades - EGET …...................................... 85

Tabela 14- Percentual de tempo gasto por atividades - SADM e CEOF ............................... 86

Tabela 15 - Cargos/Funções dos servidores/consultores e respectiva remuneração................87

Tabela 16 - Distribuição dos custos de remuneração mensal do funcionário 45 ao percentual de

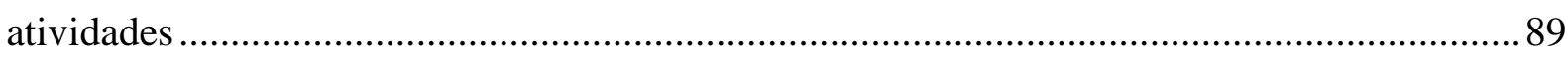

Tabela 17 - Apuração do custo das atividades - Geral .......................................................... 91

Tabela 18 - Custos das atividades por equipe / setor e percentual ........................................95

Tabela 19 - Percentual de tempo gasto por atividades após adoção do sistema - Coordenação

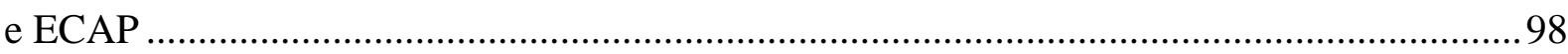

Tabela 20 - Percentual de tempo gasto por atividades após adoção do sistema - ECOMP....99

Tabela 21 - Percentual de tempo gasto por atividades após adoção do sistema -ECODE.....99

Tabela 22- Percentual de tempo gasto por atividades após adoção do sistema - Protocolo e EGET 100

Tabela 23 - Percentual de tempo gasto por atividades após adoção do sistema - SADM e CEOF

Tabela 24 - Apuração do custo das atividades mensais após a adoção do sistema - Geral.. 102

Tabela 25 - Análise comparativa dos custos das atividades por equipe / divisão. 105 


\section{LISTA DE ABREVIATURAS E SIGLAS}

\begin{tabular}{|c|c|}
\hline $\mathrm{ABC}$ & Active Base Cost \\
\hline $\mathrm{ABNT}$ & Associação Brasileira de Normas Técnicas \\
\hline BACEN & Banco Central do Brasil \\
\hline BANESPA & Banco do Estado de São Paulo \\
\hline CDJU & Coordenação de Compra por Determinação Judicial \\
\hline $\mathrm{CEOF}$ & Coordenação de Execução Orçamentária e Financeira \\
\hline CGIES & $\begin{array}{l}\text { Coordenação de Análise das Contratações de Insumos Estratégicos } \\
\text { para a Saúde }\end{array}$ \\
\hline DASP & Departamento Administrativo do Serviço Público \\
\hline DATASUS & Departamento de Informática do Sistema Único de Saúde \\
\hline DLOG & Departamento de Logística em Saúde \\
\hline E-GOV & Governo Eletrônico \\
\hline ECAP & Equipe de Cadastro e Análise Farmacêutica \\
\hline ECODE & Equipe de Controle e Devolução de Processos \\
\hline ECOMP & Equipe de Compras e Publicação \\
\hline EGET & Equipe de Gestão \\
\hline EUA & Estados Unidos da América \\
\hline GR & Gestão por Resultados \\
\hline IEC & International Electrotechnical Commission \\
\hline ISO & International Organization for Standardization \\
\hline MS & Ministério da Saúde \\
\hline NGP & Nova Gestão Pública \\
\hline NPM & New Public Management \\
\hline ONU & Organização das Nações Unidas \\
\hline PDRAE & Plano Diretor de Reforma do Aparelho do Estado \\
\hline PECJUDICIAL & $\begin{array}{l}\text { Processo Eletrônico de Compra para Atendimento de Determinação } \\
\text { Judicial }\end{array}$ \\
\hline PGE & Programas de Governo Eletrônico \\
\hline SAS & Secretaria de Atenção à Saúde \\
\hline SADM & Serviço de Armazenamento e Distribuição de Medicamentos \\
\hline SCTIE & Secretaria de Ciência e Tecnologia e Insumos Estratégicos \\
\hline SLTI & Secretaria de Logística e Tecnologia da Informação \\
\hline SEBRAE & Serviço Brasileiro de Apoio às Micro e Pequenas Empresas \\
\hline SQuaRE & Software Quality Requirements and Evaluation \\
\hline SUS & Sistema Único de Saúde \\
\hline TI & Tecnologia da Informação \\
\hline TIC & Tecnologia da Informação e Comunicação \\
\hline
\end{tabular}




\section{SUMÁRIO}

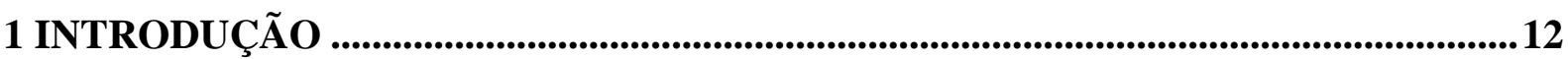

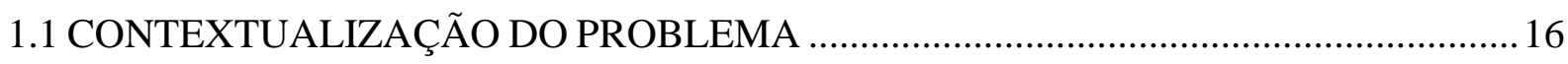

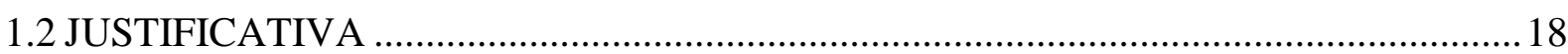

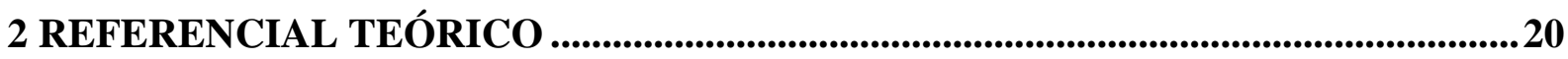

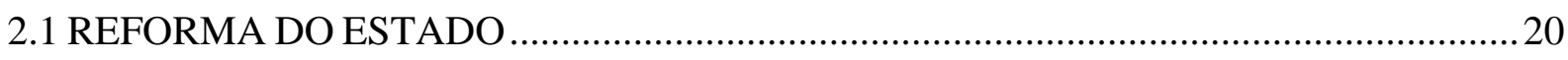

2.1.1 Modelo Patrimonialista ........................................................................................................21

2.1.2 Modelo Burocrático ................................................................................................................22

2.1.3 Modelo Gerencial e Nova Gestão Pública ........................................................................28

2.1.4 Gestão por Resultados.........................................................................................31

2.2 ANÁLISES DE CUSTOS COMO FERRAMENTA DE AUXÍLIO À GESTÃO POR

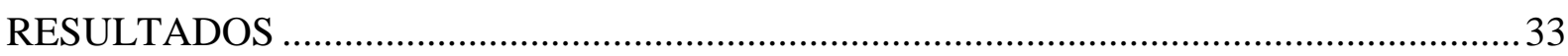

2.3 TECNOLOGIA DA INFORMAÇÃO E COMUNICAÇÃO ……………………….......... 37

2.3.1 O Uso de Tecnologia de Informação e Comunicação em Organizações Públicas ...39

2.3.2 E-GOV ou Governo Eletrônico no Brasil.........................................................................41

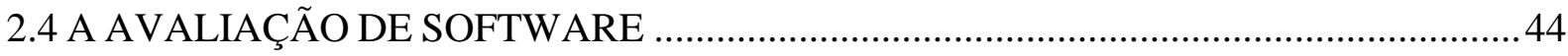

2.5 A TECNOLOGIA DA INFORMAÇÃO E COMUNICAÇÃO E A NOVA GESTÃO

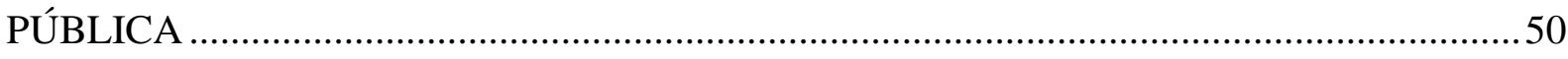

2.5.1 Barreiras à Implantação das TICs nas Organizações Públicas ...................................52

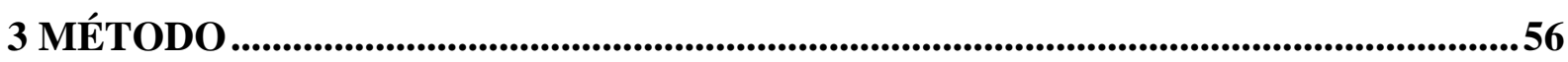

3.1 SOBRE O LOCAL DA PESQUISA E O PECJUDICIAL …………………………….....56

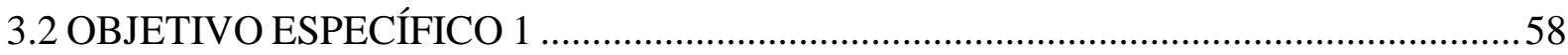

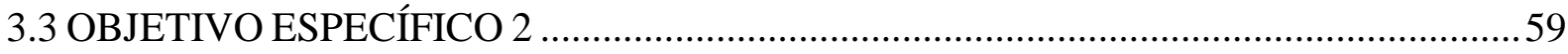

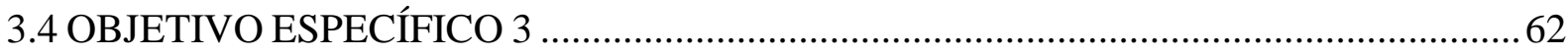

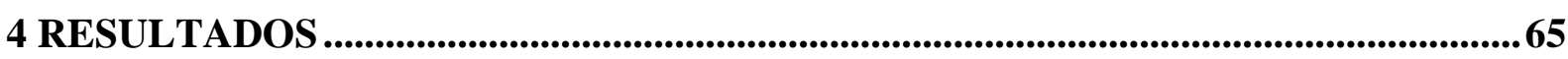

4.1 BARREIRAS E FACILITADORES NA IMPLEMENTAÇÃO DO SISTEMA

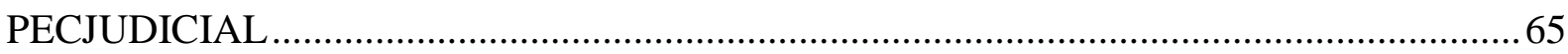

4.2 AVALIAÇÃO DO SISTEMA PECJUDICIAL NA PERSPECTIVA DOS USUÁRIOS

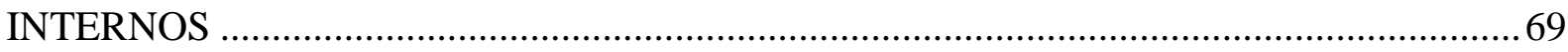

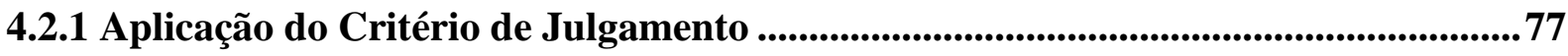

4.3 MODELO DE CUSTEIO ACTIVE BASE COST - ABC ANTES DA IMPLEMENTAÇÃO

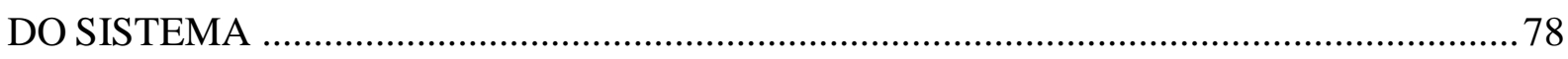

4.3.1 Atribuição dos Custos dos Recursos às Atividades ..........................................................82 
4.3.2 Modelo de Custeio Active Base Cost - ABC Após a Adoção do Sistema ...................96 4.3.3 Atribuição dos Custos dos Recursos às Atividades Após a Adoção do Sistema ...... 98

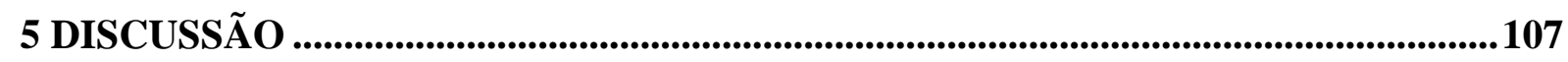

5.1 BARREIRAS E FACILITADORES À IMPLEMENTAÇÃO DO SISTEMA

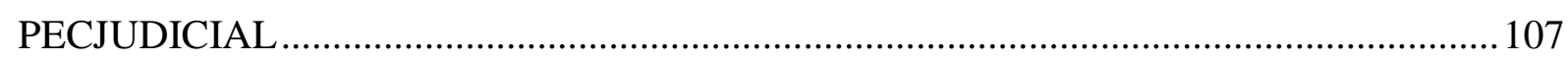

5.2 AVALIAÇÃO PRELIMINAR DO SISTEMA PECJUDICIAL NA PERSPECTIVA DOS USUÁRIOS INTERNOS.

5.3 AVALIAÇÃO DOS CUSTOS POR ATIVIDADES ANTES E APÓS IMPLEMENTAÇÃO

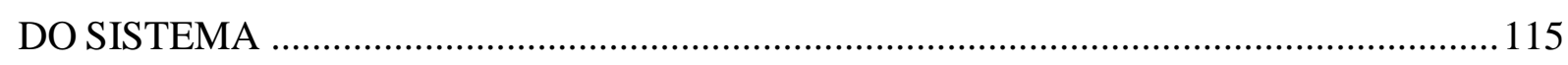

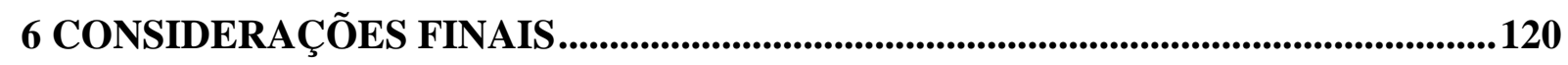

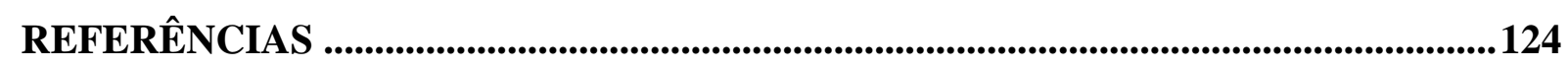

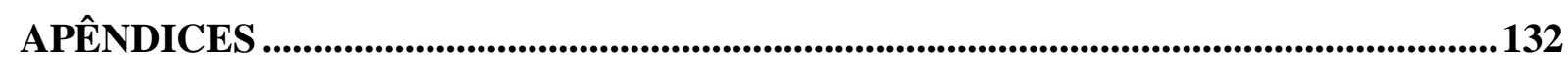

APÊNDICE A - PERGUNTAS SEMIESTRUTURADAS................................................132

APÊNDICE B - QUESTIONÁRIO PARA AVALIAÇÃo DO SISTEMA PELOS

USUÁRIOS: OBJETIVO 4 _...........................................................................................133

APÊNDICE C - FLUXOGRAMA DAS ATIVIDASDES INFORMATIZADAS PELO

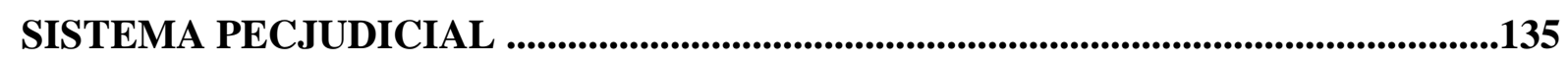




\section{INTRODUÇÃ̃o}

Devido às constantes alterações nos panoramas político, econômico, social, tecnológico, cultural e demográfico, os gestores públicos devem constantemente estar adaptados ao meio que os cerca, bem como buscar inovações, a fim de atender as demandas de cada mercado onde a organização está inserida. Nos últimos anos, os avanços identificados nos mais diversos panoramas têm exigido que o setor privado estivesse em processo de constante aprendizagem, assegurando a manutenção da eficiência e eficácia de suas atividades em seu respectivo ambiente organizacional. No entanto, os efeitos da complexidade deste ambiente não se manifestam somente nas atividades do setor privado, mas acarretam grande impacto também no setor público e em suas instituições, que sentem a pressão por reestruturar os seus processos gerenciais para atender às expectativas cada vez mais exigentes do seu cliente cidadão.

Na segunda metade do século XX tem-se o advento da era do conhecimento e da informação, caracterizada por um período de grandes transformações tecnológicas, sociais e econômicas, que impuseram novos padrões de gestão às organizações públicas e privadas. As organizações passaram e passam por um processo de reestruturação produtiva com base no desenvolvimento científico e tecnológico (GUIMARÃES, 2000).

Neste contexto, a chamada Nova Gestão Pública (NGP) (em inglês, New Public Management - NPM) vem permeando as discussões em diversos países em torno das reformas da gestão do Estado, dando ênfase ao aumento da eficiência, aos resultados e ao acesso e à utilização dos serviços (ANDREWS; KOUZMIN, 1998). No setor público, o desafio da NGP é de transformação das estruturas burocráticas, hierarquizadas, autorreferidas e pouco orientadas ao atendimento do cidadão em organizações flexíveis, empreendedoras e voltadas para a satisfação dos anseios dos cidadãos. As inovações na Administração Pública necessitam estar em sintonia com a busca da eficiência e da qualidade na prestação de serviços públicos (PEREIRA, 2015). 
O principal foco da NGP é o modelo de Gestão por Resultados (GR), que consiste em direcionar o foco e os esforços das práticas organizacionais para atingir os resultados pretendidos, visando a otimização do desempenho organizacional (PEREIRA, 2015). Neste sentido, tem-se como principal objetivo atender as necessidades dos usuários - os beneficiários das políticas públicas.

Com a evolução do uso de computadores, dos meios de comunicação e o advento da internet, definiram-se novas formas de relacionamento entre o Estado e a sociedade, com base na Tecnologia de Informação e Comunicação (TIC). A utilização das TICs tem por norte a prestação de serviços, com a revisão e a integração de processos, com maior eficiência e eficácia, além de criar mecanismos de relações digitais com o cliente (LAIA et al, 2011).

A Administração Pública no Brasil vem utilizando ferramentas de TIC para fornecer serviços e produtos de forma mais eficiente, democrática, com maior transparência e que atendam aos anseios de seus clientes cidadãos - características de um modelo gerencial. Tais tecnologias mudam a abordagem da gestão pública, devendo-se considerar que os cidadãos, as empresas e as demais organizações querem ter acesso às ações governamentais de modo cada vez mais rápido e descomplicado (PEREIRA, 1997).

As condições que estimularam e, ao mesmo tempo, pressionaram os governos a encontrar novos caminhos para a prestação de seus serviços foram decorrentes não somente da dimensão fiscal que permeou as discussões sobre a crise e a reforma dos Estados, mas também das dimensões social e administrativa (FRANZESE; ABRUCIO, 2009). A utilização de tecnologias atende às expectativas tanto na dimensão relacionada à crise fiscal, pela possível redução de custos e pelo aumento de receitas que pode proporcionar, quanto relacionada à vertente administrativa, pela introdução de inovações e mudanças na estrutura, processos internos e cultura do aparato estatal. 
Como resultado destas duas forças - a revisão das estruturas de governo e as inovações em Tecnologia da Informação (TI) - diversos governos têm feito novos arranjos, de modo a responder as novas expectativas da sociedade. Tal caminho, porém, não parece ser fácil, linear e sempre efetivo (MEDEIROS; GUIMARÃES, 2005). Além do desenvolvimento da própria tecnologia, um desafio encontrado pelos gestores públicos está na implantação e implementação de novas ferramentas desenvolvidas na organização. Segundo Dietrich (2007), os principais fatores que afetam a implantação de novos sistemas para auxiliar na gestão são: a falta de alinhamento estratégico, a dificuldade na promoção de mudanças culturais nas organizações, os processos inadequados de desenvolvimento de ferramenta e as dificuldades inerentes à tecnologia. Portanto, compreender os processos de implementação de ferramentas que auxiliem a gestão e avaliar seu funcionamento e seus resultados surgem como demanda básica e urgente para as organizações públicas.

Inserido no cenário descrito, o Ministério da Saúde (MS) desenvolveu junto ao Departamento de Informática do Sistema Único de Saúde (DATASUS) um sistema para a informatização das tarefas que envolvam o cumprimento de determinação judicial para fornecimento de insumos para saúde. O sistema foi desenvolvido na ferramenta da empresa IBM, denominada Maximo, e permite a criação de workflows eletrônicos, substituindo os processos físicos por processo eletrônico.

O sistema Processo Eletrônico de Compra para Atendimento de Determinação Judicial (PECJUDICIAL) entrou em funcionamento em agosto de 2016 e comtempla todos os envolvidos no cumprimento da determinação judicial no âmbito do MS. Com o pleno funcionamento do PECJUDICIAL, pretende-se aumentar a eficiência e a eficácia organizacional, extrair informações gerenciais estratégicas, aumentar o acesso e a transparência das informações. 
Somente no ano de 2014, o gasto com a aquisição de medicamentos para atender a ordens judiciais no âmbito da União ultrapassou 698 milhões de reais e teve um crescimento de 61\%, comparado com o ano de 2013, nos números de processos tramitados para a Coordenação de Compra por Determinação Judicial (CDJU) - área responsável pela aquisição dos medicamentos no âmbito do $\mathrm{MS}^{1}$. O crescimento no número de ações judiciais gera um grande impacto orçamentário para o Sistema Único de Saúde (SUS) e requer o constante redimensionamento da mão de obra para que não haja atrasos nas remessas dos insumos para o cumprimento das determinações judiciais. O não atendimento das determinações judiciais nos prazos estabelecidos nas decisões gera grave consequência legal para os gestores envolvidos no processo, desde multa pessoal por dia de descumprimento até mandado de prisão.

Diante do exposto, surge a questão: a implementação do PECJUDICIAL pode contribuir com melhorias para o atendimento das determinações judiciais em que a União é obrigada a fornecer insumos para saúde? Para lograr a resposta ao referido questionamento, inicialmente são necessários esforços para compreender a implementação do sistema, identificando resultados preliminares e traçando uma discussão sobre possíveis melhorias.

Assim, o presente estudo teve como objetivo geral analisar a implementação do sistema PECJUDICIAL no atendimento das determinações judiciais em que a União é obrigada a fornecer insumos para saúde. Foram propostos como objetivos específicos:

- Descrever barreiras e facilitadores para a implementação do PECJUDICIAL na organização;

- Realizar a avalição dos resultados preliminares da utilização do sistema PECJUDICIAL na perspectiva dos usuários internos;

\footnotetext{
${ }^{1}$ Informação obtida por meio do Serviço de Informação ao Cidadão - e-SIC, por meio do Sistema Eletrônico do Serviço de Informação ao Cidadão. Cf. Brasil (2015).
} 
- Realizar a análise comparativa dos resultados preliminares dos custos por atividade envolvidos no atendimento da determinação judicial pré e pós adoção do PECJUDICIAL.

\subsection{CONTEXTUALIZAÇÃO DO PROBLEMA}

A área de atendimento a demandas judiciais, no âmbito do MS, tem vivenciado constantes transformações desde a reestruturação da área de logística, com a concepção da Coordenação-Geral de Análise das Contratações de Insumos Estratégicos para a Saúde (CGIES), responsável pelo cumprimento das decisões judiciais.

Em continuidade ao trabalho iniciado em 2009, a área de demandas judiciais passou por diversas mudanças significativas e fundamentais, desde melhorias no espaço físico para prestação de serviço pelos servidores até à adoção de providências que imprimiram celeridade e eficiência no cumprimento das decisões, como a simplificação de procedimentos, orientada pela legislação pertinente e pelos princípios institucionais do MS.

Faltava, entretanto, o reconhecimento institucional à área de atendimento às decisões judiciais como setor carecedor de definição interna de competências, frente ao seu patente desenvolvimento, impulsionado pelo número crescente de ações propostas no Poder Judiciário. A ausência de formalização foi suprida com a criação da Coordenação de Demanda Judicial (CDJU), por meio da Portaria n. 3.965, de 14 de dezembro de 2010, publicada no Diário Oficial da União em 15 de dezembro de 2010, subordinada à CGIES, ambas inseridas no Departamento de Logística em Saúde (DLOG).

Em 2012 foi criado o Sistema de Ação Judicial de Medicamentos para a informatização do cadastro de pacientes e das remessas dos insumos. Entretanto, o Sistema não possuía documentação, impossibilitando a elaboração de melhorias e manutenção. 
Em março 2014, tendo em vista o aumento expressivo das demandas judiciais, foi solicitado ao DATASUS a elaboração do PECJUDICIAL, que objetivava contemplar todas as áreas envolvidas no cumprimento da determinação judicial no MS e abarcasse toda a cadeia logística dos medicamentos fornecidos para o atendimento das decisões judiciais. Com o novo sistema, os processos físicos seriam substituídos pelo processo eletrônico.

Teve início, então, o mapeamento dos requisitos do sistema no cumprimento das determinações judiciais pela empresa CTIS, contratada pelo DATASUS. O mapeamento foi concluído em dezembro de 2014, com início do seu respectivo desenvolvimento em janeiro de 2015.

Para esta etapa foi utilizada a plataforma da IBM, denominada Maximo, e a conclusão do desenvolvimento ocorreu em julho de 2015. A seguir, foi realizada a homologação com cada gestor envolvido, porém, devido ao lapso temporal entre o levantamento dos requisitos e o desenvolvimento do sistema, os gestores solicitaram novas adequações.

Realizou-se, então, o mapeamento dos requisitos das adequações e o desenvolvimento das soluções. A homologação final do sistema foi efetivada em outubro de 2015. Devido a mudanças no corpo diretivo da Consultoria Jurídica do MS, a homologação final foi adiada para dezembro de 2015.

Após a homologação, foi iniciada a implementação do sistema. Inicialmente, para o cumprimento das determinações judiciais, haveria dois tipos de processo, a saber: o físico e o eletrônico. Mas, à medida que os cumprimentos forem realizados, os processos físicos desaparecerão. Nos casos de medicamentos de uso continuo, os processos físicos serão substituídos pelo eletrônico gradativamente. 


\subsection{JUSTIFICATIVA}

O direito à saúde insere-se em uma dimensão social, fruto da evolução dos direitos humanos fundamentais e do conceito de cidadania plena. O direito à saúde pode ser considerado o direito humano e social mais importante, de caráter universal, essencial e inafastável, porque umbilicalmente está ligado ao direito à vida, o que se percebe por seus antecedentes históricos e pelo alto nível de normatização da matéria no âmbito dos direitos interno e internacional (ORDACGY, 2009).

No entanto, a precariedade do sistema público de saúde brasileiro, bem como o insuficiente fornecimento gratuito de medicamentos, muitos dos quais demasiadamente caros até para as classes de maior poder aquisitivo, têm feito a população civil amparar-se, com êxito, nas tutelas de saúde para a efetivação do seu tratamento médico, por meio de provimentos judiciais liminares, fenômeno esse que veio a ser denominado de "judicialização" da saúde (ORDACGY, 2009).

Tal fenômeno não é transitório e continuará crescendo nos próximos anos. A Administração Pública necessita se aperfeiçoar para atender com maior celeridade e transparência os anseios da população, especialmente no que tange à promoção, proteção e recuperação da vida. São insipientes os estudos sobre a avaliação de sistemas informatizados e inovadores na Administração Pública, em especial, com foco em redução de custos operacionais e o incremento da eficácia organizacional. Espera-se, portanto, contribuir para a apresentação de um outro olhar sobre a utilização da TIC no Estado como ferramenta que pode proporcionar maior eficácia, aumento da qualidade do serviço público prestado e redução dos custos processuais.

O presente estudo poderá contribuir não somente para a discussão da melhoria dos serviços prestados ao cidadão no atendimento das determinações judiciais, mas para o próprio desenvolvimento do conhecimento científico relacionado ao tema aqui proposto. 
O trabalho irá compreender a implementação do sistema, as barreiras e facilitadores existentes no processo, a análise comparativa dos resultados preliminares dos custos por atividade envolvidos no atendimento da determinação judicial antes e depois da implementação do PECJUDICIAL e a avaliação dos resultados preliminares na perspectiva dos usuários internos, fornecendo informações importantes para os gestores e possibilitando a melhor adequação das ferramentas para atingir os objetivos organizacionais e aumentar a efetividade da política pública. Indiretamente, este estudo poderá fundamentar as tomadas de decisão do gestor público, auxiliando no atendimento mais efetivo dos pacientes que ingressam com mandatos judiciais para a garantia de seu direito à saúde.

Faz-se importante destacar que o presente relato se encontra organizado em quatro capítulos. O primeiro apresenta o referencial teórico que embasou o estudo e aborda os temas: a reforma do Estado brasileiro, a Nova Administração Pública, Gestão por Resultados, Tecnologia da Informação e Comunicação na Administração Pública, avaliação de software, barreiras na implementação de sistema e E-GOV. O segundo capítulo descreve o método utilizado, incluindo o delineamento da amostra e os procedimentos de coleta e análise de dados. O terceiro capítulo apresenta os resultados encontrados. O quarto tece uma discussão a respeito dos mesmos. O quinto, por fim, apresenta as principais conclusões do estudo, destacando suas contribuições e limitações. 


\section{REFERENCIAL TEÓRICO}

No presente capítulo apresentam-se conceitos e perspectivas teóricas sobre a reforma do Estado brasileiro, Nova Administração Pública, Gestão por Resultados, Tecnologia da Informação e Comunicação na Administração Pública, avaliação de software, barreiras na implementação de sistema e E-GOV, temas diretamente relacionados com os objetivos aqui propostos. As referências apresentadas ofereceram suporte ao trabalho.

\subsection{REFORMA DO ESTADO}

Na primeira seção será realizada a análise da evolução da Administração Pública, com sua aproximação ao modelo teórico do gerencialismo e da Nova Gestão Pública (NGP). Tal evolução ocorreu em um contexto em que a gestão pública passou a ter maior enfoque no planejamento estratégico, na forma de definir prioridades e resultados desejados e criar formas hábeis para atingi-los e para mensurá-los.

O foco da ação estatal deixou de ser exclusivamente o cumprimento de leis e procedimentos e passou a envolver qualidade e resultados. O Estado, por vários motivos, especialmente os limites fiscais, precisou focar nas suas atividades essenciais e dividir com a sociedade a carga pela realização das atividades que não eram de exclusiva atuação estatal, na busca de melhores resultados que pudessem ser alcançados com os escassos recursos disponíveis.

As administrações públicas em grande parte do mundo, desde os anos 1980, realizaram alterações substanciais nas políticas de gestão pública e no desenho de organizações programáticas. Essas reformas administrativas consolidam novos discursos e práticas derivadas do setor privado e os usam como benchmarks para organizações públicas em todas as esferas de governo (SECCHI, 2009). 
Os elementos apontados como ativadores dessas ondas de "modernização" são a crise fiscal do Estado (AUCOIN, 1990; POLLITT; BOUCKAERT, 2002), a crescente competição territorial pelos investimentos privados e mão de obra qualificada (SECCHI, 2009), a disponibilidade de novos conhecimentos organizacionais e tecnologia, a ascensão de valores pluralistas e neoliberais (KOOIMAN, 1993) e a crescente complexidade, dinâmica e diversidade das nossas sociedades (KOOIMAN, 1993).

A reforma do setor público é descrita como uma resposta estratégica para o problema fiscal, derivado da necessidade do sistema político em reduzir seu consumo de recursos e produzir resultados que atendam aos anseios da população, e do problema de legitimidade do sistema político, ou a confiança dos cidadãos no sistema político, que depara com diversos desafios na medida em que o cidadão tem estado mais atento aos atos das organizações públicas (PETERS, 1984).

Segundo Pereira (2006), a reforma no setor público brasileiro é descrita pelos seus principais defensores como sendo inevitável, até o ponto de que mais cedo ou mais tarde irá acontecer em todos os países, e uma vez que seja iniciada, não há alternativa senão ir adiante com ela.

A doutrina realizou a classificação da Administração Pública em modelos, de acordo com suas características e época. Os modelos que envolvem a evolução da Administração Pública globalmente e na realidade brasileira são apresentados a seguir.

\subsubsection{Modelo Patrimonialista}

O patrimonialismo é uma herança da época feudal, vigente nas sociedades prédemocráticas. De acordo com esse modelo, a Administração Pública deve atender aos interesses do governante, que faz uso do poder que emana do povo em seu favor. 
O Estado é uma espécie de extensão do poder do soberano, não havendo distinção entre a res publica e a res principis, ou seja, a coisa pública se confunde com os bens do governante (FAORO, 2013).

Dessa forma, a Administração Pública não atende à função de defesa da coisa pública e dos interesses da coletividade, a ênfase está na satisfação dos anseios do governante e da cúpula que o acompanha. Assim, são características marcantes desse modelo de administração a corrupção e o nepotismo. Tal forma de governar passa a ser contestada e a se tornar insustentável com o advento do capitalismo e da democracia.

No Brasil, o patrimonialismo fora implantado pelo Estado colonial português, quando o processo de concessão de títulos, de terras e poderes, quase absolutos aos senhores de terra, legou à posteridade uma prática político-administrativa em que o público e o privado não se distinguem perante as autoridades. Assim, torna-se "natural" desde o período colonial (15001822), perpassando pelo período Imperial (1822-1889) e chegando à República Velha (1889 1930) (FAORO, 2013).

\subsubsection{Modelo Burocrático}

Não há um consenso quanto ao surgimento da Teoria Burocrática. Contudo, Mota (2004) evidencia que traços da burocracia se mostraram presentes há séculos, como, por exemplo, no Egito, na antiga Mesopotâmia e na China, onde os recursos hídricos eram controlados pelo Estado, o qual exercia dominação sobre os camponeses, que eram incapazes de se organizarem.

Afirmam os referidos autores que os registros das características burocráticas ganham forças em instituições como a igreja e o exército. Contudo, a Teoria Burocrática ganhou notoriedade anos depois com as críticas feitas à Teoria Clássica e à das Relações Humanas, sendo delineado pelo sociólogo alemão Max Weber. 
Nesse contexto, conforme preconiza Cruz (1997), a Teoria da Burocracia surge em função de alguns aspectos, como a necessidade de métodos teóricos que possibilitassem uma abordagem global e integrada dos problemas organizacionais, os quais não foram abordados pelas Teorias Clássica e Cientifica da administração.

O Modelo Burocrático foi uma resposta aos excessos e demais vícios experimentados pela Administração Pública no modelo anterior. Alastra-se uma ideia de desconfiança prévia dos administradores públicos por parte da sociedade como uma reação ao Modelo Patrimonialista (FAORO, 2013).

Posto isto, propôs-se a instauração do poder proveniente da autoridade racional-legal, baseado na razão e na lei, em que se garantisse a efetividade da contenção dos excessos.

No Brasil, o Modelo Burocrático teve início com a reforma administrativa de 1933 implantada por Vargas e tinha como premissa a questão da impessoalidade, a hierarquização, a formalidade nas comunicações, a separação entre o patrimônio público e o privado, em contraponto ao patrimonialismo, a meritocracia e a responsabilidade (PEREIRA, 2001).

Para tanto, criou-se o Departamento Administrativo do Serviço Público (DASP), com vista a reestruturar o Estado, tendo como principais objetivos inserir na Administração Pública brasileira, conforme preconiza: a obrigatoriedade de prestação de concursos para o ingresso nas instituições públicas, a classificação de cargos segundo critérios gerais e uniformes, o aperfeiçoamento constante dos servidores públicos, a instauração da administração orçamentária e a racionalização dos métodos.

Além das medidas estruturantes da forma de gerir o Estado, destaca-se a criação de empresas estatais, que contribuíram para desenvolver a indústria focada na substituição de importações.

Ante a implantação do Modelo Burocrático na Administração Pública brasileira, fica evidente que o Estado, após os primeiros anos de implementação das políticas de Vargas, se 
torna completamente distinto daquele que existia no início da República, quando os legados da Administração Patrimonialista haviam sido abandonados em sua grande parte, dando lugar à burocracia de Weber (PEREIRA, 2001).

Weber define a burocracia como o modelo organizacional eficiente por excelência. Corroborando este entendimento, Morgan (2002) aponta que a primeira definição de burocracia a caracterizava como uma configuração de organização que tem como estandarte a precisão, a rapidez, a clareza, a regularidade, a confiabilidade e a eficiência.

O modelo burocrático weberiano propõe que as atividades organizacionais devem ser detalhadamente previstas para alcançar o máximo de eficiência. Para tanto, Weber atribui à burocracia as seguintes características (ARAGÃO, 1997):

1) Caráter legal das normas e regulamentos;

2) Caráter formal das comunicações;

3) Caráter racional e divisão do trabalho;

4) Impessoalidade nas relações;

5) Hierarquia de autoridade;

6) Rotina e procedimentos padronizados;

7) Competência técnica e meritocracia;

8) Especialização da Administração;

9) Profissionalização dos participantes; e

10) Completa previsibilidade do funcionamento

Segundo Morgan (2002), algumas das características atribuídas à burocracia são advindas dos teóricos clássicos da administração como a hierarquia, a divisão do trabalho e a centralização de autoridade.

Apesar do Modelo Burocrático ser funcional para controlar a corrupção, o que consistia no principal objetivo da sua criação, a extrema racionalidade e o excesso de regulamentos do 
sistema acabaram por ocasionar efeitos negativos, como a lentidão de processos e a redução de eficiência (PEREIRA, 2001).

Desta forma, atualmente, a palavra burocracia costuma ser usada de forma pejorativa para designar entraves e morosidade de procedimentos, que são caracterizados pelo exacerbado formalismo e acabam por comprometer a eficiência da ação administrativa.

No entendimento de Weber, a burocracia trata de um modelo organizacional no qual a consequência almejada se resume na previsibilidade do comportamento dos membros da organização, com o escopo de alcançar a máxima eficiência organizacional. No entanto, assim como existem comportamentos previsíveis e desejáveis para a burocracia, também existem comportamentos ou consequências não previstas e não desejáveis. Este contraponto à eficiência burocrática foi identificado e estudado pelo sociólogo estadunidense Robert King Merton (1949).

Merton (1949) denomina essas características não desejáveis de disfunções da burocracia. O sociólogo salienta que os cientistas administrativos deram muita ênfase nos resultados positivos apregoados pela burocracia weberiana, não se atentando aos desvios e exageros apresentados pelo modelo. Desta forma, o referido autor apresentou as disfunções da burocracia:

1) Internalização das regras e apego aos regulamentos;

2) Excesso de formalismo e de papelório;

3) Resistência às mudanças;

4) Despersonificação do relacionamento;

5) Categorização como base do processo decisório;

6) Superconformidade às normas;

7) Exibição de sinais de autoridade; e

8) Dificuldades no atendimento a clientes e conflitos com o público. 
Neste mesmo sentido, de acordo com Català (2005), a racionalidade da administração burocrática não garante a eficiência e a eficácia do sistema, especialmente pela dificuldade de aplicação das regras à prática e pelo excesso de rigidez, que embaraça a adaptação a situações novas.

Ramos (1981) destaca que o comportamento baseado exclusivamente na racionalização instrumental, pautada somente no cálculo utilitário e no êxito econômico, mostra-se insuficiente para caracterizar a ação dos indivíduos, pois somente a racionalidade substantiva permite que a ação humana seja normatizada qualitativamente pelo "eticamente correto". Desta forma, o indivíduo, sob a influência dos seus próprios valores, racionaliza a partir dessa ética sua ação em todas as esferas da vida.

A crítica de Ramos (1981) se destacou por oferecer uma contribuição para o desenvolvimento de uma nova concepção teórica divergente das teorias tradicionais, denominada por ele de "abordagem substantiva da organização". Esta nova via abordada pelo autor acaba por assumir um espaço relevante nos estudos organizacionais no Brasil.

Para Serva (1997), as organizações substantivas são norteadas por princípios logicamente interrelacionados: primazia da ação coletiva, respeito às diferenças individuais, busca de equilíbrio entre o homem e a organização, ação calcada em identidade de valores e são organizações nas quais há relações interpessoais intensas e fortes. A racionalidade substantiva é caraterizada pelo entendimento, julgamento ético, valores emancipatórios, autonomia, autenticidade, satisfação social e autorrealização.

Serva (1997) destaca que a racionalidade instrumental é delineada pelo cálculo, orientada para o alcance de metas técnicas ou de finalidades ligadas a interesses econômicos ou de poder social, através da maximização dos recursos disponíveis. A racionalidade instrumental é caraterizada pela maximização de recursos, êxito e resultados, desempenho, utilidade e rentabilidade. A abordagem substantiva da organização, por sua vez, pressupõe que cada 
indivíduo na organização tem um conjunto de valores que irá afetar diretamente as suas decisões e, consequentemente, o seu desempenho na organização.

Para Serva et al (2015), a discussão da racionalidade se tornou o ponto de partida para possibilidades de desenvolvimento dos indivíduos dentro das organizações formais. É nesta perspectiva que a obra de Ramos ganhou um significado expressivo no campo da Administração.

No âmbito da Administração Pública, a noção de valores e objetivos é permeada por aspectos constitucionais, como os previstos no artigo 37 da Carta Magna: legalidade, impessoalidade, moralidade, publicidade e eficiência.

Nabatchi (2011) concluiu que há uma pluralidade de conjuntos e sistemas de valores na Administração Pública que, muitas vezes, estão em conflito entre si. Para exemplificar esta situação, Nabatchi (2011) destaca que as decisões políticas são, essencialmente, escolhas entre valores concorrentes, como no caso da promoção de igualdade de oportunidades que podem resultar em conflitos com valores, como eficiência.

Para a referida autora, estes valores são agrupados em "ethos burocrático" e "ethos democrático". O primeiro caso é visto em situações dominantes e envolve valores como especialização, hierarquia e legalidade, todos com critérios instrumentais e utilitários de ação. Já o "ethos democrático" abarca valores de cidadania, equidade, justiça social e interesse público, voltados para os critérios substantivos. Diante das críticas e incredulidade em relação ao modelo burocrático de Administração, no início século XXI ganha força a discussão sobre uma nova forma de Administração Pública: a Gerencial.

A crise do Modelo Burocrático, a globalização da economia, a crise fiscal do Estado e o distanciamento entre as ações da Administração e os interesses dos cidadãos, passaram a corroborar a necessidade de um modelo que apoiasse a estruturação e a gestão da Administração Pública com base em valores de eficiência, eficácia e competitividade. 


\subsubsection{Modelo Gerencial e Nova Gestão Pública}

A partir do começo dos anos 1990, um grupo de ideias ganhou notoriedade e se tornou conhecido como a Nova Gestão Pública (NGP) ou Modelo Gerencial. Os conceitos de "gestão pública” em oposição à “Administração Pública” demonstram a migração conceitual oriunda do ensino e pesquisa universitária, que despontou nos departamentos de ciência política para escolas de negócios. "Gestão" é tratada como um assunto genérico e generalizável. Governos são vistos como outro tipo de organização, que podem se beneficiar do conhecimento geral sobre "gestão" da mesma maneira que empresas privadas o fazem (POLLITT; BOUCKAERT, 2002).

Segundo Fonseca et al (2013), as reformas estatais empreendidas no Brasil seguiram, em muitos aspectos, as linhas do New Public Management (NPM), o qual estabelecia a perspectiva gerencialista como forma de superação do Modelo Burocrático. De tal perspectiva, práticas gerenciais da iniciativa privada foram adotadas como referência para o setor público, visando à geração de maior eficiência e foco em resultados (PECI; PIERANTI; RODRIGUES, 2008). Esse modelo tem como alicerce as seguintes prioridades: a eficiência e a qualidade na prestação de serviços públicos, além da redução de custos.

De forma geral, podemos pensar no conceito de eficiência como aquele relacionado ao emprego de recursos de forma a obter a melhor relação custo benefício entre os objetivos estabelecidos e os recursos utilizados. Para isso, os recursos devem ser empregados de forma racional, critério presente na base das organizações administrativas e parte integrante do paradigma dominante na Teoria Organizacional (COELHO, 2001).

Com o intuito de se alcançar maior eficiência e qualidade nos serviços, adota-se o controle do desempenho das políticas públicas com o foco no resultado. Os resultados devem ser mensurados em comparação com as expectativas do cidadão beneficiário, ou cidadão cliente. A ideia de avaliação de desempenho, dentre outros princípios basilares da 
Administração Pública Gerencial, teve como inspiração o uso de práticas de gestão provenientes da administração privada. Contudo, devem-se levar em conta certas diferenças, como o objetivo (de lucro, no caso das organizações privadas, e de realização do interesse público, no caso da Administração Pública) e a origem das receitas (PEREIRA, 2015).

A Administração Pública tem como finalidade principal o bem comum, descrito na Constituição Federal, se ajustando aos projetos e às políticas governamentais. Assim, seu orçamento e a destinação de suas verbas seguem os objetivos do Estado, diferindo de forma substancial da administração privada.

Essa característica traz consequências importantes quando se pretende transpor mecanismos ou instrumentos administrativos desenvolvidos e testados na administração de organizações privadas para as organizações públicas (HEADY, 1996).

A origem da Administração Pública Gerencial brasileira está ligada ao grande debate sobre a crise de governabilidade e a credibilidade do Estado na América Latina durante as décadas de 1980 e 1990. Esse debate se situa no contexto do movimento internacional de reforma do aparelho do Estado, que teve início na Europa e nos Estados Unidos da América (EUA). Para uma melhor compreensão desse movimento é preciso levar em consideração que ele está relacionado ao gerencialismo, ideário que floresceu durante os governos de Margareth Thatcher e de Ronald Reagan (PEREIRA, 2015).

Gonçalves et al (2013) destaca que o Brasil seguiu a tendência das reformas, sustentado pelo Plano Diretor de Reforma do Aparelho do Estado (PDRAE) (1995), coordenado pelo Ministério da Administração e Reforma do Estado. Procurou-se delinear um novo padrão de gestão pública, denominada Administração Gerencial, apoiada nos princípios da flexibilidade, ênfase em resultados, foco no cliente e controle social.

Segundo Pereira (2001), o objetivo central do PDRAE é contribuir para a formação, no Brasil, de um aparelho de Estado forte e eficiente. Ele compreende três dimensões: 
a) Uma dimensão institucional-legal, voltada à descentralização da estrutura organizacional do aparelho do Estado por meio da criação de novos formatos organizacionais, como as agências executivas, regulatórias e as organizações sociais;

b) Uma dimensão de gestão, definida pela maior autonomia e a introdução de três novas formas de responsabilização dos gestores - a administração por resultados, a competição administrada por excelência e o controle social - em substituição parcial dos regulamentos rígidos, da supervisão e da auditoria, que caracterizam a Administração Burocrática;

c) Uma dimensão cultural, de mudança de mentalidade, visando passar da desconfiança generalizada, que caracteriza a Administração Burocrática, para uma confiança maior, ainda que limitada, própria da Administração Gerencial.

A reforma do Estado deve ser percebida dentro do contexto da redefinição do papel do Estado que deixa de ser o responsável direto pelo desenvolvimento econômico e social para se tornar seu promotor e regulador (BRASIL, 1995). O Estado assume um papel menos executor ou prestador direto de serviços mantendo-se, entretanto, no papel de regulador e provedor destes.

Nesta nova perspectiva, busca-se o fortalecimento das suas funções de regulação e de coordenação, especialmente no nível federal, e a expansão da descentralização vertical, para os níveis estadual e municipal, das funções executivas nas áreas de prestação de serviços sociais e de infraestrutura.

Segundo Pereira (1998), a Administração Pública Gerencial, parte do pressuposto de que já chegamos a um nível cultural e político em que o patrimonialismo está condenado, em que o burocratismo não atende aos anseios da população, porque é ineficiente, e em que é possível ampliar as estratégias administrativas fundamentadas na ampla delegação de autoridade e na cobrança a posteriori de resultados. 
As principais características do Modelo Gerencial, segundo Pereira são:

1) Descentralização do ponto de vista político, transferindo recursos e atribuições para os níveis políticos regionais e locais;

2) Descentralização administrativa, por meio da delegação de autoridade para os administradores públicos transformados em gerentes crescentemente autônomos;

3) Organizações com poucos níveis hierárquicos ao invés de piramidal;

4) Organizações flexíveis ao invés de unitárias e monolíticas, nas quais as ideias de multiplicidade, de competição administrada e de conflito tenham lugar;

5) Pressuposto da confiança limitada e não da desconfiança total;

6) Definição dos objetivos a serem alcançados pelas unidades descentralizadas na forma de indicadores de desempenho, sempre que possível quantitativos, que constituirão o centro do contrato de gestão entre o ministro e o responsável pelo órgão que está sendo transformado em agência;

7) Controle por resultados, a posteriori, ao invés do controle rígido, passo a passo, dos processos administrativos;

8) Administração voltada para o atendimento do cidadão, ao invés de autorreferida.

Desta forma, o Modelo Gerencial mudou substancialmente a forma de atuação estatal. Entretanto, não foi uma ruptura absoluta com o Modelo Burocrático, pois ainda hoje é possível observar fortes traços da burocracia no Estado brasileiro.

\subsubsection{Gestão por Resultados}

Em relação à gestão com foco em resultados, principal prescrição da NGP, a ênfase incide sobre o uso eficaz da informação, o estabelecimento de indicadores de desempenho e, enfim, a preocupação constante com o monitoramento e a avaliação do efeito dos serviços e 
políticas públicas, visando ao aumento da eficiência, à efetividade e à economicidade da gestão pública (GOMES, 2009).

Tal ênfase remete a uma centralidade das chamadas políticas públicas de gestão, aquele conjunto de funções administrativas destinadas a zelar pelo uso racional dos recursos, como informação, mão de obra e matérias-primas, por meio de políticas de planejamento e orçamento, logística e compras, gestão de pessoas, contabilidade de custos, sistemas de informação e estruturas organizacionais.

Portanto, uma vez que a chamada reconstrução do Estado propugna o aumento da sua capacidade em ser mais eficiente, a função da gestão passa a ser sobremaneira enfatizada (EVANS, 1993).

Segundo Porpino e Stefanini (2014), a Organização das Nações Unidas (ONU) definiu a GR como uma estratégia de gestão pela qual todos os atores envolvidos, que colaboram direta ou indiretamente para alcançar um conjunto de resultados, garantem que seus processos, produtos e serviços cooperem para a realização dos resultados almejados, em termos de bens e serviços produzidos (outputs) e objetivos.

O resultado da GR é a criação de valor público, entendido como a contribuição do setor público para o bem-estar social, econômico e ambiental da sociedade (TRY; RADNOR, 2007).

Para Negri, Salerno e Castro (2005) e Cruz (1997), a eficiência está intimamente ligada à capacidade de uma organização em obter o máximo de produto a partir de um dado conjunto de insumos. A eficiência mede a habilidade de se produzir tantos produtos quanto permitem os insumos utilizados, ou usar o mínimo necessário de insumos para produzir uma quantidade de produto. A eficácia, por sua vez, é a obtenção de resultado dentro dos objetivos propostos. A economicidade pressupõe a obtenção e a utilização exata de recursos nas quantidades necessárias e suficientes e no momento adequado, sem desperdícios e observando as alternativas mais econômicas no mercado. 
Treasury (1994) e Christiansen e Mellick (1993) apontam para a informação de custos como fator crítico para o sucesso do planejamento, orçamento, controle operacional e da tomada de decisões estratégicas. Beckett (2002) enfatiza que essa informação é a base principal para a gestão pública.

\subsection{ANÁliSES DE CUSTOS COMO FERRAMENTA DE AUXÍlio À GESTÃo POR RESULTADOS}

O monitoramento dos custos fornece informações que podem servir de comparação com as metas fixadas no plano, o que propicia a avaliação e o devido controle. Com estas informações e comparações também é possível realizar auditorias de gestão, visando medir a eficiência gerencial.

Reitell (1958) e Ribeiro Filho (2002) sustentam que se a entidade pública realizar a mensuração de custos adequada, esta será a base para se acompanhar a execução das ações organizacionais e o desempenho de cada uma das divisões. Assim, será possível medir a performance da gestão pública em nível individual e global.

Devido aos problemas enfrentados com a contabilidade tradicional, o custeio baseado em atividades, Activity Based Costing $-A B C$, começou a surgir, no início dos anos 80, como uma saída para as distorções geradas pela contabilidade baseada em custos de produtos. Segundo Diehl e Souza (2008), o custeio ABC atribui primeiramente os custos dos recursos às atividades executadas pela organização. A seguir, esses custos são atribuídos aos produtos, serviços e clientes que se beneficiaram dessas atividades ou criaram demanda, conforme apresenta a Figura 1. 


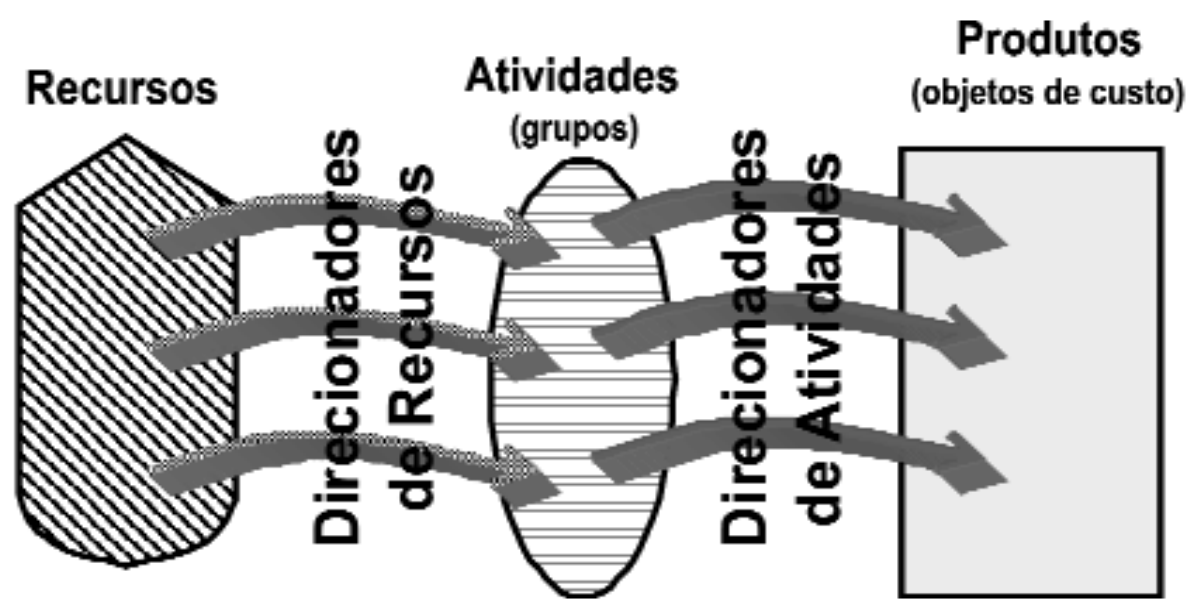

Figura 1 - Funcionamento do Active Base Cost. Fonte: Diehl e Souza (2008).

A primeira etapa do $\mathrm{ABC}$ consiste na identificação das atividades relevantes, definindo o seu nível de detalhamento, sendo necessária a identificação dos fatores que influenciaram tais atividades, ou seja, os direcionadores de recursos/custos. Nesse sentido, Nakagawa (1994, p. 43) define o direcionador de custo, também conhecido como cost driver, como “[...] o fator que determina ou influencia o consumo de recursos pelas atividades e destas para os produtos".

A segunda etapa é a transferência dos custos das atividades aos produtos que as utilizam. Isto é feito identificando um gerador de custo para cada atividade, calculando a taxa do gerador de custos, e utilizando esta taxa para destinar os custos das atividades aos produtos (KAPLAN; COOPER, 1991).

O sistema $\mathrm{ABC}$ utiliza um grande número de direcionadores de custos para rateio dos custos indiretos. Segundo Padoveze (1999), os benefícios do custeamento por atividade, como método para resultar em uma distribuição dos custos indiretos de fabricação aos produtos de forma mais precisa, parecem claros, permitindo o levantamento dos custos de forma mais precisa ao mesmo tempo em que auxiliam no processo de controle dos custos das atividades.

$\mathrm{O}$ ABC não está preocupado em segregar custos de despesas, mas em separar as atividades que agregam valor das que não agregam valor ao produto e os respectivos custos. Segundo Campiglia e Campiglia (1994), as atividades que agregam são aquelas que consomem 
recursos transformando-os em produtos e serviços que atendem as expectativas e necessidades dos clientes.

De acordo com Kaplan e Cooper (1991), não existem diferenças substanciais na análise das despesas operacionais das empresas de serviços e das empresas de manufatura. A análise deve iniciar-se pela estrutura de custos de cada departamento operacional e identificar os fatores que criam as demandas das funções desempenhadas pelo departamento. O objetivo é identificar a natureza da demanda e determinar os seus direcionadores de recursos.

O sistema de custeio $\mathrm{ABC}$ permite gerar informações que auxiliam os gestores na gerência das atividades responsáveis pelos custos dos produtos/serviços, possibilitando melhor visualização dos impactos causados por decisões e melhor controle dos custos indiretos.

Segundo Riccio e Gouveia (1995), o custeio por atividade proporciona melhor administração das atividades, visto que possibilita identificar os custos relevantes para um rol maior de decisões, tais como: fixação de preços, melhor relação entre os clientes, melhoria de processos, mix de produtos e aquisição de tecnologia.

Tendo em vista as grandes alterações no cenário de atuação das organizações públicas, a necessidade de aferição de custos e a gestão da coisa pública de forma cada vez mais eficiente e transparente estão se difundindo entre os gestores públicos. Nesse cenário, a necessidade de aperfeiçoar a gestão de custos relacionados à oferta de serviços públicos com cada vez mais qualidade vem ganhando importância, em especial para uma alocação eficiente dos escassos recursos públicos.

Trosa (2001) alerta que o orçamento público não pode, porém, basear-se somente nos recursos que se coloca à disposição, mas sim, nos resultados a atingir. Para ele, é mais cômodo aos gestores somente prestarem contas dos valores em detrimento da qualidade e o resultado econômico dos serviços prestados. 
Desta forma, na busca por maior efetividade na alocação dos recursos, os gestores públicos podem utilizar o método de custeio $\mathrm{ABC}$ para identificar os custos por atividade. Com o uso desta ferramenta, os gestores do Estado poderão identificar quais deverão ser as principais atividades a serem informatizadas, geralmente as que despendem de mais recursos, e com a informatização economizar os escassos recursos públicos e fornecer serviços de maior qualidade aos cidadãos. O modelo de custeio abordado embasa o presente projeto acerca dos resultados preliminares do PECJUDICIAL em relação ao custo total processual no cumprimento das determinações judiciais.

O Banco Central do Brasil (BACEN), instituição autárquica da Administração Pública indireta, integrante do Sistema Financeiro Nacional, vinculada ao Ministério da Fazenda, foi o pioneiro na utilização da metodologia Activity Based Costing, como ferramenta na busca pelo aumento de eficiência e de controle na utilização dos seus recursos (BACEN, 2002).

Para a definição do modelo de custeio ABC, o BACEN criou em 2000 um grupo de trabalho para a definição da metodologia. Numa primeira fase do projeto, o grupo de trabalho estudou as metodologias de apuração de custos existentes, bem como a análise da legislação referente à matéria, incluindo a Lei de Responsabilidade Fiscal, a Lei de Diretrizes Orçamentárias e o Plano Plurianual de Governo.

A equipe apresentou estudos sobre as metodologias de custeio mais utilizadas e elaborou uma revisão bibliográfica sobre o assunto. O grupo participou de seminários sobre custos e realizou visitas a órgãos que já tivessem implantado a metodologia de Custeio Baseado em Atividades, tais como: o Banco do Estado de São Paulo (BANESPA), Empresa Brasileira de Correios e Telégrafos e o Banco do Brasil. A equipe também visitou empresas de consultoria com experiência comprovada na área como KPMG, ESTRATEGE, ABCTECH, MBI Consulting, buscando verificar os resultados alcançados e subsídios sobre as metodologias. 
O grupo de trabalho elaborou um relatório técnico no qual indicava o Custeio Baseado em Atividades como sendo mais apropriado para o Banco Central do Brasil por possibilitar a alocação das despesas administrativas aos produtos e serviços e permitir a mensuração dos custos que não agregam valor, possibilitando melhor análise dos processos de trabalho, eliminando desperdícios e otimizando o uso dos recursos orçamentários. Além disso, apontaram o uso mundial da metodologia por empresas prestadoras de serviço, indústrias e instituições públicas como fator relevante para a adoção da metodologia (BACEN, 2002). O próprio Banco Mundial concedeu financiamento ao Banco Central, junto ao Sistema Financeiro Nacional, para o projeto do sistema de custos.

Além do BACEN, diversas outras instituições da Administração Pública utilizam o modelo de custeio ABC para a mensuração dos custos operacionais, tais como: Colégio Militar do Rio de Janeiro (CARMO; SILVA, 2011), Hospital das Clínicas da Faculdade de Medicina de Ribeirão Preto da USP (BONACIM; ARAÚJO, 2010), Universidade Regional Integrada do Alto Uruguai - URI (MUNARETTO, 2000), ente outras instituições públicas.

\subsection{TECNOLOGIA DA INFORMAÇÃO E COMUNICAÇÃO}

Para que os gestores atinjam o êxito organizacional são de suma importância os sistemas que fornecem informações aos administradores. Para Stoner (1999), somente com informações precisas e na hora certa, os administradores podem monitorar o progresso na direção de seus objetivos e transformar os planos em realidade.

Segundo Gonçalves (1993), a tecnologia é o fator individual de modificação de maior importância na transformação das organizações. Tais transformações não se reduzem apenas ao modo de produzir bens e serviços, mas também se referem aos novos processos e instrumentos que atingem completamente a estrutura e o comportamento das organizações, repercutindo diretamente em sua gestão. 
De acordo com Cunha et al (2012), as TICs correspondem a todas as tecnologias que interferem e medeiam os processos informacionais e comunicativos dos seres. Ainda, podem ser entendidas como um conjunto de recursos tecnológicos integrados entre si, que proporcionam, por meio das funções de hardware, software e telecomunicações, a automação e comunicação dos processos de negócios, da pesquisa científica e de ensino e aprendizagem.

Segundo Castells e Gerhardt (2000), as TICs são utilizadas de diversas formas e em vários ramos de atividades, como nas indústrias (processo de automação), no comércio (gerenciamento e publicidade), nos setores de investimentos (informações simultâneas e comunicação imediata) e na educação (processo de ensino e aprendizagem e educação à distância). Pode-se dizer que a principal responsável pelo crescimento e potencialização da utilização das TICs em diversos campos foi a popularização da internet.

Para Klumb e Azevedo (2014), a TI tornou-se essencial para que as organizações sustentem um processo decisório efetivo e um controle sobre suas operações. Entretanto, essa tecnologia trouxe também uma série de processos relacionados a sua gestão e manutenção, exigindo que aspectos relativos à qualidade, como eficiência, eficácia e efetividade das informações, sejam controlados.

Nos países do primeiro mundo, a TIC tem sido considerada como um dos principais fatores responsáveis pelo sucesso das organizações, tanto no âmbito de sobrevivência, quanto no aumento da competitividade (YONG, 1992). Corroborando este pensamento, Zuboff (1994) afirma que a TIC está proporcionando nova infraestrutura para as várias atividades produtivas e comunicativas, algo vital para a vida organizacional.

De acordo com o Serviço Brasileiro de Apoio às Micro e Pequenas Empresas (SEBRAE) (2014), as vantagens que a TIC traz para as organizações podem ser dividias em três grupos: 
a) Diminuição dos custos: a informática, quando bem utilizada, reduz os custos da organização, porque agiliza e possibilita maior segurança e confiabilidade nos processos, rotinas e controles administrativos, simplifica as tarefas burocráticas, reduz os erros e praticamente elimina a repetição do trabalho.

b) Maior produtividade: possibilita que as pessoas produzam mais, em menos tempo, com menor dispêndio de recursos, permitindo aproveitar melhor a capacidade produtiva da organização com o planejamento e o controle da produção, armazena e localiza imediatamente informações fundamentais para os negócios e agiliza os processos de tomada de decisões.

c) Maior qualidade: a qualidade dos produtos e serviços é melhorada, pois as tecnologias de informação ajudam a manter o padrão dos produtos dentro das especificações estabelecidas, proporcionando melhores condições de trabalho para os empregados e reduz esforços com a burocracia para concentrá-los nas atividades fins da empresa.

\subsubsection{O Uso de Tecnologia de Informação e Comunicação em Organizações Públicas}

Além das reformas do aparato administrativo, os governos vêm se deparando com o aparecimento de novas formas de organização e de produção em escala mundial que delinearam o que se convencionou chamar de "Sociedade da Informação", baseada no conhecimento, na educação e no desenvolvimento científico e tecnológico (KUMAR, 1997).

A TI tem sido utilizada por organizações públicas desde os anos 1950. As primeiras aplicações de TI foram desenvolvidas especialmente para o uso governamental. Durante as décadas seguintes, governos passaram a acrescentar sistemas de informações a suas operações e hoje a TI é uma ferramenta fundamental para execução de suas funções.

Na década de 1970, as pesquisas científicas descrevem o processo de inovação tecnológica como um processo político, com sua adoção dependendo de forças políticas e 
burocráticas (LAUDON, 1975). Entretanto, a tecnologia dentro dos governos era descrita como sendo fragmentada e os resultados finais do uso de tecnologias se demonstravam de difícil mensuração, já que a tecnologia era descrita como altamente flexível e podendo servir a interesses distintos (DANZIGER; ANDERSEN, 2002).

Na literatura sobre a utilização da TI em governo deste período, os autores fazem referências à Administração Pública como "gestão" (management) e aos funcionários públicos como "gerentes" (managers). Este vocabulário denota que a origem de tais pesquisadores eram escolas de administração de empresas, que em geral adotavam a premissa de que governos e empresas são tipos diferentes de organizações que podem fazer uso da mesma fonte de conhecimento a respeito de sistemas de informação.

Com o advento da internet, os governos tiveram de readequar a sua atuação, a fim de atender as necessidades dos cidadãos que querem serviços muito mais ágeis, desburocratizados e com acesso eletrônico a serviços e informações.

Conforme Teixeira (2004), essas tecnologias constituem um importante instrumento de apoio à Administração Pública, pois permitem: a oferta de novos serviços; a ampliação da eficiência e da eficácia dos serviços públicos; a melhoria da qualidade dos serviços prestados; a construção de novos padrões de relacionamento com os cidadãos e de novos espaços para a promoção da cidadania. $\mathrm{O}$ autor lembra, contudo, que é preciso garantir o acesso às informações a todos os cidadãos, evitando uma segregação entre os que podem e sabem usar as tecnologias de informação e os que não têm esta possibilidade.

O desenvolvimento das TICs e a disponibilidade de informações e serviços públicos, em meio eletrônico, aumentou significativamente nos últimos anos. Os governos parecem buscar cada vez mais a informatização dos seus serviços. A adoção das TICs não é um objetivo em si mesmo e sim um método. Ou seja, elas são ferramentas fundamentais para alcançar objetivos previamente definidos, particularmente dois, considerados primordiais do ponto de 
vista da gestão pública, que são a transparência e a eficiência da gestão (JAMBEIRO; SOBREIRA; RABEIRO, 2011).

\subsubsection{E-GOV ou Governo Eletrônico no Brasil}

O Governo Eletrônico (E-GOV) é um tema relativamente novo no campo da Administração Pública (GRÖNLUND e HORAN, 2004). Embora já houvesse estudos sobre o uso de tecnologia na automação e auxílio da tomada de decisão desde a década de 1970, foi somente com a popularização da internet, na década de 90, que os estudos sobre E-GOV começaram a ter maior relevância acadêmica.

Governo Eletrônico refere-se ao uso, por agências governamentais, de tecnologias de informação (como redes de longa distância, internet e computação móvel) capazes de transformar as relações com os cidadãos, empresas e outras unidades do governo. Essas tecnologias podem servir a diferentes fins, como: melhor prestação de serviços aos cidadãos, interações mais eficazes com as empresas e a indústria, empowerment do cidadão por meio do acesso a informações ou mais eficiência na administração governamental (BANCO MUNDIAL, 2003).

Segundo Santos e Honorífica (2002), E-GOV é a contínua otimização de oferta de serviço, participação do eleitorado e governança mediante a transformação das interfaces internas e externas com o uso da tecnologia, da internet e da nova mídia.

Para Reis, Dacorso e Tenório (2015), a crescente popularização da internet nas duas últimas décadas promoveu uma revolução nos meios de informação. Iniciativas de E-GOV podem ser encontradas em quase todos os programas de modernização das democracias ocidentais.

No Governo Federal brasileiro, a expressão Governo Eletrônico começa a ser utilizada a partir do ano de 1996, com a implantação pela Receita Federal do ReceitaNet. O objetivo do 
sistema era auxiliar o contribuinte no envio das declarações de imposto de renda via web. $\mathrm{O}$ sistema foi reconhecido por profissionais da área fiscal de organismos internacionais como inovador no processo e um dos exemplos a ser seguido como excelência em boas práticas de Governo Eletrônico (SRF, 2008).

Outro destaque de pioneirismo de E-GOV no Brasil é a realização em 2000 da votação eletrônica em todo o território nacional. Foi o primeiro país com dimensões continentais a realizar uma eleição totalmente informatizada. De acordo com Reis (2004), a eficiência da votação e a rapidez na apuração dos votos tornaram a operação um caso de sucesso reconhecido internacionalmente, despertando interesse de diversos países latino-americanos, além dos Estados Unidos, Holanda, Japão e França.

A Casa Civil da Presidência da República, em 2002, publicou um documento abordando os dois primeiros anos do Governo Eletrônico no Brasil, denominado 2 Anos de Governo Eletrônico: Balanço de Realizações e Desafios Futuros. O documento apresentou as diretrizes, as linhas de ação, o arranjo institucional e os projetos integrantes do Programa Governo Eletrônico.

No ano de 2006, O TCU publicou um relatório de avaliação do Governo Eletrônico brasileiro, pontuando que a Secretaria de Logística e Tecnologia da Informação (SLTI) não havia definido ainda a política de monitoramento e avaliação da qualidade dos serviços de Governo Eletrônico.

No ano seguinte, a SLTI apresentou um relatório denominado Indicadores e métricas para avaliação de e-Serviços, com o objetivo de avaliar a qualidade dos serviços públicos prestados por meios eletrônicos de acordo com a necessidade do cidadão.

Segundo Almeida (2015), apesar das iniciativas e ações do Governo Eletrônico Brasileiro despontarem no início do século XXI como uma referência internacional nas avaliações de diversos estudos (PWC CONSULTING, 2002; UNITED NATIONS, 2002; 
CENTER FOR INTERNATIONAL DEVELOPMENT, 2001; ACCENTURE, 2001), as iniciativas de E-GOV passaram a esboçar uma descontinuidade dos seus propósitos.

Para corroborar essa afirmação, em 2001 o Brasil era tipificado pela ONU como uma nação com alta capacidade de Governo Eletrônico, classificado como o $18^{\circ}$ melhor do mundo. Em 2015, passou a ocupar a $57^{\mathrm{a}}$ colocação no Índice de Desenvolvimento de Governo Eletrônico (EGDI), também legitimado pela ONU.

A realidade do Governo Eletrônico no Brasil é caracterizada por duas dimensões distintas. Se por um lado, existe a dimensão associada ao avanço do Governo Eletrônico, por outro, apesar do aumento do acesso à internet pela população brasileira, não se pode deixar de considerar a dimensão da exclusão digital em nosso país, que mantém a maior parte da população brasileira distante da posse e do uso das TICs (DINIZ, 2009).

Para o Governo Brasileiro, os objetivos do Governo Eletrônico são: universalização e democratização do acesso aos serviços, melhoria da gestão e qualidade dos serviços públicos, transparência, redução dos custos unitários, simplificação de processos, informação como fator estratégico e convergência e integração das redes e sistemas de informação (FERNANDES; AFONSO, 2001).

As Centrais de Atendimento ao Cidadão por meio de serviços eletrônicos vêm crescendo de forma significativa em inúmeros governos. Estas centrais possuem nomes diferentes, dependendo do Estado em que foram implantadas (SAC, na Bahia, de grande notoriedade no país e exterior, tendo servido de modelo a Portugal; Poupatempo, em São Paulo; PSIU, em Minas Gerais, que, em 2008, mudou o nome para "UAI"; Tudo Fácil, no Rio Grande do Sul; Vapt-Vupt, em Goiás, etc.), mas possuem uma filosofia muito parecida. Os objetivos declarados são qualidade e rapidez no atendimento à população e respeito ao cidadão (CUNHA; ANNENBERG; AGUNE, 2007). 
Para atender melhor os cidadãos, o Governo Federal criou o site <http://www.governoeletronico.com.br> para o desenvolvimento de Programas de Governo Eletrônico (PGE). O princípio basilar do PGE é a utilização das modernas tecnologias de informação e comunicação (TICs) para democratizar o acesso à informação, ampliar discussões e dinamizar a prestação de serviços públicos com foco na eficiência e efetividade das funções governamentais (BRASIL, 2015).

No Brasil, a política de Governo Eletrônico segue um conjunto de diretrizes que atuam em três frentes fundamentais: junto ao cidadão, na melhoria da sua própria gestão interna e na integração com parceiros e fornecedores (BRASIL, 2015).

O que se pretende com o PGE brasileiro é a transformação das relações do Governo com os cidadãos, empresas e, também, entre os órgãos do próprio Governo, de forma a aprimorar a qualidade dos serviços prestados; promover a interação com empresas e indústrias; e fortalecer a participação cidadã por meio do acesso à informação e a uma Administração mais eficiente (BRASIL, 2015).

Cabe ressaltar que o E-GOV não se restringe à simples automação dos processos e disponibilização de serviços públicos por meio de serviços online na internet, mas na mudança da maneira como o Governo, pelo uso da TIC, atinge os seus objetivos para cumprimento do papel do Estado (ABRAMSON; MEANS, 2001).

\subsection{A AVALIAÇÃO DE SOFTWARE}

Uma das principais ferramentas utilizadas na TIC são os softwares. O software consiste em uma sequência de instruções escritas para serem interpretadas por um computador com o objetivo de executar tarefas específicas. Também pode ser definido como os programas que comandam o funcionamento de um computador (PRESSMAN, 2011). Os softwares de sistema são o conjunto de informações processadas pelo sistema interno de um computador que permite 
a interação entre usuário e os periféricos do computador por meio de uma interface gráfica (PRESSMAN, 2011).

Nos últimos anos, a utilização de sistemas computacionais comandados por softwares tem crescido exponencialmente em todos os setores de atividades da sociedade, atingindo um número cada vez mais expressivo de usuários. A demanda por softwares de qualidade é crescente e os usuários exigem cada vez mais eficácia e eficiência dentre outras características de qualidade para o produto.

A avaliação de produtos de software tem como principal objetivo a melhoria da sua qualidade. Para que tal processo seja mais efetivo, é importante utilizar um modelo validado que seja capaz de mesurar a qualidade do software para atingir os objetivos da organização e proporcionar a realização de uma análise comparativa.

Existe um movimento nacional e internacional que estabeleceu normas na área de Engenharia de Software, como é o caso da International Organization for Standardization (ISO) (em português, Organização Internacional de Normalização). A ISO, estabelecida em 1947, com sede em Genebra, Suíça, tem como principal objetivo o desenvolvimento de padrões mundiais, com vistas a facilitar o intercâmbio internacional de produtos e serviços e a criar uma cooperação intelectual, científica, econômica e técnica (OLIVEIRA, 2012).

A International Electrotechnical Commission (IEC), fundada em 1906, é a organização mundial que publica normas internacionais relacionadas à eletricidade, à eletrônica e a áreas afins.

A ISO e a IEC elaboraram um conjunto de normas, as séries ISO/IEC 9126 e ISO/IEC 14598, que versam sobre a qualidade dos produtos de software. Recentemente, as normas ISO/IEC 9126 e 14598 foram reestruturadas e incorporadas à nova série ISO/IEC 25000 Software Quality Requirements and Evaluation (SQuaRE) (em português, Requisitos e Avaliação da Qualidade de Software). O modelo de qualidade da norma ISO/IEC 25010 pode 
ser aplicado a qualquer tipo de software e se divide em duas partes: qualidade de produto e qualidade em uso.

O modelo de qualidade de produto especifica oito características de qualidade, as quais são subdivididas em subcaracterísticas, conforme a Figura 2, a seguir.

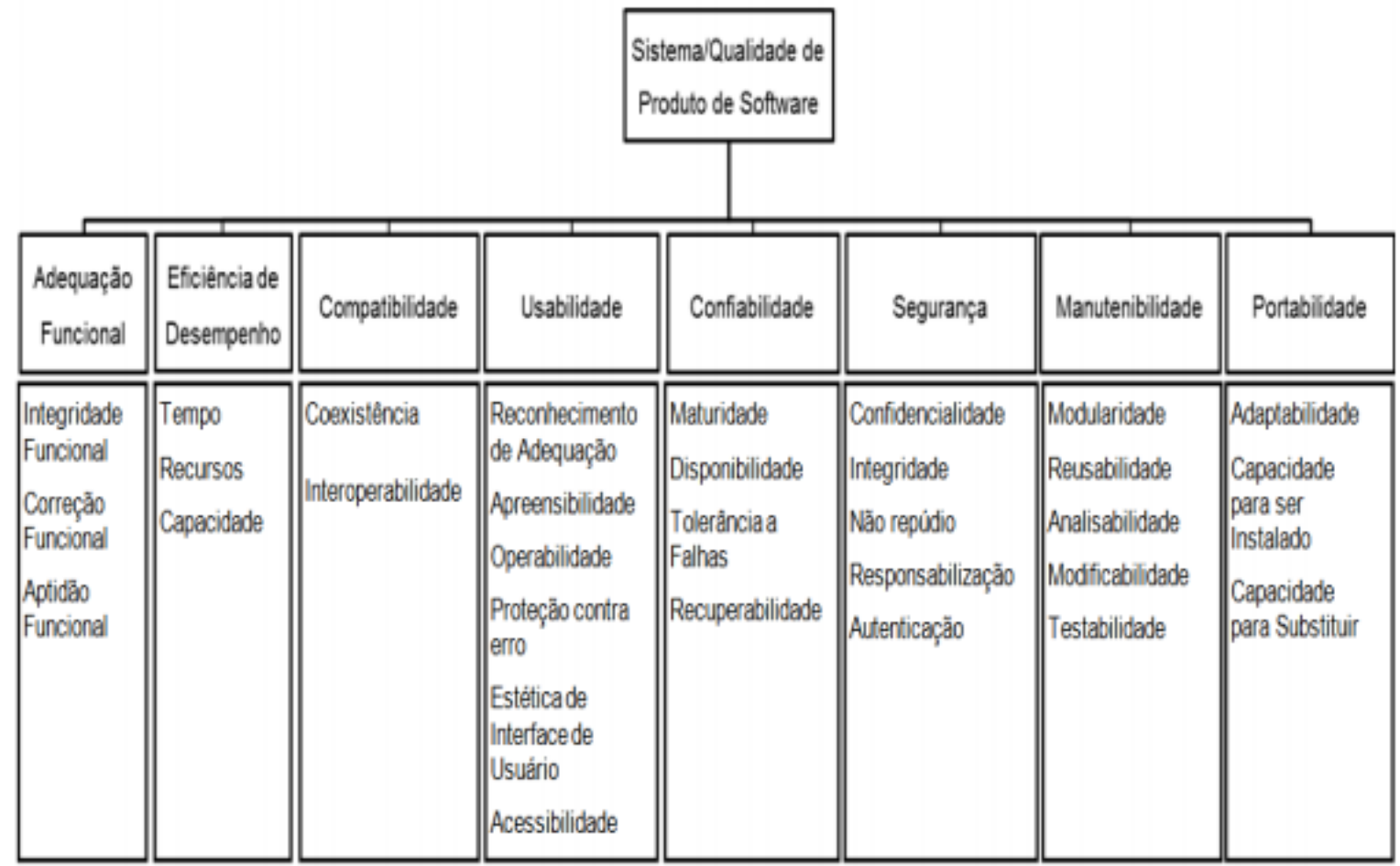

Figura 2 - Modelo de qualidade do produto Fonte: Oliveira (2012).

Essas características e subcaracterísticas estão assim definidas na norma ISO/IEC 25010, conforme tradução realizada por Oliveira (2012).

Adequação Funcional envolve o conjunto de atributos que evidenciam a existência de um conjunto de funções e suas propriedades específicas. Tal nível de qualidade é alcançado quando as funcionalidades do software atendem ao que foi solicitado em seus requisitos. Como subcaracterísticas têm-se: integridade funcional (atende às demandas dos usuários e permite o cumprimento dos objetivos e tarefas), correção funcional (fornece resultados corretos e precisos) e aptidão funcional (facilitam as tarefas dos usuários). 
Eficiência de desempenho aborda o conjunto de atributos que evidenciam o relacionamento entre o nível de desempenho do software e a quantidade de recursos usados, sob condições estabelecidas. Este nível de qualidade é alcançado quando o software atinge o desempenho previsto nos requisitos. Como subcaracterísticas têm-se: tempo (tempo de processamento do sistema atende aos requisitos), recursos (quantidade e tipos de recursos ao executar as suas funções) e capacidade (tamanho do banco de dados, número de usuários simultâneos, banda de comunicação, taxa de transferência de transações e tamanho do banco de dados).

Compatibilidade engloba o nível de troca de informações entre um produto, sistema ou componente com outros produtos, sistemas ou componentes, e/ou realizar suas funções imperativas, enquanto dividem o mesmo ambiente de hardware ou software. Este nível de qualidade é alcançado quando o software consegue trocar informações com outros sistemas no mesmo ambiente operacional. Como subcaracterísticas têm-se: coexistência (eficiência do sistema em alcançar suas funções em ambientes compartilhados) e interoperabilidade (troca e utilização de informações entre dois ou mais sistemas).

A usabilidade, por sua vez, envolve o conjunto de atributos que evidenciam o esforço necessário para utilizar o software, bem como o julgamento individual deste uso, por um conjunto explícito ou implícito de usuários. Este nível de qualidade é alcançado quando o software pode ser utilizado por usuários peculiares com níveis determinados de eficácia, eficiência e satisfação. Como subcaracterísticas têm-se: reconhecimento de adequação (reconhecimento se o sistema é adequado para suas necessidades), apreensibilidade (capacidade de aprender a usar o sistema com eficácia, eficiência e satisfação), proteção contra erro (sistema protege os usuários de cometer erros), operabilidade (características que tornam mais fácil operar e controlar), estética da interface do usuário (interface é agradável e gratificante para o 
usuário) e acessibilidade (sistema pode ser usado por pessoas com a mais ampla gama de características).

A confiabilidade aborda o conjunto de atributos que evidenciam a capacidade do software de manter seu nível de desempenho sob condições estabelecidas durante um período de tempo. Este nível de qualidade é alcançado quando o software, sob determinadas condições, consegue executar as suas funcionalidades de forma confiável. Como subcaracterísticas têmse: maturidade (confiabilidade do sistema sob condições normais de operação), tolerância a falhas (funcionamento conforme o esperado, apesar de falhas no hardware ou software), recuperabilidade (capacidade de recuperação dos dados afetados por falhas e restabelecer o estado desejado do sistema) e disponibilidade (disponibilidade para uso quando necessário).

Segurança envolve o grau em que um produto ou sistema protege informações e dados e controla o nível de acesso de pessoas, produtos ou sistemas de acordo com os tipos e níveis de autorização. Este nível de qualidade é alcançado quando o software protege suas informações e dados de acordo com níveis de autorização. Como subcaracterísticas têm-se: confidencialidade (garante que os dados sejam acessíveis somente às pessoas autorizadas), integridade (impede acessos não autorizados ou modificação de dados), não repúdio (ações e eventos podem ser provados, sem contestação), responsabilização (garantia de origem dos dados) e autenticação (garantia de identidade).

Manutenibilidade diz respeito ao conjunto de atributos que evidenciam o esforço necessário para fazer modificações especificadas do software. Este nível de qualidade é alcançado quando o software pode ser mantido ou modificado com eficácia e eficiência. Como subcaracterísticas têm-se: analisabilidade (possibilidade de diagnosticar falhas ou partes a serem modificadas no sistema), modificabilidade (capacidade de modificação sem introduzir defeitos ou degradar a qualidade do produto existente), modularidade (a mudança de um componente tem um impacto mínimo sobe outros componentes), reusabilidade (capacidade de 
reutilização ou reaproveitado na construção de outro software) e testabilidade (grau de eficácia e eficiência com que testes podem ser executados para determinar se os critérios estabelecidos foram atingidos).

Por fim, a portabilidade aborda o conjunto de atributos que evidenciam a capacidade de o software ser transferido de um ambiente para outro. Este nível de qualidade é alcançado quando o software pode ser transferido para outro ambiente operacional definido nos seus requisitos com eficiência e eficácia. Como subcaracterísticas têm-se: adaptabilidade (capacidade do software de se adaptar a diferentes ambientes operacionais ou capacidade de expansão de capacidade interna), capacidade de ser instalado (instalação ou desinstalação com êxito em um determinado ambiente) e capacidade para substituir (substituição de outro software com a mesma finalidade ou facilidade de atualizar em uma nova versão).

O modelo de qualidade em uso especifica cinco características de qualidade, das quais algumas estão subdivididas em subcaracterísticas, conforme a Figura 3, a seguir.

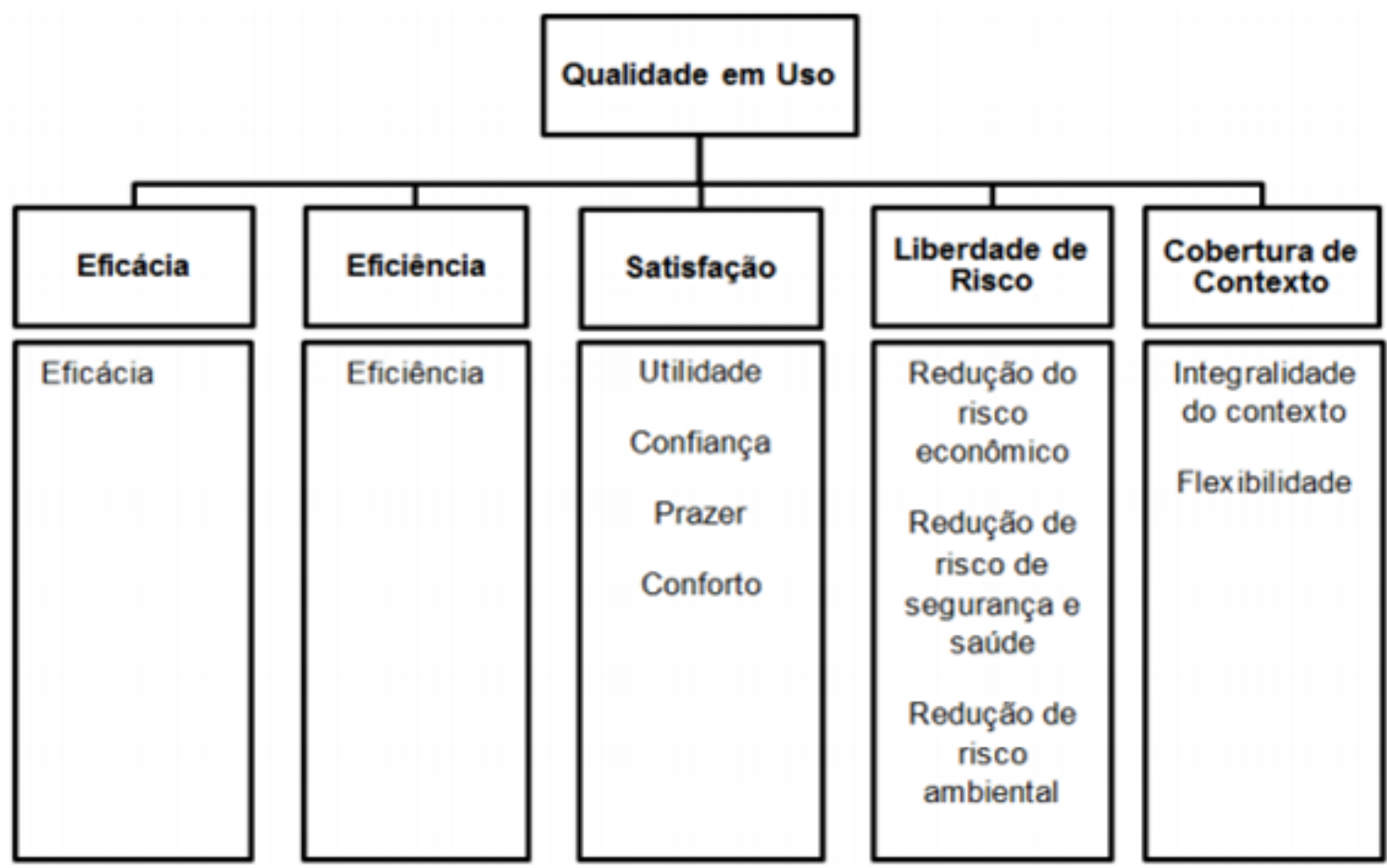

Figura 3 - Modelo de qualidade em uso Fonte: Oliveira (2012). 
Segundo Morais e Costa (2014), o modelo de avaliação da qualidade do software desenvolvido pela ISO e a IEC tem como principal objetivo fornecer resultados qualitativos e quantitativos sobre a qualidade por meio de resultados que sejam compreensíveis, aceitáveis e confiáveis.

Cabe ressaltar que a norma ISO/IEC 25010 pode ser estritamente empregada para avaliação de software em produção e após seu desenvolvimento. Outras técnicas permitem medir a qualidade do processo de desenvolvimento de software, nas diversas outras etapas de seu ciclo de vida do projeto à implementação.

O modelo de qualidade da norma ISO/IEC 25010 embasa o presente projeto acerca da avaliação do sistema PECJUDICIAL na perspectiva dos usuários internos.

\subsection{A TECNOLOGIA DA INFORMAÇÃO E COMUNICAÇÃO E A NOVA GESTÃO PÚBLICA}

Os pesquisadores que abordaram o tema da reforma do setor público pouco discutiram a respeito das tecnologias. Entretanto, a partir do final dos anos 1990, passaram a dar maior atenção à introdução de TI nos governos, sob o rótulo E-GOV. Este tema parecia ser alinhado com a agenda da NGP, pois os objetivos de eficiência, uso de mecanismos de mercado e prestação de contas estavam presentes em ambos os preceitos teóricos (HUGHES, 2012).

Os sistemas de informação facilitariam focalizar os esforços do governo na prestação de serviços e apoiariam a revisão de processos. A TI não apenas era ligada à NGP, mas também descrita como um dos motores das reformas, e uma das razões pelas quais os cidadãos estariam demandando que governos oferecessem serviços análogos aos do setor privado (HUGHES, 2012). 
A inovação em TI poderia ser usada pelos governos como uma forma de tornar possíveis as mudanças propostas pela NGP, o que reforçaria a ideia de que ambos poderiam até ser vistos como parte de um mesmo movimento (HUGHES, 2012).

Danziger e Andersen (2002) revisaram a literatura de 1987 a 2000 a respeito dos impactos de TI na Administração Pública e buscaram identificar a distribuição de efeitos positivos e negativos nos atores e instituições afetados por TI. Os efeitos da adoção de TI foram agrupados em quatro categorias: capacidades, interações entre as unidades políticas, orientações nas decisões e ações políticas e a distribuição de valor. Segundo os autores, a maior parte dos impactos positivos se relaciona às capacidades de departamentos governamentais e está ligada a um aumento na eficiência.

Por sua vez, não há a consenso sobre a utilização de TIC e o efetivo incremento de resultados para o cidadão. Por exemplo, no Reino Unido há relatos de que a implementação de serviços intermediados por TI não levou em consideração princípios democráticos e de inclusão social (DAMODARAN et al, 2005). Segundo esta pesquisa, o envolvimento dos cidadãos somente é requisitado para a avaliação de sites governamentais.

Segundo Damian e Merlo (2013), apesar dos inúmeros benefícios oferecidos pelas TICs na atuação do Estado, muitas barreiras ainda precisam ser vencidas. Nesta mesma vertente, West (2004) identificou uma série de dificuldades a serem superadas como: a preocupação dos cidadãos com relação à privacidade e à segurança dos sites do governo; a falta de recursos para atender as necessidades de populações especiais; a indisponibilidade de computadores e da internet; a necessidade de educar o cidadão quanto à existência de serviços e informações onlines e o custo da infraestrutura do Governo Eletrônico.

Ainda segundo os autores, outro desafio é a necessidade de atuação dos governos em um novo panorama que é marcado por novas exigências impostas pelos cidadãos e pela própria multiplicidade e velocidade de desenvolvimento das soluções tecnológicas, que acabam 
infligindo aos gestores públicos a necessidade de realização de análises mais criteriosas dos objetivos, estratégias e metas dos governos para o uso das inúmeras possíveis soluções tecnológicas.

Frente à importância das TICs nos modelos atuais de gestão pública, estudar os processos de implementação e os resultados de sistemas voltados à gestão contribuem para a compreensão de gestores e pesquisadores sobre barreiras, alternativas e perspectivas nas organizações a serem discutidas nas organizações públicas.

\subsubsection{Barreiras à Implantação das TICs nas Organizações Públicas}

Segundo Seldin, Rainho e Caulliraux (2003), os elementos da cultura organizacional são, na maioria dos casos, de difícil entendimento e, ao mesmo tempo, determinam o que é ou não aceitável e desejável dentro da organização.

A implantação de uma tecnologia de informação e comunicação pode enfrentar diversos bloqueios culturais internos, sendo necessário um acompanhamento mais próximo dos processos operacionais aplicados, focando nos agentes internos e externos que influenciam as diversas variáveis que compõem o sistema.

De acordo com Mendes e Abrahão (1996), a cultura organizacional é o conjunto de valores compartilhados pelos seus membros, em todos os níveis hierárquicos, que distingue uma organização das demais. Trata-se de um conjunto de características-chave que a organização aprecia, partilha e utiliza para atingir seus objetivos.

Segundo Escrivão e Veiga (2002), a adoção de uma TIC significa mais que uma simples implantação de tecnologia. Implica em um processo de mudança organizacional, envolvendo não apenas a revisão nos processos, mas a realização de uma releitura no contexto cultural da organização.

Mas não é apenas a cultura organizacional que influencia o sucesso da implantação e implementação das TICs nas organizações. Segundo Prado et al (2010), a implantação de uma 
TIC em uma organização é influenciada por diversos fatores, como todo fenômeno organizacional. Desenvolver um modelo teórico que considere todos os possíveis fatores consiste em uma tarefa inexequível. Assim, Prado et al. (2010) propuseram um modelo de referência que considerasse os fatores mais relevantes envolvidos nesse fenômeno.

A Figura 4 apresenta quais variáveis podem se configurar como barreiras à implantação das TICs.

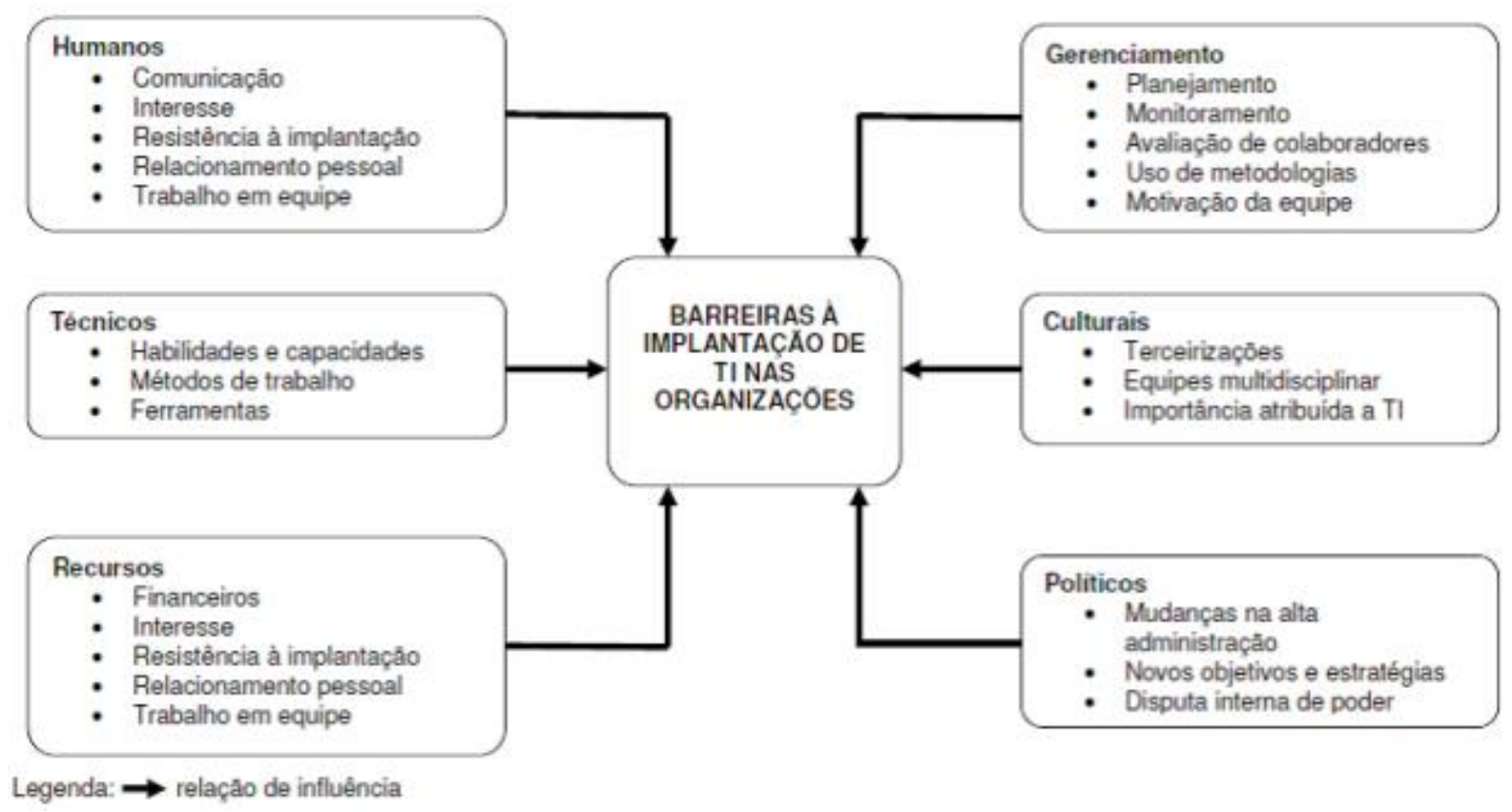

Figura 4 - Modelo de referência para as barreiras à implantação de TI nas organizações Fonte: Prado et al (2010).

Os fatores humanos abordam a comunicação entre os envolvidos no projeto e seu relacionamento interpessoal e os interesses pessoais, que podem provocar resistência à implantação da TIC e prejudicar o trabalho em equipe. Referências ao fator humano podem ser encontrados nos trabalhos de Adam e O’Doherty (2000) e Prado e Takaoka (2007), por exemplo, com especial ênfase na influência dos aspectos pessoais dos envolvidos na utilização das TICs e os resultados gerados na efetiva utilização da tecnologia.

Os fatores técnicos referem-se a todas as características e recursos técnicos disponíveis no projeto. É representado pelas habilidades e capacidades dos colaboradores, bem como pelos 
métodos. Goguen e Linde (1993) destacam a importância da utilização de métodos participativos na implementação do sistema, pois quanto maior a participação dos usuários na construção do sistema menor serão as barreiras na sua implementação.

Os recursos referem-se a todos os recursos materiais utilizados no projeto. Trata dos investimentos e recursos financeiros, bem como o software, o hardware, a infraestrutura de TI e o treinamento. Goguen e Linde (1993) e Prado e Takaoka (2007) destacaram a importância da escolha da ferramenta correta para alcançar diretamente os objetivos da organização. Antes de iniciar a utilização das TICs, o gestor deve verificar se a ferramenta utilizada irá de fato contribuir para melhor o desempenho organizacional. Grande parte da frustação dos usuários está na utilização de ferramentas inadequadas ou que não retratam a sua necessidade.

Os fatores de gerenciamento referem-se às atividades de gerenciamento como o planejamento, o monitoramento e a motivação da equipe. Bingi et al (1999) e Prado e Takaoka (2007) destacam que devido à complexidade do desenvolvimento e à implementação, existem diversas metodologias próprias para gerenciamento de projetos de TI. É fundamental que no projeto de TI haja um planejamento estratégico para a implementação, pois em diversos casos os projetos podem demorar anos e precisam ser constantemente revistos para melhor adequação da solução aos usuários e aos objetivos organizacionais.

Os fatores culturais referem-se às diferenças culturais que surgem pelo convívio de equipes multidisciplinares e pela participação de colaboradores terceirizados, que trazem consigo valores e práticas de outra cultura organizacional. Prado e Takaoka (2007) reforçam a necessidade da elaboração da solução de forma participativa, realizando o alinhamento entre os técnicos da área de TI, os usuários diretos e os objetivos estratégicos da organização.

Os fatores políticos referem-se ao apoio da alta administração ao projeto. Pode ser influenciado pelas mudanças no quadro da alta administração, bem como pelas mudanças nos objetivos e estratégias organizacionais. Albertin (2001) destaca que a grande rotatividade nos 
cargos, a existência de disputas internas na alta administração e no corpo gerencial da organização afetam diretamente a implementação das TICs.

As barreiras para a adoção e funcionamento das TICs em uma organização devem ser observadas pelos gestores, a fim de que haja um melhor alinhamento das estratégias de implementação e transposição de todos os empecilhos para a utilização e efetividade da tecnologia.

Os estudos, conceitos e modelos apontados no referencial teórico deste relato embasaram a condução da presente pesquisa. A seguir, tem-se a apresentação do método da pesquisa. 


\section{MÉTODO}

O escopo do presente estudo é profissional aplicado, empírico, de natureza descritiva e abordagem mista, ou seja, qualitativa e quantitativa (SEVERINO, 2014). Foi contemplado um órgão da esfera pública, o Ministério da Saúde (MS).

\subsection{SOBRE O LOCAL DA PESQUISA E O PECJUDICIAL}

A área de atendimento a demandas judiciais, no âmbito do MS, tem vivenciado constantes transformações desde a reestruturação da área de logística, com a concepção da Coordenação-Geral de Análise das Contratações de Insumos Estratégicos para a Saúde (CGIES), responsável pelo cumprimento das decisões judiciais.

Em continuidade ao trabalho iniciado em 2009, a área de demandas judiciais passou por diversas mudanças significativas e fundamentais. Compreendeu desde melhorias no espaço físico para prestação de serviço pelos servidores até à adoção de providências que imprimiram celeridade e eficiência no cumprimento das decisões, como a simplificação de procedimentos, orientada pela legislação pertinente e pelos princípios institucionais do MS.

Faltava, entretanto, o reconhecimento institucional à área de atendimento às decisões judiciais como setor carecedor de definição interna de competências, frente ao seu patente desenvolvimento, impulsionado pelo número crescente de ações propostas no Poder Judiciário. A ausência de formalização foi suprida com a criação da Coordenação de Demanda Judicial (CDJU), por meio da Portaria n. 3.965, de 14 de dezembro de 2010, publicada no Diário Oficial da União em 15 de dezembro de 2010, subordinada à CGIES, ambas inseridas no Departamento de Logística em Saúde (DLOG).

Em 2012 foi criado o Sistema de Ação Judicial de Medicamentos para a informatização do cadastro dos pacientes e das remessas dos insumos. Entretanto, o Sistema não possuía documentação, impossibilitando a elaboração de melhorias e manutenção. 
Em março 2014, tendo em vista o aumento expressivo das demandas judiciais, foi solicitado ao DATASUS a elaboração do PECJUDICIAL, sistema que contemplasse todas as áreas envolvidas no cumprimento da determinação judicial no MS e abarcasse toda a cadeia logística dos medicamentos fornecidos para o atendimento das decisões judiciais. Com o novo sistema, os processos físicos devem ser substituídos pelo processo eletrônico.

Teve início, então, o mapeamento dos requisitos do sistema no cumprimento das determinações judiciais pela empresa CTIS, contratada pelo DATASUS. O mapeamento foi concluído em dezembro de 2014, com início do desenvolvimento do sistema em janeiro de 2015.

Para o desenvolvimento do sistema foi utilizada a plataforma da IBM, denominada Maximo, e a conclusão do desenvolvimento ocorreu em julho de 2015. Após o desenvolvimento do sistema, foi realizada a homologação com cada gestor envolvido. Entretanto, devido ao lapso temporal entre o levantamento dos requisitos e o desenvolvimento do sistema, os gestores solicitaram novas adequações.

Realizou-se, então, o mapeamento dos requisitos das adequações e o desenvolvimento das soluções. A homologação final do sistema foi realizada em outubro de 2015. Devido a mudanças no corpo diretivo da Consultoria Jurídica do MS, a homologação final foi adiada para dezembro de 2015. Na fase inicial do funcionamento do PECJUDICIAL haveria dois tipos de processo, a saber: o físico e o eletrônico. Mas, à medida que os cumprimentos forem realizados, os processos físicos desaparecerão. Nos casos de medicamentos de uso continuo, os processos físicos deverão ser substituídos pelo eletrônico gradativamente.

O PECJUDICIAL irá informatizar todas as rotinas de trabalho no cumprimento das determinações judiciais e contemplará todas as áreas envolvidas do Ministério da Saúde conforme fluxograma de atividades constantes no Apêndice C. 
A implantação do PECJUDICIAL ocorreu em setembro de 2016 e a coleta de dados para alcance dos objetivos propostos iniciou-se em abril de 2016 e foi finalizada em outubro deste mesmo ano.

Em função dos diferentes objetivos específicos propostos no presente estudo, foram utilizadas diferentes técnicas para levantamento e análise de dados. Para facilitar a compreensão do leitor, as técnicas são apresentadas a seguir, de acordo com os objetivos correspondentes.

\subsection{OBJETIVO ESPECÍFICO 1}

Tem-se como objetivo 1: descrever barreiras e facilitadores para a implementação do PECJUDICIAL na organização. Para a avaliação dos facilitadores e das barreiras na implementação do sistema, foram conduzidas entrevistas semiestruturadas individuais com os chefes das principais áreas envolvidas no cumprimento da determinação judicial, conforme o Quadro 1. Os ocupantes de cargos de chefia foram escolhidos porque foram os pontos focais para o levantamento dos requisitos do sistema PECJUDICIAL nas respectivas áreas.

Quadro 1 - Participantes das entrevistas semiestruturadas

\begin{tabular}{|l|c|}
\hline \multicolumn{1}{|c|}{ ÁREA DO MINISTÉRIO DA SAÚDE } & $\begin{array}{l}\text { QUANTIDADE DE } \\
\text { PARTICIPANTES }\end{array}$ \\
\hline Consultoria do Ministério da Saúde & 1 \\
\hline Secretaria de Ciência, Tecnologia e Insumos Estratégicos & 1 \\
\hline Secretaria de Atenção à Saúde & 1 \\
\hline $\begin{array}{l}\text { Coordenação de Compra por Determinação Judicial } \\
\text { (CDJU) }\end{array}$ & 1 \\
\hline Serviço de Armazenagem e Distribuição de Medicamentos & 1 \\
\hline Departamento de Informática do SUS & 1 \\
\hline
\end{tabular}

Fonte: elaborado pelo autor.

O coordenador da CDJU não foi incluído nas entrevistas por ser o pesquisador e autor deste trabalho. Assim, foi entrevistado seu substituto. É importante ressaltar que todos esses participantes ocupantes de cargos de chefia fazem parte do corpo efetivo de servidores do MS. Considerando a rotatividade comum nos cargos de chefia da Administração Pública, foi 
importante considerar pessoas que acompanharam todo o processo de implementação do sistema.

As entrevistas foram realizadas no mês de setembro de 2016, pois para levantar barreiras e facilitadores era necessário o acompanhamento da implementação e a efetiva utilização e avaliação da ferramenta. Para viabilizar a coleta dos dados, foram estabelecidos os seguintes passos: contato inicial com os chefes, a fim de explicar os objetivos da pesquisa e esclarecer alguns conceitos que podem auxiliar na compreensão das perguntas e realizar o agendamento das entrevistas; segundo contato com chefes, em horários agendados, para a realização da entrevista. O roteiro completo de perguntas encontra-se no Apêndice A.

Quanto às respostas referentes às barreiras e facilitadores de implementação, o conteúdo foi analisado primeiramente com base em análises categoriais temáticas iniciais (barreiras ou facilitadores) e finais, a partir das categorias identificadas na literatura sobre fatores que afetam a implementação de TICs nas organizações: humanos, técnicos, recursos, gerenciamento, culturais e políticos (BARDIN, 2011; ADAM; O’DOHERTY, 2000; PRADO; TAKAOKA, 2007). Também foram indicadas as frequências das categorias encontradas e a relevância atribuída pelo respondente à categoria.

\subsection{OBJETIVO ESPECÍFICO 2}

Tem-se como objetivo 2: realizar a avalição dos resultados preliminares da utilização do sistema PECJUDICIAL na perspectiva dos usuários internos. Para tanto, foi aplicado o questionário de avaliação do sistema modelo ISO/IEC 25010 - Software Quality Requirements and Evaluation (SQuaRE) - em português denominado de Requisitos e Avaliação da Qualidade de Software, proposto por Oliveira (2012). O Modelo de Qualidade utilizado como referência foi justamente o da norma ISO/IEC 25010, que especifica os requisitos de qualidade em termos de características e subcaracterísticas do sistema, as quais estão expressas nos itens do questionário adotado. 
O questionário de Oliveira (2012) envolve itens orientados à avaliação de especialistas em tecnologia da informação e questões orientadas à avaliação de usuários do software. Para este estudo, foi contemplada a avaliação dos usuários do software. Foram apresentados 36 itens fechados, os quais se organizam em torno das seguintes características de sistema: adequação funcional, confiabilidade, usabilidade, eficiência de desempenho, compatibilidade e segurança. Os itens deviam ser respondidos de acordo com as seguintes opções: A - Acordo; D Desacordo; e NA - Não se Aplica.

O nível A (Acordo) significa que o PECJUDICIAL atende ao requisito; o nível D (Desacordo) indica que não atende ao requisito e o nível NA (Não se Aplica) corresponde ao atributo que não foi avaliado ou que não é aplicável ao software. Os itens avaliados em (D) contribuíram para identificar as necessidades de melhorias no PECJUDICIAL. O questionário, com seus itens e respectivas características, encontra-se no Apêndice B.

Para a obtenção dos valores das características e subcaracterísticas de qualidade, os dados foram calculados e analisados de acordo com as seguintes regras, extraídas da Associação Brasileira de Normas Técnicas (ABNT) - NBR ISO-IEC 14598-6, conforme a equação que se segue:

$$
\begin{gathered}
\mathrm{Vc}=\sum \mathrm{Vsc} / \mathrm{nsc} \\
\mathrm{Vsc}=\sum \mathrm{m} /(\mathrm{n}-\mathrm{nd})
\end{gathered}
$$

Onde:

$\mathrm{Vc}=$ valor medido da característica;

Vsc = valor medido da subcaracterística;

nsc $=$ número de subcaracterísticas;

$\mathrm{m}=1$, se a resposta for positiva; senão, é 0 ;

$\mathrm{n}=$ número total de medidas; $\mathrm{e}$

nd = número de questões descartadas. 
Para obter o valor da característica de forma direta e em valores percentuais, neste estudo aplicou-se a fórmula apresentada anteriormente onde:

$\mathrm{Vc}=$ valor medido da característica;

Vsca = valor das subcaracterísticas com resposta acordo;

$\mathrm{a}=$ resposta acordo;

$\mathrm{d}=$ resposta desacordo; $\mathrm{e}$

na $=$ resposta não se aplica.

Para julgar os resultados obtidos, foi utilizada a escala de avaliação para subcaracterísticas, proposta na norma ABNT NBR ISO-IEC 14598-6, que indica os valores esperados para cada uma das características e subcaracterísticas, comparando-as com os valores obtidos na aplicação da fórmula matemática acima. Os percentuais de todas as subcaracterísticas devem estar relacionados com o valor esperado, ou seja, mais de $70 \%$ de respostas positivas que apontem concordância com as características avaliadas.

Para responder ao questionário, foram selecionados representantes de cada equipe envolvida no cumprimento da determinação judicial. Os representantes escolhidos são os chefes de equipe e o respectivo substituto. No DATASUS, os representantes foram os responsáveis pela construção do sistema.

Inicialmente foram escolhidos somente os chefes e os respectivos substitutos de cada setor, pois como o sistema foi recém implementado são os únicos que possuem atividades diárias no sistema, tendo desta forma maior capacidade de avalia-lo. O total de usuários internos do sistema no cumprimento das determinações judiciais são 67 usuários.

O Quadro 2 demonstra a quantidade de participantes por área. 
Quadro 2 - Respondentes do questionário para avaliação do PECJUDICIAL

\begin{tabular}{|c|c|}
\hline ÁREA DO MINISTÉRIO DA SAÚDE & $\begin{array}{l}\text { QUANTIDADE DE } \\
\text { PARTICIPANTES }\end{array}$ \\
\hline Consultoria do Ministério da Saúde & 3 \\
\hline Secretaria de Ciência, Tecnologia e Insumos Estratégicos & 2 \\
\hline Secretaria de Atenção à Saúde & 2 \\
\hline Secretaria de Vigilância Sanitária & 2 \\
\hline Coordenação de Compra por Determinação Judicial - CDJU & 2 \\
\hline Serviço de Armazenagem e Distribuição de Medicamentos & 2 \\
\hline Coordenação de Execução Orçamentária e Financeira & 2 \\
\hline Departamento de Informática do SUS & 3 \\
\hline
\end{tabular}

Fonte: elaborado pelo autor

Os formulários foram enviados via FORMSUS que é um serviço do Departamento de Informática do Sistema Único de Saúde (DATASUS) para a criação de formulários na web, destinado ao uso do Sistema Único de Saúde (SUS) e de órgãos públicos parceiros, para atividades de interesse público. Foi informado aos participantes que a participação era voluntária e anônima, ou seja, os respondentes não seriam identificados.

\subsection{OBJETIVO ESPECÍFICO 3}

Tem-se como objetivo 3: realizar a análise comparativa dos resultados preliminares dos custos por atividade envolvidos no atendimento da determinação judicial pré e pós adoção do PECJUDICIAL. Para a avaliação dos resultados preliminares do custo total processual no cumprimento das determinações judiciais, foi realizada a análise comparativa entre o custo por atividade antes e depois da adoção do sistema.

A metodologia adotada para levantamento dos custos operacionais foi o modelo de custeio Active Base Cost (ABC) e o levantamento dos custos operacionais foi realizado somente no Departamento de Logística em Saúde (DLOG).

A aplicação do modelo em questão exigiu a observância de algumas etapas que, na concepção de Corrêa (2002), devem ser divididas da seguinte forma: 
I. Identificação das atividades relevantes;

II. Levantamento dos custos consumidos pelas atividades;

III. Identificação e seleção dos direcionadores de custos;

IV. Atribuição de custos às atividades.

Para a identificação das atividades relevantes desempenhadas, foram realizadas entrevistas com todos os colaboradores participantes do DLOG que possuem alguma atividade no cumprimento das determinações judicias através de entrevista com perguntas abertas, conforme Apêndice A, totalizando 45 colaboradores.

Após as entrevistas, foi atribuído o percentual do tempo gasto com cada atividade para atribuir o custo da mão de obra. Foram também analisados os documentos internos de custo do departamento para identificar e selecionar os direcionadores de custos para posterior atribuição de custos às atividades. Para a definição de salários e gratificações dos colaboradores foi realizada consulta ao site: www.transparência.gov, através de busca por nome.

Para levantamento dos custos por atividade foram analisados os documentos internos do DLOG e o site www.transparência.gov para a definição dos salários e das gratificações dos colaboradores.

O Quadro 3 apresenta uma matriz de amarração sobre as técnicas adotadas para alcance de cada objetivo da pesquisa.

Quadro 3 - Técnicas adotadas para alcance dos objetivos da pesquisa

\begin{tabular}{|c|c|c|c|c|c|c|}
\hline \multicolumn{2}{|c|}{ OBJETIVO GERAL: Analisar a implementação do sistema PECJUDICIAL no atendimento das determinações judiciais } \\
em que a União é obrigada a fornecer insumos para saúde.
\end{tabular}




\begin{tabular}{|c|c|c|c|c|c|}
\hline $\begin{array}{c}\text { sistema PECJUDICIAL } \\
\text { na organização }\end{array}$ & & & & & \\
\hline $\begin{array}{l}\text { 2. Realizar a avalição } \\
\text { dos resultados } \\
\text { preliminares da } \\
\text { utilização do sistema } \\
\text { PECJUDICIAL na } \\
\text { perspectiva dos usuários } \\
\text { internos }\end{array}$ & & Apêndice B & & & $\begin{array}{l}\text { Análise } \\
\text { estatística } \\
\text { descritiva }\end{array}$ \\
\hline \multirow{5}{*}{$\begin{array}{l}\text { 3. Realizar a análise } \\
\text { comparativa dos } \\
\text { resultados preliminares } \\
\text { dos custos por atividade } \\
\text { envolvidos no } \\
\text { atendimento da } \\
\text { determinação judicial } \\
\text { pré e pós adoção do } \\
\text { PECJUDICIAL }\end{array}$} & $\begin{array}{c}\text { Identificação das } \\
\text { atividades } \\
\text { relevantes }\end{array}$ & & & $\begin{array}{c}\text { Apêndice } \\
\text { A }\end{array}$ & $\begin{array}{c}\text { Análise de } \\
\text { categorização }\end{array}$ \\
\hline & $\begin{array}{l}\text { Levantamento dos } \\
\text { custos consumidos } \\
\text { pelas atividades }\end{array}$ & & $\begin{array}{l}\text { Relatório de } \\
\text { custos do } \\
\text { DLOG }\end{array}$ & & $\begin{array}{c}\text { Análise } \\
\text { documental }\end{array}$ \\
\hline & $\begin{array}{c}\text { Identificação e } \\
\text { seleção dos } \\
\text { direcionadores de } \\
\text { custos }\end{array}$ & & $\begin{array}{l}\text { Relatório de } \\
\text { custos do } \\
\text { DLOG }\end{array}$ & & $\begin{array}{c}\text { Análise } \\
\text { documental }\end{array}$ \\
\hline & $\begin{array}{l}\text { Atribuição de } \\
\text { custos às } \\
\text { atividades } \\
\end{array}$ & & $\begin{array}{l}\text { Relatório de } \\
\text { custos do } \\
\text { DLOG }\end{array}$ & & $\begin{array}{c}\text { Análise } \\
\text { documental }\end{array}$ \\
\hline & $\begin{array}{l}\text { Atribuição dos } \\
\text { custos das } \\
\text { atividades aos } \\
\text { produtos. }\end{array}$ & & $\begin{array}{l}\text { Relatório de } \\
\text { custos do } \\
\text { DLOG }\end{array}$ & & $\begin{array}{c}\text { Análise } \\
\text { documental }\end{array}$ \\
\hline
\end{tabular}

Fonte: Adaptação do modelo elaborado por Darcy Hanashiro

Considerando que o pesquisador também é servidor do MS, foram tomados alguns cuidados durante a coleta de dados para evitar o enviesamento dos achados em função de desejabilidade social nas respostas dos participantes. Antes do levantamento de informação, quer presencial ou por formulário eletrônico, foi informado que os dados obtidos seriam utilizados como avaliação do sistema e que era fundamental que os respondentes / entrevistados fossem honestos nas informações prestadas, a fim de que informações geradas retratassem de forma fidedigna a realidade do Ministério da Saúde para compor um relatório de melhorias ao sistema PECJUDICIAL. De forma alguma os resultados seriam utilizados para fins não acadêmicos ou que não fossem voltados para melhorias do sistema. Vale ressaltar que os participantes de todas as etapas são colaboradores do quadro do MS. 


\section{RESULTADOS}

Este capítulo foi organizado em três seções principais, seguindo a ordem de apresentação dos objetivos específicos. Portanto, iniciou-se pela identificação das barreiras e facilitadores presentes na implantação do sistema PECJUDICIAL no Ministério da Saúde. Em segundo lugar, tratou-se apresentar os resultados da avaliação do sistema na perspectiva dos usuários internos, em conformidade com as métricas estabelecidas a partir dos conjuntos de normas estabelecidos pela ISO/IEC 25000 - Software Quality Requirements and Evaluation (SQuaRE). Finalmente, foram apresentados os resultados iniciais associados aos custos envolvidos no processo de aquisição de insumos para saúde para atendimento de determinação judicial antes e após adoção do sistema PECJUDICIAL.

\subsection{BARREIRAS E FACILITADORES NA IMPLEMENTAÇÃO DO SISTEMA PECJUDICIAL}

As barreiras e facilitadores presentes na implementação do Sistema foram levantadas por meio de entrevista, conforme informações apresentadas na seção de método. Ao todo, foram 6 participantes que apontaram 35 barreiras e 12 facilitadores. As evocações foram classificadas de acordo com categorias identificadas na literatura como as possíveis barreiras e facilitadores na implementação de sistemas levantadas por Prado et al (2010). Foram, portanto, utilizadas as categorias: fatores humanos, fatores políticos, fatores recursos, fatores técnicos, fatores gerenciais e fatores culturais

Foram contabilizadas as evocações referentes a cada categoria. Caso houvesse alguma evocação que não se enquadrasse nas categorias pré-estabelecidas, uma categoria seria formada, explicada e elucidada. Não foi o caso verificado. A Tabela 1 apresenta as categorias, exemplos de evocações de cada uma e a frequência com que foram mencionadas pelos participantes. 
Tabela 1 - Fatores que influenciaram a implementação do sistema

\begin{tabular}{|c|c|c|c|}
\hline \multicolumn{4}{|c|}{ BARREIRAS } \\
\hline Fator & Exemplos & $\begin{array}{c}\text { Total de } \\
\text { evocações }\end{array}$ & $\begin{array}{c}\text { Percentual do } \\
\text { total de evocações }\end{array}$ \\
\hline Humano & $\begin{array}{l}\text { Áreas relutantes a mudança } \\
\text { Falta de comprometimento dos envolvidos } \\
\text { Dificuldade de agendamento das reuniões de } \\
\text { levantamento de requisito } \\
\text { Resistência a informatização das atividades } \\
\text { Receio da perda dos empregos para os consultores, } \\
\text { com a informatização das atividades }\end{array}$ & 12 & $34 \%$ \\
\hline Técnico & $\begin{array}{l}\text { Dificuldade de adequação da ferramenta } \\
\text { Grande número de envolvidos no sistema } \\
\text { Morosidade no desenvolvimento da ferramenta } \\
\text { Descumprimento dos prazos estabelecidos nos } \\
\text { cronogramas pela equipe do DATASUS } \\
\text { Falta de desenvolvedores da plataforma MAXIMO no } \\
\text { mercado }\end{array}$ & 9 & $26 \%$ \\
\hline Político & $\begin{array}{l}\text { Rotatividade do } 1^{\circ} \text { escalão gerando descontinuidade, } \\
\text { retrabalho e falta de direcionamento } \\
\text { Falta de apoio da alta gestão } \\
\text { Saída dos gestores envolvidos no processo de } \\
\text { cumprimento da determinação judicial, especialmente } \\
\text { nas áreas finalísticas } \\
\text { Priorização de outros projetos pelo DATASUS }\end{array}$ & 7 & $20 \%$ \\
\hline Recursos & $\begin{array}{l}\text { Limitações da ferramenta MAXIMO } \\
\text { Dificuldade de adequação da ferramenta } \\
\text { Ferramenta ineficiente e não retrata as necessidades do } \\
\text { departamento } \\
\text { Impossibilidade de adequação da ferramenta às rotinas } \\
\text { de trabalho }\end{array}$ & 4 & $11 \%$ \\
\hline Gerenciamento & $\begin{array}{l}\text { Falta de reunião de alinhamento } \\
\text { Falta de comunicação entre os interessados no sistema } \\
\text { Dificuldade de alinhamento das informações }\end{array}$ & 3 & $9 \%$ \\
\hline TOTAL & & 41 & $100 \%$ \\
\hline
\end{tabular}

Fonte: elaborado pelo autor 
As barreiras mais recorrentes na implementação, sob a ótica dos participantes, foram de natureza humana, seguidas pelas barreiras técnicas e políticas. Não foram relatadas barreiras de natureza cultural.

Após o levantamento das barreiras, cada participante apontou a principal barreira para a implementação do sistema PECJUDICAL, dentre aquelas por ele mencionadas. O Quadro 4 apresenta os resultados encontrados.

Quadro 4 - Principais barreiras à implementação do sistema

\begin{tabular}{|c|l|c|}
\hline ENTREVISTADO & \multicolumn{1}{|c|}{ PRINCIPAL BARREIRA } & FATOR \\
\hline 1 & $\begin{array}{l}\text { Rotatividade do } 1^{\mathbf{o}} \text { escalão gerando descontinuidade, } \\
\text { retrabalho e falta de direcionamento }\end{array}$ & Político \\
\hline 2 & Falta de apoio da alta gestão & Político \\
\hline 3 & Rotatividade dos envolvidos no processo & Técnico \\
\hline 4 & $\begin{array}{l}\text { Ferramenta ineficiente e não retrata as necessidades do } \\
\text { departamento }\end{array}$ & Político \\
\hline 5 & $\begin{array}{l}\text { Saída dos gestores envolvidos no processo de cumprimento da } \\
\text { determinação judicial, especialmente nas áreas finalísticas }\end{array}$ & Político \\
\hline 6 & Rotatividade dos gestores &
\end{tabular}

Fonte: elaborado pelo autor.

Dos seis entrevistados, cinco informaram que a principal barreira à implementação do sistema é de natureza política. Um respondente indicou as próprias características da ferramenta, ou seja, um fator técnico, como principal barreira. Para a interpretação de tal barreira técnica, os resultados referentes à avaliação dos usuários podem oferecer informações adicionais e auxiliar o leitor.

Após o levantamento das barreiras, foi realizado o levantamento dos fatores que facilitaram a implantação do sistema PECJUDICIAL. Foram identificadas 12 evocações, que puderam ser classificadas de acordo com três categorias. A Tabela 2 apresenta os resultados. 
Tabela 2 - Principais facilitadores à implementação do sistema

\begin{tabular}{|c|c|c|c|}
\hline \multicolumn{4}{|c|}{ FACILITADORES } \\
\hline Fator & Exemplo & $\begin{array}{c}\text { Total de } \\
\text { evocações }\end{array}$ & $\begin{array}{c}\text { Percentual do total de } \\
\text { evocações }\end{array}$ \\
\hline Gerenciamento & $\begin{array}{l}\text { Gestor do sistema persistente } \\
\text { Gestor único para a ferramenta }\end{array}$ & 2 & $17 \%$ \\
\hline Político & $\begin{array}{l}\text { Patrocinadores do sistema no alto escalão } \\
\text { do Ministério da Saúde } \\
\begin{array}{l}\text { Mesma equipe de mapeamento das } \\
\text { atividades do início ao fim do projeto }\end{array} \\
\begin{array}{l}\text { Necessidade de atendimento das } \\
\text { determinações judiciais de forma mais } \\
\text { rápida devido a penalização de agentes } \\
\text { públicos. }\end{array}\end{array}$ & 4 & $33 \%$ \\
\hline Recurso & $\begin{array}{l}\begin{array}{l}\text { Disponibilidade orçamentária para a } \\
\text { realização de atualizações e mudanças }\end{array} \\
\text { Ferramenta escolhida para o } \\
\text { desenvolvimento do sistema } \\
\text { Ferramenta permite mudanças com baixo } \\
\text { impacto na configuração do sistema }\end{array}$ & 4 & $33 \%$ \\
\hline Humano & Equipe de apoio adequada & 2 & $17 \%$ \\
\hline TOTAL & & 12 & $100 \%$ \\
\hline
\end{tabular}

Fonte: elaborado pelo autor.

Os fatores humanos, políticos, recursos e gerenciamento foram aqueles que concentraram os facilitadores do processo de implementação. Os fatores mais relevantes foram os de recursos e políticos, pois ambos possuem 33\% do total de evocações levantadas.

Cabe ressaltar que o número de barreiras (35) apontadas pelos entrevistados foi superior ao número de facilitadores (12), demonstrando que, na visão dos usuários, o PECJUDICIAL teve muito mais fatores que retardaram e dificultaram a sua implementação do que fatores que favoreceram o processo. 


\subsection{AVALIAÇÃO DO SISTEMA PECJUDICIAL NA PERSPECTIVA DOS USUÁRIOS INTERNOS}

O sistema PECJUDICIAL foi avaliado pelos seus usuários internos com base em cinco características: adequação funcional, confiabilidade, usabilidade, eficiência de desempenho e compatibilidade.

A avaliação da característica adequação funcional foi realizada considerando-se as subcaracterísticas integridade funcional, correção funcional e aptidão funcional, conforme mostra a Tabela 3.

Tabela 3 - Distribuição das respostas relativas à Adequação Funcional do PECJUDICIAL

\begin{tabular}{|c|c|c|c|c|}
\hline ADEQUAÇÃO FUNCIONAL & ACORDO* & DESACORDO $*$ & $\begin{array}{c}\text { NÃO SE } \\
\text { APLICA* }\end{array}$ & TOTAL \\
\hline \multicolumn{5}{|c|}{ 1.1 INTEGRIDADE FUNCIONAL } \\
\hline $\begin{array}{l}\text { 1.1.1 O PECJUDICIAL atende as } \\
\text { necessidades de sua equipe no } \\
\text { cumprimento das determinações } \\
\text { judiciais }\end{array}$ & $14(78 \%)$ & $4(22 \%)$ & $0(0 \%)$ & 18 \\
\hline $\begin{array}{l}\text { 1.1.2 O PECJUDICIAL dispõe de } \\
\text { todas as funções necessárias para } \\
\text { execução de suas atividades? }\end{array}$ & $10(56 \%)$ & $8(44 \%)$ & $0(0 \%)$ & 18 \\
\hline \multicolumn{5}{|c|}{ 1.2 CORREÇÃO FUNCIONAL } \\
\hline $\begin{array}{l}\text { 1.2.1 O PECJUDICIAL permite o } \\
\text { correto cumprimento da } \\
\text { determinação judicial? }\end{array}$ & $16(89 \%)$ & $1(6 \%)$ & $1(6 \%)$ & 18 \\
\hline $\begin{array}{l}\text { 1.2.2 O PECJUDICIAL é preciso na } \\
\text { execução das funções no } \\
\text { cumprimento da determinação } \\
\text { judicial? }\end{array}$ & $15(83 \%)$ & $1(6 \%)$ & $2(11 \%)$ & 18 \\
\hline $\begin{array}{l}\text { 1.2.3 O PECJUDICIAL é preciso } \\
\text { nos resultados desejados para o } \\
\text { cumprimento da determinação } \\
\text { judicial? }\end{array}$ & $13(72 \%)$ & $2(11 \%)$ & $3(17 \%)$ & 18 \\
\hline \multicolumn{5}{|c|}{1.3 APTIDÃO FUNCIONAL } \\
\hline $\begin{array}{l}\text { 1.3.1 O PECJUDICIAL facilita o } \\
\text { cumprimento da determinação } \\
\text { judicial? }\end{array}$ & $18(100 \%)$ & $0(0 \%)$ & $0(0 \%)$ & 18 \\
\hline
\end{tabular}


Observa-se por meio da Tabela que na subcaracterística integridade funcional, $78 \%$ dos respondentes concordaram que o PECJUDICIAL atende as necessidades de sua equipe no que diz respeito ao cumprimento das determinações judiciais, enquanto $22 \%$ não concordaram. Ao ser avaliado se o sistema realmente dispõe de todas as funções necessárias para a plena execução das atividades da equipe, $56 \%$ dos respondentes estariam de acordo, enquanto $44 \%$ discordaram de tal opinião.

Levando-se em consideração a subcaracterística correção funcional, nota-se pelo estudo que $88 \%$ dos respondentes concordaram que o PECJUDICIAL permite o correto comprimento da determinação judicial. Apenas $6 \%$ dos respondentes disseram que a pergunta não se aplica ao sistema estudado ou não souberam responder à pergunta.

Dentre os 18 respondentes, $83 \%$ concordaram que o sistema executa as funções no cumprimento da determinação judicial com precisão e apenas $11 \%$ dos respondentes disseram que a pergunta não se aplica ao sistema estudado ou não souberam responder à pergunta. Um número menor de respondentes, $72 \%$, acredita que o sistema alcança os resultados desejados e $17 \%$ disse que a pergunta não se aplica ao sistema estudado ou não souberam responder à pergunta. Já na subcaracterística aptidão funcional, 100\% dos respondentes concordaram que o PECJUDICIAL de fato facilita o cumprimento da determinação judicial.

Portanto, no que diz respeito à adequação funcional do PECJUDICIAL, a característica que mais carece de melhorias na ótica dos usuários é a integridade funcional, pois foi aquela que agregou maior número de avaliações negativas.

A avaliação da característica confiabilidade foi realizada considerando-se as subcaracterísticas maturidade, tolerância a falhas, recuperabilidade e disponibilidade, conforme mostra a Tabela 4. 
Tabela 4 - Distribuição das respostas relativas à Confiabilidade do PECJUDICIAL

\begin{tabular}{|c|c|c|c|c|}
\hline CONFIABILIDADE & ACORDO * & DESACORDO* & $\begin{array}{c}\text { NÃO SE } \\
\text { APLICA* }\end{array}$ & TOTAL \\
\hline \multicolumn{5}{|c|}{ 2.1 MATURIDADE } \\
\hline $\begin{array}{l}\text { 2.1.1 O PECJUDICIAL não apresenta } \\
\text { falhas ou erros com frequência? }\end{array}$ & $14(78 \%)$ & $3(17 \%)$ & $1(6 \%)$ & 18 \\
\hline \multicolumn{5}{|c|}{ 2.2 TOLERÂNCIA A FALHAS } \\
\hline $\begin{array}{l}\text { 2.2.1.Quando ocorrem falhas o } \\
\text { PECJUDICIAL continua funcionando } \\
\text { conforme o esperado? }\end{array}$ & $10(56 \%)$ & $2(13 \%)$ & $6(33 \%)$ & 18 \\
\hline \multicolumn{5}{|c|}{ 2.3 RECUPERABILIDADE } \\
\hline $\begin{array}{l}\text { 2.3.1 O PECJUDICIAL é capaz de } \\
\text { recuperar dados afetados por falhas? }\end{array}$ & $4(22 \%)$ & $0(0 \%)$ & $14(78 \%)$ & 18 \\
\hline \multicolumn{5}{|c|}{ 2.4 DISPONIBILIDADE } \\
\hline $\begin{array}{l}\text { 2.4.1 O PECJUDICIAL fica acessível } \\
\text { para uso quando necessário? }\end{array}$ & $18(100 \%)$ & $0(0 \%)$ & $0(0 \%)$ & 18 \\
\hline
\end{tabular}

Pela análise da Tabela 4, conclui-se que para a subcaracterística maturidade, $78 \%$ dos respondentes concordaram que o sistema não apresenta falhas ou erros com frequência e apenas $6 \%$ dos respondentes disseram que a pergunta não se aplica ao sistema estudado ou não souberam responder à pergunta.

As subcaracterísticas tolerância a falhas e recuperabilidade teve um grande número de respondentes que disse que a pergunta não se aplica ao sistema estudado ou não soube responder à pergunta, 33\% e 78\% respectivamente. Percebe-se que as subcaracterísticas são técnicas e, portanto, o resultado obtido está dentro do esperado, tendo em vista que a maioria dos usuários respondentes não possui conhecimento específico na área de sistemas.

A subcaracterística disponibilidade obteve a avaliação mais positiva, pois todos os 18 respondentes concordaram que o PECJUDICIAL é realmente acessível para uso quando necessário.

Portanto, no que diz respeito à confiabilidade do PECJUDICIAL, as características que mais carecem de melhorias na ótica dos usuários são maturidade e tolerância a falhas, pois foram aquelas que agregaram maior número de avaliações negativas. 
A avaliação da característica usabilidade foi realizada considerando-se as subcaracterísticas reconhecimento de adequação, apreensibilidade, operabilidade, acessibilidade, proteção contra erros e estética de interface de usuário, conforme mostra a Tabela 5.

Tabela 5 - Distribuição das respostas relativas à Usabilidade do PECJUDICIAL

\begin{tabular}{|c|c|c|c|c|}
\hline USABILIDADE & ACORDO * & DESACORDO* & $\begin{array}{c}\text { NÃO SE } \\
\text { APLICA* }\end{array}$ & TOTAL \\
\hline \multicolumn{5}{|c|}{ 3.1 RECONHECIMENTO DE ADEQUAÇÃO } \\
\hline 3.1.1. É fácil entender o conceito e a aplicação? & $14(78 \%)$ & $4(22 \%)$ & $0(0 \%)$ & 18 \\
\hline 3.1.2. É fácil executar suas funções? & $13(72 \%)$ & $5(28 \%)$ & $0(0 \%)$ & 18 \\
\hline 3.1.3 O PECJUDICIAL possui tutorial/ajuda? & $10(56 \%)$ & $2(11 \%)$ & $6(33 \%)$ & 18 \\
\hline \multicolumn{5}{|c|}{ 3.2 APREENSIBILIDADE } \\
\hline 3.2.1. É fácil aprender a usar? & $13(72 \%)$ & $5(28 \%)$ & $0(0 \%)$ & 18 \\
\hline $\begin{array}{l}\text { 3.2.2 O PECJUDICIAL facilita a entrada de } \\
\text { dados pelo usuário? }\end{array}$ & $15(83 \%)$ & $3(17 \%)$ & $0(0 \%)$ & 18 \\
\hline $\begin{array}{l}\text { 3.2.3 O PECJUDICIAL facilita a saída de dados } \\
\text { pelo usuário? }\end{array}$ & $8(44 \%)$ & $3(17 \%)$ & $7(39 \%)$ & 18 \\
\hline \multicolumn{5}{|c|}{ 3.3 OPERABILIDADE } \\
\hline $\begin{array}{l}\text { 3.3.1 O PECJUDICIAL possui atributos que } \\
\text { torna mais fácil a realização do cumprimento de } \\
\text { determinação judicial? }\end{array}$ & $16(89 \%)$ & $2(11 \%)$ & $0(0 \%)$ & 18 \\
\hline $\begin{array}{l}\text { 3.3.2 O PECJUDICIAL fornece ajuda de forma } \\
\text { clara? }\end{array}$ & $13(72 \%)$ & $2(11 \%)$ & $3(17 \%)$ & 18 \\
\hline \multicolumn{5}{|c|}{ 3.4 ACESSIBILIDADE } \\
\hline $\begin{array}{l}\text { 3.4.1 O PECJUDICIAL pode ser utilizado por } \\
\text { pessoas com deficiência? }\end{array}$ & $14(78 \%)$ & $2(11 \%)$ & $2(11 \%)$ & 18 \\
\hline \multicolumn{5}{|c|}{ 3.5 PROTEÇÃO CONTRA ERROS } \\
\hline $\begin{array}{l}\text { 3.5.1 O PECJUDICIAL informa ao usuário a } \\
\text { entrada de dados inválidos? }\end{array}$ & $15(83 \%)$ & $0(0 \%)$ & $3(17 \%)$ & 18 \\
\hline \multicolumn{5}{|c|}{ 3.6 ESTÉTICA DE INTERFACE DE USUÁRIO } \\
\hline 3.6.1 O design gráfico é agradável ao usuário? & $13(72 \%)$ & $5(28 \%)$ & $0(0 \%)$ & 18 \\
\hline 3.6.2 A cor é agradável? & $14(78 \%)$ & $4(22 \%)$ & $0(0 \%)$ & 18 \\
\hline
\end{tabular}

Pode-se notar que para a subcaracterística reconhecimento de adequação, $78 \%$ dos respondentes consideram o sistema fácil de entender, enquanto os $22 \%$ restantes discordaram. No quesito facilidade na execução das funções, $72 \%$ responderam estarem de acordo, enquanto 
$28 \%$ estariam em desacordo. Sobre se o PECJUDICIAL possui um tutorial/ajuda, $56 \%$ dos respondentes concordaram, entretanto $33 \%$ não souberam responder. O número de não respondentes para este item é bastante elevado, pois o acesso ao tutorial para os usurários deve ser amplamente divulgado, gerando desta forma um alerta ao gestor.

Na subcaracterística apreensibilidade, quando questionados se realmente o sistema é fácil de aprender a usar, $28 \%$ dos respondentes discordaram, enquanto os $72 \%$ restantes disseram estar de acordo. Dos 18 respondentes, $83 \%$ disseram que a entrada de dados pelo usuário é facilitada pelo sistema PECJUDICIAL enquanto os $17 \%$ restantes acreditam no contrário. Já na saída de dados pelo usuário, 39\% dos respondentes não responderam, 44\% responderam que o sistema facilita a saída de dados pelo usuário e apenas $17 \%$ discordaram da opinião anterior.

A terceira subcaracterística avaliada, operabilidade, obteve avaliações positivas dos respondentes, pois $89 \%$ concordaram que o sistema possui atributos que torna mais fácil a realização do cumprimento da determinação judicial. Um total de $87 \%$ também disse que o PECJUDICIAL disponibiliza ajuda de forma clara e sucinta.

Sobre a subcaracterística da usabilidade, a acessibilidade, $78 \%$ dos respondentes concordaram quando foram indagados que o Sistema pode ser usado por pessoas portadoras de deficiência. Apenas $11 \%$ dos respondentes não souberam responder ao questionamento.

Um total de $83 \%$ dos respondentes também concordou que o sistema informa corretamente aos usuários quando os dados de entrada são inválidos. Com relação à estética da interface de usuário, $72 \%$ das pessoas responderam que o design é agradável ao usuário. Já com relação à cor, $78 \%$ dos respondentes concordaram que a cor é agradável.

Assim, sobre a usabilidade as características que merecem maior atenção e cuidado, a fim de aprimorar a avaliação, consistem em reconhecimento de aplicação e apreensibilidade, pois foram aquelas que agregaram maior número de avaliações negativas. 
A avaliação da característica eficiência de desempenho foi realizada considerando-se as subcaracterísticas tempo, recursos e capacidade, conforme mostra a Tabela 6.

Tabela 6 - Distribuição das respostas relativas à Eficiência do Desempenho do PECJUDICIAL

\begin{tabular}{|c|c|c|c|c|}
\hline EFICIÊNCIA DE DESEMPENHO & ACORDO* & DESACORDO $*$ & $\begin{array}{c}\text { NÃO SE } \\
\text { APLICA* }\end{array}$ & TOTAL \\
\hline \multicolumn{5}{|c|}{ 4.1 TEMPO } \\
\hline $\begin{array}{l}\text { 4.1.1 O tempo de resposta do software é } \\
\text { adequado? }\end{array}$ & $15(83 \%)$ & $1(6 \%)$ & $2(11 \%)$ & 18 \\
\hline $\begin{array}{l}\text { 4.1.2 O tempo de execução do software é } \\
\text { adequado? }\end{array}$ & $15(83 \%)$ & $3(17 \%)$ & $0(0 \%)$ & 18 \\
\hline \multicolumn{5}{|c|}{ 4.2 RECURSOS } \\
\hline $\begin{array}{l}\text { 4.2.1. Os recursos utilizados pelo software são } \\
\text { adequados? }\end{array}$ & $6(33 \%)$ & $2(11 \%)$ & $10(56 \%)$ & 18 \\
\hline \multicolumn{5}{|c|}{ 4.3 CAPACIDADE } \\
\hline $\begin{array}{l}\text { 4.3.1 O PECJUDICIAL permite uma boa } \\
\text { navegação? }\end{array}$ & $16(89 \%)$ & $2(11 \%)$ & $0(0 \%)$ & 18 \\
\hline 4.3.2 O PECJUDICIAL é rápido? & $15(83 \%)$ & $3(17 \%)$ & $0(0 \%)$ & 18 \\
\hline
\end{tabular}

Na subcaracterística tempo, $83 \%$ respondentes acreditam que o tempo de execução do software do sistema é adequado e somente $11 \%$ dos respondentes acreditam que a pergunta não se aplica ao sistema ou não souberam responder à pergunta.

$\mathrm{Na}$ subcaracterística recursos, $56 \%$ disseram que a pergunta não se aplica ao sistema estudado ou não souberam responder à pergunta. Entretanto, 75\% dos respondentes que souberam responder a esta pergunta acreditam que os recursos são adequados. Sobre a capacidade do sistema, quando indagados se o PECJUDICIAL permite uma boa navegação, $89 \%$ responderam estar de acordo enquanto os $11 \%$ restantes responderam estar em desacordo. Com relação à velocidade do sistema, $83 \%$ responderam acreditar que o sistema é rápido e apenas $17 \%$ disseram o contrário.

Portanto, no que diz respeito à eficiência de desempenho do PECJUDICIAL, a característica que mais carece de melhorias na ótica dos usuários é a de recursos, pois foi aquela 
que agregou maior número de avaliações negativas, considerando os usuários que souberam responder à pergunta.

A avaliação da característica compatibilidade foi realizada considerando-se as subcaracterísticas interoperabilidade e coexistência, conforme mostra a Tabela 7.

Tabela 7 - Distribuição das respostas relativas à Compatibilidade PECJUDICAL

\begin{tabular}{|c|c|c|c|c|}
\hline COMPATIBILIDADE & ACORDO* & DESACORDO* & $\begin{array}{c}\text { NÃO SE } \\
\text { APLICA* }\end{array}$ & TOTAL \\
\hline \multicolumn{5}{|c|}{ 5.1 INTEROPERABILIDADE } \\
\hline $\begin{array}{l}\text { 5.1.1 O PECJUDICIAL tem capacidade para } \\
\text { trocar informações com outros sistemas? }\end{array}$ & $17(94 \%)$ & $0(0 \%)$ & $1(6 \%)$ & 18 \\
\hline \multicolumn{5}{|c|}{ 5.2 COEXISTÊNCIA } \\
\hline $\begin{array}{l}\text { 5.2.1 O PECJUDICIAL realiza suas funções } \\
\text { com eficiência mesmo quando os outros } \\
\text { sistemas estão em uso, compartilhado a mesma } \\
\text { rede? }\end{array}$ & $11(61 \%)$ & $4(22 \%)$ & $3(17 \%)$ & 18 \\
\hline
\end{tabular}

Fonte: elaborado pelo autor

Quanto à compatibilidade do sistema, 94\% dos respondentes concordaram que o sistema PECJUDICIAL é capaz de trocar informações com outros sistemas, caso seja necessário. Entretanto, apenas $61 \%$ dos respondentes acreditam que o sistema realiza suas funções com eficiência mesmo quando outros sistemas estão em uso, quando compartilhando uma mesma rede e $17 \%$ dos respondentes disseram que a pergunta não se aplica ao sistema estudado ou não souberam responder à pergunta.

Portanto, no que diz respeito à compatibilidade do PECJUDICIAL, a característica que mais carece de melhorias na ótica dos usuários é a coexistência, pois foi aquela que agregou maior número de avaliações negativas.

A avaliação da característica segurança foi realizada considerando-se as subcaracterísticas confidencialidade, integridade, não repúdio, responsabilização e autenticação, conforme mostra a Tabela 8 . 
Tabela 8 - Distribuição das respostas relativas à Segurança do PECJUDICIAL

\begin{tabular}{|c|c|c|c|c|}
\hline SEGURANÇA & ACORDO* & DESACORDO* & $\begin{array}{c}\text { NÃO SE } \\
\text { APLICA* }\end{array}$ & TOTAL \\
\hline \multicolumn{5}{|c|}{ 6.1 CONFIDENCIALIDADE } \\
\hline $\begin{array}{l}\text { 6.1.1 O PECJUDICIAL dispõe de segurança } \\
\text { de acesso através de senhas? }\end{array}$ & $18(100 \%)$ & $0(0 \%)$ & $0(0 \%)$ & 18 \\
\hline \multicolumn{5}{|c|}{ 6.2 INTEGRIDADE } \\
\hline $\begin{array}{l}\text { 6.2.1 O PECJUDICIAL impede o acesso de } \\
\text { pessoas não autorizadas? }\end{array}$ & $12(67 \%)$ & $0(0 \%)$ & $6(33 \%)$ & 18 \\
\hline $\begin{array}{llll}6.2 .2 \text { O } & \text { PECJUDICIAL } & \text { impede } & \text { a } \\
\text { modificação de dados por pessoas não } \\
\text { autorizadas? }\end{array}$ & $8(44 \%)$ & $0(0 \%)$ & $10(56 \%)$ & 18 \\
\hline $\begin{array}{l}\text { 6.2.3 O PECJUDICIAL é capaz de impedir a } \\
\text { exclusão ou alteração das informações } \\
\text { armazenadas? }\end{array}$ & $10(56 \%)$ & $0(0 \%)$ & $8(44 \%)$ & 18 \\
\hline \multicolumn{5}{|c|}{ 6.3 NÃO REPÚDIO } \\
\hline $\begin{array}{l}\text { 6.3.1 O PECJUDICIAL é capaz de identificar } \\
\text { o autor/data e hora dos registros? }\end{array}$ & $14(78 \%)$ & $0(0 \%)$ & $4(22 \%)$ & 18 \\
\hline \multicolumn{5}{|c|}{ 6.4 RESPONSABILIZAÇÃO } \\
\hline $\begin{array}{l}\text { 6.4.2 O PECJUDICIAL é capaz de identificar } \\
\text { de maneira confiável e inequívoca os } \\
\text { usuários que registram os dados no sistema? }\end{array}$ & $13(72 \%)$ & $0(0 \%)$ & $5(28 \%)$ & 18 \\
\hline \multicolumn{5}{|c|}{ 6.5 AUTENTICAÇÃO } \\
\hline $\begin{array}{l}\text { 6.5.1 O PECJUDICIAL utiliza um método de } \\
\text { autenticação de forma a garantir a } \\
\text { irretratabilidade da autenticação realizada? }\end{array}$ & $2(11 \%)$ & $6(33 \%)$ & $10(56 \%)$ & 18 \\
\hline
\end{tabular}

Entre todas as subcaracterísticas da característica segurança, a única que não obteve $100 \%$ de aprovação pelos participantes que souberam responder à pergunta foi a subcaracterística autenticação (que obteve apenas $25 \%$ de aprovação pelos respondentes, de um total de 8). Ao serem questionados se o sistema dispõe de segurança de acesso através de senhas, todos souberam responder e $100 \%$ concordaram que sim.

Vale ressaltar a quantidade de usuários que indicaram as opções não se aplica ou não souberam responder para inúmeras subcaracterísticas associadas à segurança. Os resultados encontrados serão discutidos na seção Discussão do presente relato. 


\subsubsection{Aplicação do Critério de Julgamento}

Os resultados da avaliação do PECJUDICIAL foram comparados com os critérios de julgamento, cujo valor esperado foi acima de $70 \%$ de respostas que apontaram concordância com as características avaliadas, conforme Figura 5.

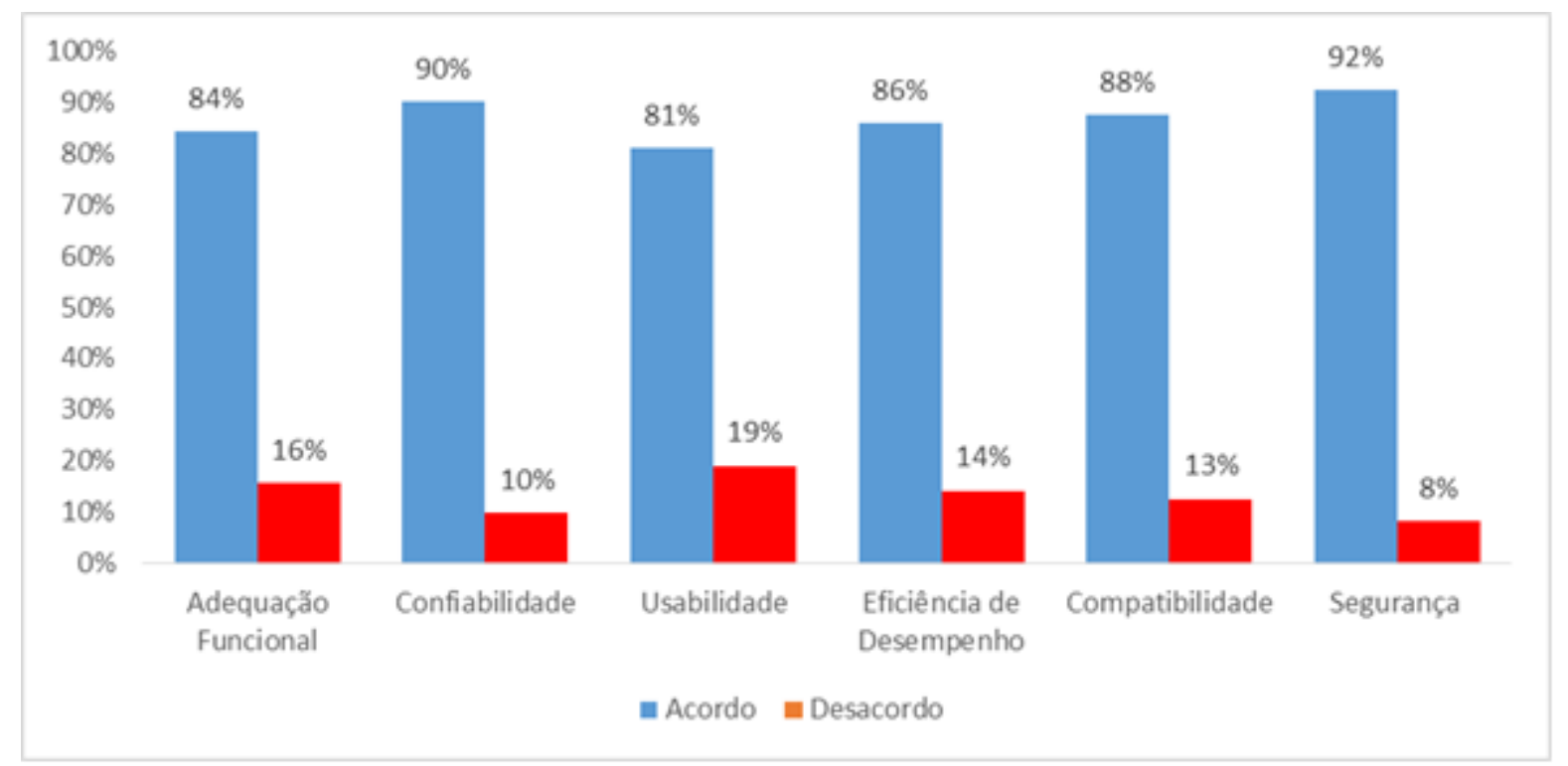

Figura 5 - Avaliação das características: adequação funcional, confiabilidade, usabilidade, eficiência de desempenho, compatibilidade e segurança do PECJUDICIAL

Pode-se verificar que todas as características foram avaliadas positivamente pelos respondentes, uma vez que todas superaram o percentual de $70 \%$ para as respostas positivas.

Cabe destaque que as características confiabilidade e segurança tiveram $90 \%$ e $92 \%$, respectivamente, de avaliação positiva pelos usuários. A característica que obteve o pior desempenho foi a usabilidade, atingindo $81 \%$ de avaliações negativas.

A Figura 6 apresenta a frequência acumulada das respostas negativas das características aplicadas ao questionário. 


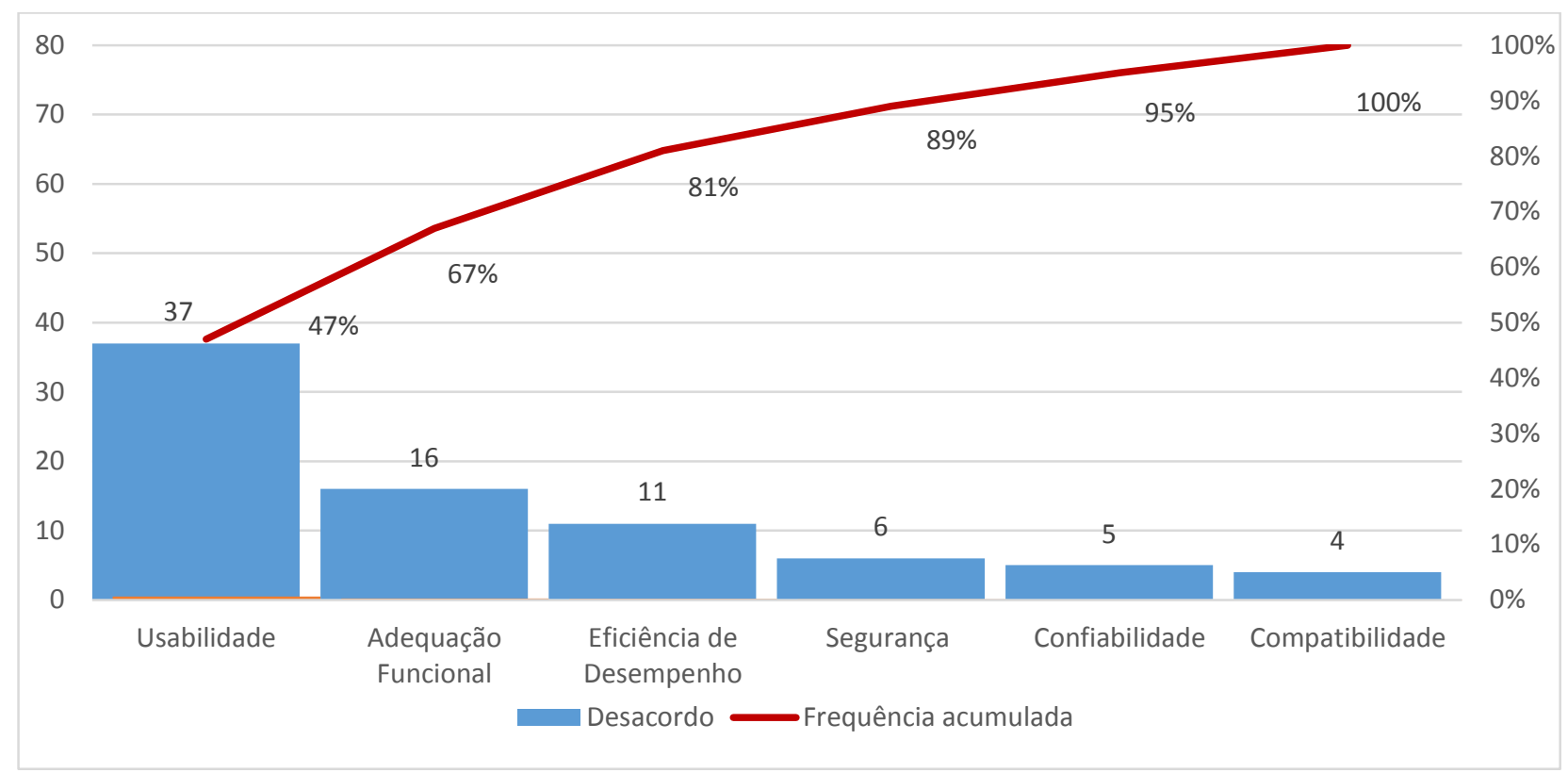

Figura 6 - Estratificação dos itens em desacordo das características de qualidade do PECJUDICIAL

Observa-se na Figura 6 que, na avaliação dos usuários do sistema, das 87 respostas em desacordo, 37 (47\%) estão concentradas em usabilidade, 16 (20\%) na adequação funcional e 11 (14\%) na eficiência de desempenho. Deste modo, na avaliação dos usuários, $81 \%$ dos itens em desacordo estão concentrados nestas três características.

\subsection{MODELO DE CUSTEIO ACTIVE BASE COST - ABC ANTES DA IMPLEMENTAÇÃO DO SISTEMA}

Devido ao aumento expressivo das aquisições de insumos para saúde por determinação judicial, o Ministério da Saúde criou por meio da Portaria n 3.965, de 14 de dezembro de 2010, a Coordenação de Compra por Determinação Judicial (CDJU), objetivando dar maior celeridade nos cumprimentos das ordens judiciais e organizar as aquisições para que as compras fossem feitas com a maior economicidade possível.

A Portaria que criou a CDJU contemplou somente o cargo de coordenador, sem a criação de qualquer outra divisão que apoie a coordenação nos desempenhos de suas atividades. Entretanto, devido à necessidade de organização das atividades desempenhadas pela 
coordenação, foram criadas equipes de apoio informais com atribuições específicas no fluxo logístico de cumprimento da determinação judicial.

No caso da CDJU, foram levantadas as principais atividades das cinco equipes de trabalho que a integram, bem como de outras duas divisões do Ministério da Saúde que executam atividades relacionadas à compra de medicamentos/insumos para a saúde em razão de ações judiciais.

Todas as aquisições para atendimento de determinação judicial são realizadas através de consulta e tramitação de processos físicos, sendo necessário desta forma a tramitação do processo para as execuções das tarefas e a análise do processo físico para a extração de informações gerenciais.

Para a aplicação do ABC, observaram-se as etapas as quais na concepção de Crepaldi (2002) são: I - identificação das atividades relevantes; II - levantamento dos custos consumidos pelas atividades; III - identificação e seleção dos direcionadores de custos; IV - atribuição de custos às atividades; e V - atribuição dos custos das atividades aos produtos.

Quadro 5 - Atividades relevantes identificadas por setor/equipe antes do PECJUDICIAL

(Continua)

\begin{tabular}{|c|c|}
\hline ATIVIDADES & SETOR/EQUIPE \\
\hline Coordenação do Setor & CDJU \\
\hline Coordenação da equipe ECAP & \multirow{10}{*}{ ECAP } \\
\hline Cadastrar e atualizar os dados do processo no Sistema de Ação Judicial & \\
\hline Análise dos documentos tramitados para a Coordenação & \\
\hline Pendências de Entrega & \\
\hline Realizar a análise farmacêutica & \\
\hline Definição da quantidade a ser adquirida & \\
\hline Definição da forma de cumprimento da decisão judicial & \\
\hline Cadastramento do medicamento no Sistema de Ação Judicial & \\
\hline Programação das planilhas de compra agrupada por medicamento & \\
\hline Inserção dos medicamentos na planilha de agrupada geral & \\
\hline Coordenação da ECOMP & \multirow{3}{*}{ ECOMP } \\
\hline Enviar e receber proposta de preço & \\
\hline Solicitar retificação de proposta de preço & \\
\hline
\end{tabular}

Fonte: dados de pesquisa 
Quadro 5 - Atividades relevantes identificadas por setor/equipe antes do PECJUDICIAL

(Continuação)

\begin{tabular}{|c|c|}
\hline ATIVIDADES & SETOR/EQUIPE \\
\hline Analisar propostas de preço & \\
\hline Fazer despacho de aquisição individual & \\
\hline Fazer despacho de aquisição agrupada & \\
\hline Revisar despacho de aquisição & \\
\hline Solicitar a retirada de medicamentos do estoque & \\
\hline Publicar a compra na Imprensa Oficial & \\
\hline Coordenação da ECODE & \multirow{9}{*}{ ECODE } \\
\hline Encaminhar Nota de Empenho à empresa vencedora & \\
\hline Emitir Autorização de Entrega & \\
\hline Cobrar os fornecedores nos casos de atraso na entrega de medicamentos & \\
\hline Autorizar entrega parcelada & \\
\hline Fazer despacho de devolução & \\
\hline Revisar despacho de devolução & \\
\hline Solicitar recolhimento de medicamentos & \\
\hline Recebimento dos comprovantes de entrega da medicação & \\
\hline Coordenação do Protocolo & \multirow{4}{*}{ Protocolo } \\
\hline Triar processo/documento & \\
\hline Tramitar e Receber processos & \\
\hline Suspender procedimento de compra & \\
\hline Coordenação da EGET & \multirow{5}{*}{ EGET } \\
\hline Solicitar depósito judicial & \\
\hline Realizar atendimento telefônico & \\
\hline Realizar atendimento via e-mail & \\
\hline $\begin{array}{l}\text { Elaboração de respostas aos órgãos de controle e demais stakeholders do processo } \\
\text { de compra }\end{array}$ & \\
\hline Emissão da Guia de Remessa & \multirow{9}{*}{ SADM } \\
\hline Solicitação de coleta de medicamentos no aeroporto & \\
\hline Solicitação de recolhimento de medicamentos & \\
\hline Recebimento de Medicamentos & \\
\hline Preparo dos medicamentos para envio & \\
\hline Resolução de pendências de entrega & \\
\hline Entrada do medicamento no Sistema & \\
\hline Controle e supervisão do estoque & \\
\hline Envio de nota fiscal para pagamento & \\
\hline Disponibilidade orçamentária & \multirow{5}{*}{ CEOF } \\
\hline Empenho & \\
\hline Solicitação de abertura da LI & \\
\hline Autorização da ANVISA & \\
\hline Pagamento & \\
\hline
\end{tabular}

Fonte: dados de pesquisa 
Quadro 5 - Atividades relevantes identificadas por setor/equipe antes do PECJUDICIAL

(Conclusão)

\begin{tabular}{|l|c|}
\hline \multicolumn{1}{|c|}{ ATIVIDADES } & SETOR/EQUIPE \\
\cline { 1 - 1 } Solicitação de Embarque & \multirow{2}{*}{ CEOF } \\
\cline { 1 - 1 } Devolução do processo para a CDJU & \\
\hline
\end{tabular}

Fonte: dados de pesquisa

ECAP - Equipe de Cadastro e Análise Farmacêutica; ECOMP - Equipe de Compras e Publicação; ECODE - Equipe de Controle e Devolução de Processos; EGET - Equipe de Gestão; SADM - Serviço de Armazenamento e Distribuição de Medicamentos; CEOF - Coordenação de Execução Orçamentária e Financeira.

Assim, foram identificadas 54 atividades relevantes no processo de compra de medicamentos distribuídas entre as sete divisões envolvidas no ciclo de compra, incluindo a própria coordenação da área de compras, haja vista a participação do coordenador na execução, orientação e controle das atividades levantadas.

Seguindo as etapas de utilização do ABC sugeridas pela literatura sobre o tema, logo após a identificação das atividades relevantes realizadas, foram identificados os direcionadores de recursos das atividades. Os direcionadores de recursos nada mais são do que a forma como as atividades consomem os recursos (RIBEIRO; CAMANCHO, 2008). Desta forma, a Tabela 9 mostra essa ligação.

Tabela 9 - Recursos e direcionadores de recursos

\begin{tabular}{|c|c|c|c|}
\hline RECURSOS CONSUMIDOS & $\begin{array}{c}\text { VALOR } \\
\text { MENSAL (R\$) }\end{array}$ & $\begin{array}{c}\text { VALOR ANUAL } \\
(\text { R\$) }\end{array}$ & $\begin{array}{c}\text { DIRECIONADOR DE } \\
\text { RECURSO } \\
\end{array}$ \\
\hline Salários + Gratificações & $261.129,72$ & $3.318 .344,69$ & Tempo em minutos \\
\hline $\begin{array}{l}\text { Materiais administrativos e de } \\
\text { expediente }\end{array}$ & 695,65 & $8.347,80$ & Apropriação Direta \\
\hline Contrato de Logística & $381.930,78$ & $4.583 .169,33$ & Apropriação Direta \\
\hline Licença de Importação & $14.945,56$ & $179.346,70$ & Apropriação Direta \\
\hline Aluguel (almoxarifado) & $15.268,65$ & $183.223,80$ & $\mathrm{M}^{2}$ \\
\hline Publicação & $6.265,41$ & $75.184,86$ & $\mathrm{~N}^{\mathrm{o}}$ de publicações \\
\hline TOTAL & $680.235,77$ & 8.347.617,18 & \\
\hline
\end{tabular}

Fonte: dados de pesquisa 
As informações quanto aos salários e às gratificações foram levantadas por meio de consulta ao Portal da Transparência do Governo Federal. O $13^{\circ}$ salário foi contabilizado ao valor anual. Com relação aos consultores, os valores foram calculados com base no valor do contrato de prestação de serviços sem o acréscimo do $13^{\circ}$ salário.

Os valores gastos com materiais administrativos e de expedientes foram calculados com base no valor unitário licitado pelo Ministério da Saúde e uma média da quantidade mensal utilizada pelos servidores no desempenho de suas atividades. Foram considerados para este fim os seguintes materiais: resma de papel, canetas esferográficas azul e preta, marca texto, lápis, borracha, bloco para recado adesivo e impressão.

Os valores referentes aos gastos com a logística de medicamentos, bem como do aluguel dos locais de armazenagem dos produtos adquiridos, foram obtidos tendo como base as informações prestadas pela Coordenação Geral de Armazenagem e Distribuição (CGAD), Departamento responsável para gestão do contrato de transporte de medicamentos no âmbito do Ministério da Saúde.

Os valores correspondentes às publicações das compras na Imprensa Oficial e os valores gastos com a abertura de licenças de importação no caso de aquisição de fármacos importados, foram obtidos por meio do levantamento do número de dispensas de licitação no sistema COMPRASNET e SISCOMEX, respectivamente.

\subsubsection{Atribuição dos Custos dos Recursos às Atividades}

Finda a etapa da identificação dos direcionadores de recursos (custos), é necessário a alocação dos custos às atividades levantadas. Os custos mais significativos referem-se à mão de obra, ou seja, aos salários e às gratificações, cujo direcionador definido foi o tempo em minutos na execução de cada atividade.

Foi realizada entrevista semiestruturada de forma individual com todos os servidores e consultores, perfazendo um total de 45 entrevistados, sendo possível a partir daí a obtenção 
efetiva do tempo gasto por cada um em cada atividade. $\mathrm{O}$ tempo em minutos das atividades foram convertidos em termos percentuais, a exemplo do que foi proposto por Ribeiro e Camacho (2008), quando discorreram sobre a implantação do ABC em entidades públicas de educação infantil. Assim, as tabelas 10 a 14 demonstram os valores do total do tempo gasto percentualmente distribuídos em cada atividade por funcionário. Na Tabela 14, por exemplo, o funcionário 45 teve o seu tempo percentual dividido em três atividades distintas: solicitação de abertura de licença de importação, autorização da ANVISA e pagamento, correspondendo respectivamente a $20 \%, 10 \%$ e $70 \%$ de seu tempo de trabalho. As Tabelas foram separadas por equipe e divisão.

A Tabela 10 apresenta o percentual de tempo gasto com as atividades da Equipe de Cadastro e Análise Farmacêutica (ECAP).

Tabela 10 - Percentual de tempo gasto por atividades - Coordenação e ECAP

\begin{tabular}{|c|c|c|c|c|c|c|c|c|c|}
\hline \multirow{2}{*}{ ATIVIDADES } & \multicolumn{9}{|c|}{ FUNCIONÁRIOS } \\
\hline & & $\mathbf{1}$ & 2 & 3 & 4 & 5 & 6 & 7 & 8 \\
\hline Coordenação do Setor & CDJU & $100 \%$ & & & & & & & \\
\hline $\begin{array}{l}\text { Cadastrar e atualizar os dados do } \\
\text { processo no Sistema de Ação } \\
\text { Judicial }\end{array}$ & ECAP & & $19 \%$ & $75 \%$ & & & & & \\
\hline $\begin{array}{l}\text { Análise dos documentos tramitados } \\
\text { para a Coordenação }\end{array}$ & ECAP & & $19 \%$ & $25 \%$ & & & & & \\
\hline Pendências de Entrega & ECAP & & $25 \%$ & & & & & & \\
\hline Coordenação de Equipe (1) & ECAP & & $38 \%$ & & & & & & \\
\hline Realizar a análise farmacêutica & ECAP & & & & $30 \%$ & $19 \%$ & $21 \%$ & $22 \%$ & $29 \%$ \\
\hline $\begin{array}{l}\text { Definição da quantidade a ser } \\
\text { adquirida }\end{array}$ & ECAP & & & & $30 \%$ & $23 \%$ & $32 \%$ & $22 \%$ & $23 \%$ \\
\hline $\begin{array}{l}\text { Definição da forma de cumprimento } \\
\text { da decisão judicial }\end{array}$ & ECAP & & & & $15 \%$ & $19 \%$ & $26 \%$ & $17 \%$ & $13 \%$ \\
\hline $\begin{array}{l}\text { Cadastramento do medicamento no } \\
\text { Sistema de Ação Judicial }\end{array}$ & ECAP & & & & $10 \%$ & $8 \%$ & $5 \%$ & $11 \%$ & $13 \%$ \\
\hline $\begin{array}{l}\text { Programação das planilhas de } \\
\text { compra agrupada por medicamento }\end{array}$ & ECAP & & & & $5 \%$ & $15 \%$ & & $11 \%$ & $6 \%$ \\
\hline \multirow[t]{2}{*}{$\begin{array}{l}\text { Inserção dos medicamentos na } \\
\text { planilha de agrupada geral }\end{array}$} & ECAP & & & & $10 \%$ & $15 \%$ & $16 \%$ & $17 \%$ & $15 \%$ \\
\hline & TOTAL & $100 \%$ & $100 \%$ & $100 \%$ & $100 \%$ & $100 \%$ & $100 \%$ & $100 \%$ & $100 \%$ \\
\hline
\end{tabular}


A Tabela 11 apresenta o percentual de tempo gasto com as atividades da Equipe de Compras e Publicação (ECOMP).

Tabela 11 - Percentual de tempo gasto por atividades - ECOMP

\begin{tabular}{|c|c|c|c|c|c|c|c|c|c|}
\hline \multirow{2}{*}{ ATIVIDADES } & \multicolumn{9}{|c|}{ FUNCIONÁRIOS } \\
\hline & & 9 & 10 & 11 & 12 & 13 & 14 & 15 & 16 \\
\hline Coordenação da Equipe (2) & ECOMP & $20 \%$ & & & & & & & \\
\hline $\begin{array}{l}\text { Enviar e receber proposta de } \\
\text { preço }\end{array}$ & ECOMP & & $72 \%$ & & & & $8 \%$ & & \\
\hline $\begin{array}{l}\text { Solicitar retificação de proposta } \\
\text { de preço }\end{array}$ & ECOMP & & $28 \%$ & & & & $4 \%$ & & \\
\hline Analisar propostas de preço & ECOMP & & & & $67 \%$ & & & & $29 \%$ \\
\hline $\begin{array}{l}\text { Fazer despacho de aquisição } \\
\text { individual }\end{array}$ & ECOMP & & & $44 \%$ & $33 \%$ & & & & $57 \%$ \\
\hline $\begin{array}{l}\text { Fazer despacho de aquisição } \\
\text { agrupada }\end{array}$ & ECOMP & & & $50 \%$ & & & $88 \%$ & & \\
\hline Revisar despacho de aquisição & ECOMP & $40 \%$ & & $6 \%$ & & $40 \%$ & & & \\
\hline $\begin{array}{l}\text { Solicitar a retirada } \\
\text { medicamentos do estoque }\end{array}$ & ECOMP & & & & & & & 100 & $14 \%$ \\
\hline \multirow[t]{2}{*}{$\begin{array}{l}\text { Publicar a compra na Imprensa } \\
\text { Oficial }\end{array}$} & ECOMP & $40 \%$ & & & & $60 \%$ & & & \\
\hline & TOTAL & $100 \%$ & $100 \%$ & $100 \%$ & $100 \%$ & $100 \%$ & $100 \%$ & $100 \%$ & $100 \%$ \\
\hline
\end{tabular}

Fonte: dados de pesquisa

A Tabela 12 apresenta o percentual de tempo gasto com as atividades da Equipe de Controle e Devolução de Processos (ECODE).

Tabela 12- Percentual de tempo gasto por atividades - ECODE

(Continua)

\begin{tabular}{|c|c|c|c|c|c|c|c|c|c|c|c|}
\hline \multirow{2}{*}{ ATIVIDADES } & \multicolumn{11}{|c|}{ FUNCIONÁRIOS } \\
\hline & & 17 & 18 & 19 & 20 & 21 & 22 & 23 & 24 & 26 & 26 \\
\hline Coordenação da Equipe (3) & ECODE & & & & & & & & $50 \%$ & & \\
\hline $\begin{array}{l}\text { Encaminhar Nota de } \\
\text { Empenho à empresa } \\
\text { vencedora }\end{array}$ & ECODE & $14 \%$ & $29 \%$ & & & & & $94 \%$ & & & \\
\hline $\begin{array}{l}\text { Emitir Autorização de } \\
\text { Entrega }\end{array}$ & ECODE & $9 \%$ & $14 \%$ & $7 \%$ & & & & & & $100 \%$ & \\
\hline
\end{tabular}

Fonte: dados de pesquisa 
Tabela 12- Percentual de tempo gasto por atividades - ECODE

(Conclusão)

\begin{tabular}{|c|c|c|c|c|c|c|c|c|c|c|c|}
\hline \multirow{2}{*}{ ATIVIDADES } & \multicolumn{11}{|c|}{ FUNCIONÁRIOS } \\
\hline & & 17 & 18 & 19 & 20 & 21 & 22 & 23 & 24 & 26 & 26 \\
\hline $\begin{array}{l}\text { Cobrar os } \\
\text { fornecedores nos } \\
\text { casos de atraso na } \\
\text { entrega de } \\
\text { medicamentos }\end{array}$ & ECODE & $60 \%$ & & $7 \%$ & & & & $2 \%$ & & & \\
\hline $\begin{array}{l}\text { Autorizar entrega } \\
\text { parcelada }\end{array}$ & ECODE & & & $70 \%$ & & & & & & & \\
\hline $\begin{array}{l}\text { Fazer despacho de } \\
\text { devolução }\end{array}$ & ECODE & & & & $50 \%$ & & $80 \%$ & & & & $100 \%$ \\
\hline $\begin{array}{l}\text { Revisar despacho de } \\
\text { devolução }\end{array}$ & ECODE & & & & $33 \%$ & $100 \%$ & & & & & \\
\hline $\begin{array}{l}\text { Solicitar } \\
\text { recolhimento de } \\
\text { medicamentos }\end{array}$ & ECODE & $17 \%$ & $57 \%$ & $16 \%$ & & & $20 \%$ & $3 \%$ & & & \\
\hline \multirow[t]{2}{*}{$\begin{array}{l}\text { Recebimento dos } \\
\text { comprovantes de } \\
\text { entrega da } \\
\text { medicação }\end{array}$} & ECODE & & & & $17 \%$ & & & $2 \%$ & $50 \%$ & & \\
\hline & TOTAL & $100 \%$ & $100 \%$ & $100 \%$ & $100 \%$ & $100 \%$ & $100 \%$ & $100 \%$ & $100 \%$ & $100 \%$ & $100 \%$ \\
\hline
\end{tabular}

Fonte: dados de pesquisa

A Tabela 13 apresenta o percentual de tempo gasto com as atividades da equipe de gestão (EGET).

Tabela 13 - Percentual de tempo gasto por atividades - EGET

(Continua)

\begin{tabular}{|c|c|c|c|c|c|c|c|c|c|}
\hline \multirow[b]{2}{*}{ ATIVIDADES } & \multicolumn{9}{|c|}{ FUNCIONÁRIOS } \\
\hline & & 27 & 28 & 29 & 30 & 31 & 32 & 33 & 34 \\
\hline Coordenação da Equipe (4) & Protocolo & $42 \%$ & & & & & & & \\
\hline Triar processo/documento & Protocolo & $25 \%$ & $71 \%$ & $33 \%$ & & & & & \\
\hline Tramitar e Receber processos & Protocolo & $17 \%$ & & $33 \%$ & & & & & \\
\hline $\begin{array}{l}\text { Suspender procedimento de } \\
\text { compra }\end{array}$ & Protocolo & $17 \%$ & $29 \%$ & $33 \%$ & & & & & \\
\hline Coordenação de Equipe (5) & EGET & & & & & & & & $65 \%$ \\
\hline Solicitar depósito judicial & EGET & & & & $1 \%$ & $40 \%$ & $30 \%$ & $15 \%$ & \\
\hline Realizar atendimento telefônico & EGET & & & & $4 \%$ & $40 \%$ & $0 \%$ & & $5 \%$ \\
\hline
\end{tabular}

Fonte: dados de pesquisa 
Tabela 13 - Percentual de tempo gasto por atividades - EGET

(Conclusão)

\begin{tabular}{l|c|c|c|c|c|c|c|c|c}
\hline \multirow{2}{*}{ ATIVIDADES } & \multicolumn{7}{c}{ FUNCIONÁRIOS } \\
\cline { 2 - 9 } & & $\mathbf{2 7}$ & $\mathbf{2 8}$ & $\mathbf{2 9}$ & $\mathbf{3 0}$ & $\mathbf{3 1}$ & $\mathbf{3 2}$ & $\mathbf{3 3}$ & $\mathbf{3 4}$ \\
\hline Realizar atendimento via e-mail & EGET & & & & $5 \%$ & $20 \%$ & $60 \%$ & $80 \%$ & $10 \%$ \\
\hline $\begin{array}{l}\text { Elaboração de respostas aos } \\
\text { órgãos de controle e demais } \\
\text { stakeholders do processo de } \\
\text { compra }\end{array}$ & EGET & & & & $90 \%$ & $0 \%$ & $10 \%$ & $5 \%$ & $20 \%$ \\
\hline
\end{tabular}

Fonte: dados de pesquisa

A Tabela 14 apresenta o percentual de tempo gasto com as atividades do Serviço de Armazenamento e Distribuição de Medicamentos (SADM) e Coordenação de Execução Orçamentária e Financeira (CEOF).

Tabela 14- Percentual de tempo gasto por atividades - SADM e CEOF

(Continua)

\begin{tabular}{|c|c|c|c|c|c|c|c|c|c|c|c|c|}
\hline \multirow{2}{*}{ ATIVIDADES } & \multicolumn{12}{|c|}{ FUNCIONÁRIOS } \\
\hline & & 35 & 36 & 37 & 38 & 39 & 40 & 41 & 42 & 43 & 44 & 45 \\
\hline $\begin{array}{llll}\text { Emissão da } & \text { Guia } & \text { de } \\
\text { Remessa } & & & \\
\end{array}$ & SADM & $5 \%$ & $75 \%$ & & $70 \%$ & & $40 \%$ & & & & & \\
\hline $\begin{array}{ll}\text { Solicitação de coleta } & \text { de } \\
\text { medicamentos } & \text { no } \\
\text { aeroporto } & \\
\end{array}$ & SADM & & & & $20 \%$ & & $20 \%$ & & & & & \\
\hline $\begin{array}{ll}\text { Solicitação } & \text { de } \\
\text { recolhimento } & \text { de } \\
\text { medicamentos } & \\
\end{array}$ & SADM & & $15 \%$ & $90 \%$ & $3 \%$ & & & & & & & \\
\hline $\begin{array}{ll}\text { Recebimento } & \text { de } \\
\text { Medicamentos } & \\
\end{array}$ & SADM & & & $5 \%$ & $4 \%$ & $50 \%$ & & $60 \%$ & & & & \\
\hline $\begin{array}{l}\text { Preparo dos } \\
\text { medicamentos para envio }\end{array}$ & SADM & & & $5 \%$ & $3 \%$ & $20 \%$ & & $30 \%$ & & & & \\
\hline $\begin{array}{l}\text { Resolução de pendências } \\
\text { de entrega }\end{array}$ & SADM & $25 \%$ & $5 \%$ & & & & & & & & & \\
\hline $\begin{array}{l}\text { Entrada do medicamento } \\
\text { no Sistema }\end{array}$ & SADM & $70 \%$ & $5 \%$ & & & & & & & & & \\
\hline $\begin{array}{l}\text { Controle e supervisão do } \\
\text { estoque }\end{array}$ & SADM & & & & & $30 \%$ & & $10 \%$ & & & & \\
\hline $\begin{array}{l}\text { Envio de nota fiscal para } \\
\text { pagamento }\end{array}$ & SADM & & & & & & $40 \%$ & & & & & \\
\hline $\begin{array}{l}\text { Disponibilidade } \\
\text { orçamentária }\end{array}$ & CEOF & & & & & & & & & $25 \%$ & & \\
\hline Empenho & CEOF & & & & & & & & & $75 \%$ & & \\
\hline $\begin{array}{l}\text { Solicitação de abertura da } \\
\text { LI }\end{array}$ & CEOF & & & & & & & & & & $20 \%$ & $20 \%$ \\
\hline
\end{tabular}

Fonte: dados de pesquisa 
Tabela 14- Percentual de tempo gasto por atividades - SADM e CEOF

(Conclusão)

\begin{tabular}{|c|c|c|c|c|c|c|c|c|c|c|c|c|}
\hline \multirow{2}{*}{ ATIVIDADES } & \multicolumn{12}{|c|}{ FUNCIONÁRIOS } \\
\hline & & 35 & 36 & 37 & 38 & 39 & 40 & 41 & 42 & 43 & 44 & 45 \\
\hline Autorização da ANVISA & CEOF & & & & & & & & & & $20 \%$ & $10 \%$ \\
\hline Pagamento & CEOF & & & & & & & & $100 \%$ & & $40 \%$ & $70 \%$ \\
\hline Solicitação de Embarque & CEOF & & & & & & & & & & $10 \%$ & \\
\hline $\begin{array}{l}\text { Devolução do processo } \\
\text { para a CDJU }\end{array}$ & CEOF & & & & & & & & & & $10 \%$ & \\
\hline
\end{tabular}

Fonte: dados de pesquisa

A Tabela 15 descreve os cargos/funções exercidas por cada servidor/consultor e as suas respectivas remunerações mensais, além de indicar se há a existência de algum tipo de gratificação.

Tabela 15 - Cargos/Funções dos servidores/consultores e respectiva remuneração

(Continua)

\begin{tabular}{|c|c|c|c|}
\hline $\begin{array}{l}\text { SERVIDOR / } \\
\text { CONSULTOR }\end{array}$ & CARGO/FUNÇÃO & GRATIFICAÇÃO & $\begin{array}{l}\text { REMUNERAÇÃO } \\
\text { EM REAIS }\end{array}$ \\
\hline 01 & Administrador & GSISTE & $11.663,80$ \\
\hline 02 & Administrador & GSISTE & $8.863,80$ \\
\hline 03 & Administrador & & $5.000,00$ \\
\hline 04 & Consultor & & $5.708,33$ \\
\hline 05 & Consultor & & $4.475,00$ \\
\hline 06 & Consultor & & $6.510,00$ \\
\hline 07 & Consultor & & $5.202,50$ \\
\hline 08 & Consultor & & $5.729,17$ \\
\hline 09 & $\begin{array}{l}\text { ATPS - Analista Técnico de Políticas } \\
\text { Sociais }\end{array}$ & GSISTE & $8.899,69$ \\
\hline 10 & CTU - Contrato temporário da União & & $6.503,00$ \\
\hline 11 & Consultor & & $6.000,00$ \\
\hline 12 & Analista Técnico Administrativo & & $6.258,00$ \\
\hline 13 & Consultor & & $6.500,00$ \\
\hline 14 & Agente administrativo & & $4.020,83$ \\
\hline 15 & Administrador & & $5.000,00$ \\
\hline 16 & Agente administrativo & & $4.413,13$ \\
\hline 17 & Consultor & & $4.632,17$ \\
\hline 18 & Consultor & & $4.635,50$ \\
\hline 19 & Administrador & & $5.000,00$ \\
\hline
\end{tabular}

Fonte: dados de pesquisa 
Tabela 15 - Cargos/Funções dos servidores/consultores e respectiva remuneração

(Conclusão)

\begin{tabular}{|c|c|c|c|}
\hline $\begin{array}{l}\text { SERVIDOR / } \\
\text { CONSULTOR }\end{array}$ & CARGO/FUNÇÃO & GRATIFICAÇÃO & $\begin{array}{l}\text { REMUNERAÇÃO } \\
\text { EM REAIS }\end{array}$ \\
\hline 20 & Consultor & & $5.159,67$ \\
\hline 21 & Agente administrativo & & $3.994,94$ \\
\hline 22 & Administrador & & $5.000,00$ \\
\hline 23 & CTU - Contrato temporário da União & & $6.503,00$ \\
\hline 24 & Analista Técnico Administrativo & GSISTE & $8.863,80$ \\
\hline 25 & Agente administrativo & & $3.158,37$ \\
\hline 26 & $\begin{array}{l}\text { ATPS - Analista Técnico de Políticas } \\
\text { Sociais }\end{array}$ & & $6.294,69$ \\
\hline 27 & Administrador & GSISTE & $8.863,80$ \\
\hline 28 & CTU - Contrato temporário da União & & $6.503,00$ \\
\hline 29 & Agente administrativo & & $4.091,29$ \\
\hline 30 & Consultor & & $5.798,17$ \\
\hline 31 & Técnico em secretariado & & $1.500,00$ \\
\hline 32 & Consultor & & $5.798,17$ \\
\hline 33 & Analista Técnico Administrativo & & $6.258,00$ \\
\hline 34 & Administrador & GSISTE & $8.863,80$ \\
\hline 35 & Administrador & & $5.000,00$ \\
\hline 36 & Agente administrativo & FG1 & $4.415,95$ \\
\hline 37 & Consultor & & $5.200,00$ \\
\hline 38 & Agente administrativo & FG1 & $4.415,95$ \\
\hline 39 & Consultor & & $4.993,00$ \\
\hline 40 & Administrador & & $5.000,00$ \\
\hline 41 & $\begin{array}{l}\text { ATPS - Analista Técnico de Políticas } \\
\text { Sociais }\end{array}$ & & $6.294,69$ \\
\hline 42 & Agente administrativo & FC3 & $5.642,89$ \\
\hline 43 & Agente administrativo & FC3 & $5.642,89$ \\
\hline 44 & Agente administrativo & & $3.994,94$ \\
\hline 45 & Administrador & GSISTE & $8.863,80$ \\
\hline & & TOTAL & 261.129,72 \\
\hline
\end{tabular}

Fonte: dados de pesquisa

Tomando como exemplo o funcionário 45 e tendo como base as Tabelas 10 a 14, a apropriação dos custos de remuneração deste funcionário à distribuição percentual de suas atividades pode ser exemplificada na Tabela 16. 
Tabela 16 - Distribuição dos custos de remuneração mensal do funcionário 45 ao percentual de atividades

\begin{tabular}{l|c|c}
\hline \multicolumn{1}{c|}{ ATIVIDADES } & MÃO DE OBRA \% & CUSTO \\
\hline Solicitação de abertura da LI & $20 \%$ & $1.772,76$ \\
Autorização da ANVISA & $10 \%$ & 886,38 \\
Pagamento & $70 \%$ & $6.204,66$ \\
\hline TOTAL & $\mathbf{1 0 0 \%}$ & $\mathbf{8 . 8 6 3 , 8 0}$ \\
\hline
\end{tabular}

Fonte: dados de pesquisa

Neste caso, a atividade que mais consome recursos é o pagamento. Esta apropriação foi realizada com todos os servidores e consultores.

A Tabela 17 apresenta o custo por atividade total sendo incorporado todos os custos mensurados tais como: material de expediente, transporte, aluguel de almoxarifado, licença de importação, publicação e salários e gratificações. Os custos com material de expediente foram rateados entre todas as atividades, tendo em vista não impactar de forma relevante nos custos por atividade. Os custos de transporte e aluguel de almoxarifado foram atribuídos às atividades que envolvem a armazenagem e a distribuição dos insumos para saúde. 
Tabela 17 - Apuração do custo das atividades - Geral

(Continua)

\begin{tabular}{|c|c|c|c|c|c|c|c|}
\hline ATIVIDADES & $\begin{array}{l}\text { MATERIAL DE } \\
\text { EXPEDIENTE }\end{array}$ & TRANSPORTE & \begin{tabular}{|c|} 
ALUGUEL DE \\
ALMOXARIFADO \\
\end{tabular} & $\begin{array}{l}\text { LICENÇA DE } \\
\text { IMPORTAÇÃA }\end{array}$ & PUBLICAÇÃOO & SALÁRIOS & TOTAL \\
\hline Coordenação do Setor & 12,64 & & & & & $11.663,80$ & $11.676,44$ \\
\hline $\begin{array}{l}\text { Cadastrar e atualizar os dados do } \\
\text { processo no Sistema de Ação Judicial }\end{array}$ & 12,64 & & & & & $5.434,12$ & $5.446,76$ \\
\hline $\begin{array}{l}\text { Análise dos documentos tramitados } \\
\text { para a Coordenação }\end{array}$ & 12,64 & & & & & $2.934,12$ & $2.946,76$ \\
\hline Pendências de Entrega & 12,64 & & & & & $2.127,31$ & $2.139,95$ \\
\hline Coordenação de Equipe (1) & 12,64 & & & & & $3.368,24$ & $3.380,88$ \\
\hline Realizar a análise farmacêutica & 12,64 & & & & & $6.735,86$ & $6.748,50$ \\
\hline Definição da quantidade a ser adquirida & 12,64 & & & & & $7.287,21$ & $7.299,85$ \\
\hline $\begin{array}{l}\text { Definição da forma de cumprimento da } \\
\text { decisão judicial }\end{array}$ & 12,64 & & & & & $5.028,32$ & $5.040,96$ \\
\hline $\begin{array}{l}\text { Cadastramento do medicamento no } \\
\text { Sistema de Ação Judicial }\end{array}$ & 12,64 & & & & & $2.616,15$ & $2.628,79$ \\
\hline $\begin{array}{l}\text { Programação das planilhas de compra } \\
\text { agrupada por medicamento }\end{array}$ & 12,64 & & & & & $1.929,98$ & $1.942,62$ \\
\hline $\begin{array}{l}\text { Inserção dos medicamentos na planilha } \\
\text { de agrupada geral }\end{array}$ & 12,64 & & & & & $4.027,48$ & $4.040,12$ \\
\hline Coordenação da Equipe (2) & 12,64 & & & & & $1.779,94$ & $1.792,58$ \\
\hline Enviar e receber proposta de preço & 12,64 & & & & & $4.842,99$ & $4.855,63$ \\
\hline
\end{tabular}

Fonte: dados de pesquisa 
Tabela 17 - Apuração do custo das atividades - Geral

(Continuação)

\begin{tabular}{|c|c|c|c|c|c|c|c|}
\hline ATIVIDADES & $\begin{array}{l}\text { MATERIAL DE } \\
\text { EXPEDIENTE }\end{array}$ & TRANSPORTE & $\begin{array}{c}\text { ALUGUEL DE } \\
\text { ALMOXARIFADO }\end{array}$ & $\begin{array}{c}\text { LICENÇA DE } \\
\text { IMPORTAÇÃO }\end{array}$ & PUBLICAÇÃO & SALÁRIOS & TOTAL \\
\hline Analisar propostas de preço & 12,64 & & & & & $5.472,67$ & $5.485,31$ \\
\hline $\begin{array}{l}\text { Fazer despacho de aquisição } \\
\text { individual }\end{array}$ & 12,64 & & & & & $7.220,62$ & $7.233,26$ \\
\hline Fazer despacho de aquisição agrupada & 12,64 & & & & & $6.538,33$ & $6.550,97$ \\
\hline Revisar despacho de aquisição & 12,64 & & & & & $6.519,88$ & $6.532,52$ \\
\hline $\begin{array}{l}\text { Solicitar a retirada de medicamentos } \\
\text { do estoque }\end{array}$ & 12,64 & & & & & $5.617,84$ & $5.530,48$ \\
\hline Publicar a compra na Imprensa Oficial & 12,64 & & & & $6.254,41$ & $7.459,88$ & $7.472,52$ \\
\hline Coordenação da Equipe (3) & 12,64 & & & & & $4.431,90$ & $4.487,98$ \\
\hline $\begin{array}{l}\text { Encaminhar Nota de Empenho à } \\
\text { empresa vencedora }\end{array}$ & 12,64 & & & & & $8.105,62$ & $8.118,26$ \\
\hline Emitir Autorização de Entrega & 12,64 & & & & & $4.574,24$ & $4.630,32$ \\
\hline $\begin{array}{l}\text { Cobrar os fornecedores nos casos de } \\
\text { atraso na entrega de medicamentos }\end{array}$ & 12,64 & & & & & $3.259,36$ & $3.315,44$ \\
\hline Autorizar entrega parcelada & 12,64 & & & & & $3.500,00$ & $3.556,08$ \\
\hline Fazer despacho de devolução & 12,64 & & & & & $12.874,52$ & $12.887,16$ \\
\hline Revisar despacho de devolução & 12,64 & & & & & $5.697,63$ & $5.710,27$ \\
\hline $\begin{array}{l}\text { Solicitar recolhimento de } \\
\text { medicamentos }\end{array}$ & 12,64 & & & & & $5.359,76$ & $5.372,40$ \\
\hline $\begin{array}{l}\text { Solicitar retificação de proposta de } \\
\text { preço }\end{array}$ & 12,64 & & & & & $2.142,51$ & $2.155,15$ \\
\hline
\end{tabular}

Fonte: dados de pesquisa 
Tabela 17 - Apuração do custo das atividades - Geral

(Continuação)

\begin{tabular}{|c|c|c|c|c|c|c|c|}
\hline ATIVIDADES & $\begin{array}{l}\text { MATERIAL DE } \\
\text { EXPEDIENTE }\end{array}$ & TRANSPORTE & $\begin{array}{c}\text { ALUGUEL DE } \\
\text { ALMOXARIFADO }\end{array}$ & $\begin{array}{l}\text { LICENÇA DE } \\
\text { IMPORTAÇÃO }\end{array}$ & PUBLICAÇÃO & SALÁRIOS & TOTAL \\
\hline $\begin{array}{l}\text { Recebimento dos comprovantes de } \\
\text { entrega da medicação }\end{array}$ & 12,64 & & & & & $5.439,10$ & $5.495,19$ \\
\hline Coordenação da Equipe (4) & 12,64 & & & & & $3.722,80$ & $3.735,44$ \\
\hline Triar processo/documento & 12,64 & & & & & $8.131,82$ & $8.215,17$ \\
\hline Tramitar e Receber processos & 12,64 & & & & & $2.870,61$ & $2.910,53$ \\
\hline Suspender procedimento de compra & 12,64 & & & & & $4.732,86$ & $4.772,78$ \\
\hline Coordenação de Equipe (5) & 12,64 & & & & & $5.761,47$ & $5.774,11$ \\
\hline Solicitar depósito judicial & 12,64 & & & & & $3.337,13$ & $3.349,77$ \\
\hline Realizar atendimento telefônico & 12,64 & & & & & $1.274,12$ & $1.287,76$ \\
\hline Realizar atendimento via e-mail & 12,64 & & & & & $9.961,59$ & $9.974,23$ \\
\hline $\begin{array}{l}\text { Elaboração de respostas aos órgãos de } \\
\text { controle e demais stakeholders do } \\
\text { processo de compra }\end{array}$ & 12,64 & & & & & $7.883,83$ & $7.896,47$ \\
\hline Emissão da Guia de Remessa & 12,64 & & $1.696,52$ & & & $8.653,14$ & $21.461,00$ \\
\hline $\begin{array}{l}\text { Solicitação de coleta de medicamentos } \\
\text { no aeroporto }\end{array}$ & 12,64 & $127.310,26$ & $1.696,52$ & & & $1.883,17$ & $140.317,18$ \\
\hline $\begin{array}{l}\text { Solicitação de recolhimento de } \\
\text { medicamentos }\end{array}$ & 12,64 & $127.310,26$ & $1.696,52$ & & & $5.444,87$ & $143.908,88$ \\
\hline Recebimento de Medicamentos & 12,64 & $127.310,26$ & $1.696,52$ & & & $6.709,95$ & $150.037,12$ \\
\hline
\end{tabular}

Fonte: dados de pesquisa 
Tabela 17 - Apuração do custo das atividades - Geral

(Conclusão)

\begin{tabular}{|c|c|c|c|c|c|c|c|}
\hline ATIVIDADES & $\begin{array}{l}\text { MATERIAL DE } \\
\text { EXPEDIENTE }\end{array}$ & TRANSPORTE & $\begin{array}{c}\text { ALUGUEL DE } \\
\text { ALMOXARIFADO } \\
\end{array}$ & $\begin{array}{c}\text { LICENÇA DE } \\
\text { IMPORTAÇÃO } \\
\end{array}$ & PUBLICAÇÃO & SALÁRIOS & TOTAL \\
\hline Preparo dos medicamentos para envio & 12,64 & & $1.696,52$ & & & $3.279,49$ & $20.035,24$ \\
\hline Resolução de pendências de entrega & 12,64 & & $1.696,52$ & & & $1.500,80$ & $17.652,07$ \\
\hline Entrada do medicamento no Sistema & 12,64 & & $1.696,52$ & & & $3.720,80$ & $17.481,05$ \\
\hline Controle e supervisão do estoque & 12,64 & & $1.696,52$ & & & $2.127,37$ & $15.123,81$ \\
\hline Envio de nota fiscal para pagamento & 12,64 & & $1.696,52$ & & & $2.000,00$ & $17.261,08$ \\
\hline Disponibilidade orçamentária & 12,64 & & & & & $1.410,71$ & $1.423,36$ \\
\hline Empenho & 12,64 & & & & & $4.232,17$ & $4.244,81$ \\
\hline Solicitação de abertura da LI & 12,64 & & & $14.945,56$ & & $2.571,75$ & $17.529,95$ \\
\hline Autorização da ANVISA & 12,64 & & & & & $1.685,37$ & $1.698,01$ \\
\hline Pagamento & 12,64 & & & & & $13.445,53$ & $13.457,97$ \\
\hline Solicitação de Embarque & 12,64 & & & & & 399,49 & 412,13 \\
\hline Devolução do processo para a CDJU & 12,64 & & & & & 399,49 & 412,13 \\
\hline
\end{tabular}

Fonte: dados de pesquisa 
Conforme a consolidação das informações contidas no Tabela 17, finalmente é possível conhecer os custos totais de cada atividade desenvolvida pela CDJU e as demais áreas do Ministério da Saúde na compra e na entrega de medicamentos e outros insumos.

Conforme se observa, as atividades de maior custo foram às atividades relacionadas à entrega e à coleta de medicamentos, pois nelas foram apropriados os custos do contrato de transporte do Ministério com a empresa de operação logística.

A Tabela 18 apresenta o custo total por equipe e o respectivo percentual gasto com as atividades, levando em consideração o custo total.

Tabela 18 - Custos das atividades por equipe / setor e percentual

\begin{tabular}{l|c|c}
\multicolumn{1}{c|}{ EQUIPE } & CUSTO TOTAL & PERCENTUAL \\
\cline { 1 - 1 } Coordenação & $\mathrm{R} \$ 11.663,80$ & $2 \%$ \\
\cline { 1 - 1 } ECAP & $\mathrm{R} \$ 41.617,60$ & $6 \%$ \\
\cline { 1 - 1 } ECOMP & $\mathrm{R} \$ 53.975,98$ & $8 \%$ \\
\cline { 1 - 1 } ECODE & $\mathrm{R} \$ 53.358,05$ & $8 \%$ \\
\cline { 1 - 1 } Protocolo & $\mathrm{R} \$ 19.509,61$ & $3 \%$ \\
\cline { 1 - 1 } EGET & $\mathrm{R} \$ 28.282,52$ & $4 \%$ \\
\cline { 1 - 1 } SADM & $\mathrm{R} \$ 432.647,78$ & $64 \%$ \\
\cline { 1 - 1 } CEOF & $\mathrm{R} \$ 39.180,30$ & $6 \%$ \\
\hline TOTAL & $\mathbf{R} \$ \mathbf{6 8 0 . 2 3 5 , 6 4}$ & $\mathbf{1 0 0 \%}$ \\
\hline Fon
\end{tabular}

Fonte: dados de pesquisa

Pode-se verificar que o setor que mais consome recursos nas atividades de cumprimento de determinação judicial é o SADM, correspondendo a $64 \%$ do total dos recursos. Nas atividades desempenhadas pelo SADM, o que elevou sobremaneira os custos foram os gastos com o pagamento de aluguel do almoxarifado e, especialmente, os gastos com o transporte dos medicamentos. 


\subsubsection{Modelo de Custeio Active Base Cost - ABC Após a Adoção do Sistema}

Com a implementação do sistema PECJUDICIAL, foi necessária a realização de nova rodada de entrevistas com os mesmos participantes para a identificação das atividades relevantes após a adoção do Sistema. O Quadro 6 apresenta as principais atividades mapeadas após a adoção do Sistema.

Quadro 6 - Principais atividades após a adoção do PECJUDICIAL

(Continua)

\begin{tabular}{|c|c|}
\hline ATIVIDADES & SETOR/EQUIPE \\
\hline Coordenação da Setor & $\mathrm{CDJU}$ \\
\hline Coordenação de Equipe (1) & \multirow{7}{*}{ ECAP } \\
\hline Cadastrar e atualizar os dados do processo no Sistema de Ação Judicial & \\
\hline Pendências de Entrega & \\
\hline Realizar a análise farmacêutica & \\
\hline Definição da quantidade a ser adquirida & \\
\hline Definição da forma de cumprimento da decisão judicial & \\
\hline Cadastramento do medicamento no Sistema de Ação Judicial & \\
\hline Coordenação da Equipe (2) & \multirow{6}{*}{ ECOMP } \\
\hline Solicitar retificação de proposta de preço & \\
\hline Analisar propostas de preço & \\
\hline Realizar o agrupamento das aquisições por período & \\
\hline Solicitar a retirada de medicamentos do estoque & \\
\hline Publicar a compra na Imprensa Oficial & \\
\hline Coordenação da Equipe (3) & \multirow{7}{*}{ ECODE } \\
\hline Cobrar os fornecedores nos casos de atraso na entrega de medicamentos & \\
\hline Autorizar entrega parcelada & \\
\hline Conferir a documentação apresentada pela transportadora & \\
\hline Agendar entrega no SADM & \\
\hline Solicitar recolhimento de medicamentos & \\
\hline Recebimento dos comprovantes de entrega da medicação & \\
\hline Coordenação de Equipe (4) & \multirow{5}{*}{ EGET } \\
\hline Solicitar depósito judicial & \\
\hline Realizar atendimento telefônico & \\
\hline Realizar atendimento via e-mail & \\
\hline $\begin{array}{l}\text { Elaboração de respostas aos órgãos de controle e demais stakeholders do } \\
\text { processo de compra }\end{array}$ & \\
\hline
\end{tabular}

Fonte: dados de pesquisa 
Quadro 6 - Principais atividades após a adoção do sistema

(Conclusão)

\begin{tabular}{|l|l|}
\hline \multicolumn{1}{|c|}{ ATIVIDADES } & SETOR/EQUIPE \\
\hline Emissão da Guia de Remessa & \\
\hline Solicitação de coleta de medicamentos no aeroporto & \\
\hline Solicitação de recolhimento de medicamentos & \\
\hline Recebimento de Medicamentos & \\
\hline Preparo dos medicamentos para envio & \\
\hline Resolução de pendências de entrega & \\
\hline Controle e supervisão do estoque & \\
\hline Envio de nota fiscal para pagamento & \\
\hline Disponibilidade orçamentária & \\
\hline Empenho & \\
\hline Solicitação de abertura da LI & \\
\hline Autorização da ANVISA & \\
\hline Pagamento & \\
\hline Solicitação de Embarque & \\
\hline Fonte: dados de pesquisa & \\
\hline
\end{tabular}

Fonte: dados de pesquisa

Após a adoção do Sistema, foram identificadas 40 atividades relevantes no processo de compra de medicamentos distribuídas entre as sete equipes/divisões envolvidas no ciclo de compra. Neste total, foram consideradas três novas atividades incorporadas com a utilização do Sistema e 17 atividades automatizadas que antes eram desempenhadas por colaboradores.

Para a realização da análise comparativa dos custos, foi necessária a realização da comparação dentro de um mesmo cenário, ou seja, quais são os direcionadores de custos afetados pela implementação do Sistema, excluídos os valores gastos com os recursos consumidos das atividades automatizadas e incluídos os valores com as novas atividades dentro do mesmo período. 


\subsubsection{Atribuição dos Custos dos Recursos às Atividades Após a Adoção do Sistema}

Após a fase de identificação dos direcionadores de recursos (custos), é necessário a alocação dos custos às atividades levantadas. Foi realizada nova entrevista semiestruturada de forma individual após a implementação do Sistema com todos os servidores e consultores, perfazendo um total de 45 entrevistados, sendo possível a partir daí a obtenção efetiva do tempo gasto por cada um em cada atividade.

A Tabela 19 apresenta o percentual de tempo gasto com as atividades da Equipe de Cadastro e Análise Farmacêutica (ECAP) após a adoção do Sistema.

Tabela 19 - Percentual de tempo gasto por atividades após adoção do sistema - Coordenação e ECAP

\begin{tabular}{|c|c|c|c|c|c|c|c|c|c|}
\hline \multirow{2}{*}{ ATIVIDADES } & \multicolumn{9}{|c|}{ FUNCIONÁRIOS } \\
\hline & & 1 & 2 & 3 & 4 & 5 & 6 & 7 & 8 \\
\hline Coordenação do Setor & CDJU & $100 \%$ & & & & & & & \\
\hline $\begin{array}{l}\text { Cadastrar e atualizar os dados do processo } \\
\text { no Sistema de Ação Judicial }\end{array}$ & ECAP & & $19 \%$ & $75 \%$ & & & & & \\
\hline Pendências de Entrega & ECAP & & $25 \%$ & & & & & & \\
\hline Coordenação de Equipe (1) & ECAP & & $38 \%$ & & & & & & \\
\hline Realizar a análise farmacêutica & ECAP & & & & $30 \%$ & $19 \%$ & $21 \%$ & $22 \%$ & $29 \%$ \\
\hline Definição da quantidade a ser adquirida & ECAP & & & & $30 \%$ & $23 \%$ & $32 \%$ & $22 \%$ & $23 \%$ \\
\hline $\begin{array}{l}\text { Definição da forma de cumprimento da } \\
\text { decisão judicial }\end{array}$ & ECAP & & & & $15 \%$ & $19 \%$ & $26 \%$ & $17 \%$ & $13 \%$ \\
\hline \multirow[t]{2}{*}{$\begin{array}{l}\text { Cadastramento do medicamento no } \\
\text { Sistema de Ação Judicial }\end{array}$} & ECAP & & & & $10 \%$ & $8 \%$ & $5 \%$ & $11 \%$ & $13 \%$ \\
\hline & TOTAL & $100 \%$ & $81 \%$ & $75 \%$ & $85 \%$ & $70 \%$ & $84 \%$ & $72 \%$ & $89 \%$ \\
\hline
\end{tabular}

Fonte: dados de pesquisa

A Tabela 20 apresenta o percentual de tempo gasto com as atividades da Equipe de Compras e Publicação (ECOMP) após a adoção do sistema. 
Tabela 20 - Percentual de tempo gasto por atividades após adoção do sistema - ECOMP

\begin{tabular}{|c|c|c|c|c|c|c|c|c|c|}
\hline \multirow{2}{*}{ ATIVIDADES } & \multicolumn{9}{|c|}{ FUNCIONÁRIOS } \\
\hline & & 9 & 10 & 11 & 12 & 13 & 14 & 15 & 16 \\
\hline Coordenação da Equipe (2) & ECOMP & $20 \%$ & & & & & & & \\
\hline $\begin{array}{l}\text { Solicitar retificação de proposta } \\
\text { de preço }\end{array}$ & ECOMP & & $28 \%$ & & & & $4 \%$ & & \\
\hline Analisar propostas de preço & ECOMP & & & & $67 \%$ & & & & $29 \%$ \\
\hline $\begin{array}{l}\text { Realizar o agrupamento das } \\
\text { aquisições por período }\end{array}$ & ECOMP & & & $30 \%$ & & & & & \\
\hline $\begin{array}{lll}\text { Solicitar a retirada } & \text { de } \\
\text { medicamentos do estoque } & \end{array}$ & ECOMP & & & & & & & $100 \%$ & $14 \%$ \\
\hline $\begin{array}{l}\text { Publicar a compra na Imprensa } \\
\text { Oficial }\end{array}$ & ECOMP & $40 \%$ & & & & $60 \%$ & & & \\
\hline & TOTAL & $60 \%$ & $28 \%$ & $30 \%$ & $67 \%$ & $60 \%$ & $4 \%$ & $100 \%$ & $33 \%$ \\
\hline
\end{tabular}

Fonte: dados de pesquisa

A Tabela 21 apresenta o percentual de tempo gasto com as atividades da Equipe de Controle e Devolução de Processos (ECODE) após a adoção do sistema.

Tabela 21 - Percentual de tempo gasto por atividades após adoção do sistema -ECODE

\begin{tabular}{|c|c|c|c|c|c|c|c|c|c|c|c|}
\hline \multirow{2}{*}{ ATIVIDADES } & \multicolumn{11}{|c|}{ FUNCIONÁRIOS } \\
\hline & & 17 & 18 & 19 & 20 & 21 & 22 & 23 & 24 & 26 & 26 \\
\hline $\begin{array}{l}\text { Coordenação da } \\
\text { Equipe (3) }\end{array}$ & ECODE & & & & & & & & $50 \%$ & & \\
\hline $\begin{array}{l}\text { Conferir a } \\
\text { documentação } \\
\text { apresentada pela } \\
\text { transportadora }\end{array}$ & ECODE & & & & $83 \%$ & & & $93 \%$ & & & \\
\hline $\begin{array}{l}\text { Agendar entrega no } \\
\text { SADM }\end{array}$ & ECODE & & & & & & & & & $35 \%$ & \\
\hline $\begin{array}{l}\text { Cobrar os } \\
\text { fornecedores nos } \\
\text { casos de atraso na } \\
\text { entrega de } \\
\text { medicamentos }\end{array}$ & ECODE & $60 \%$ & & $7 \%$ & & & & $2 \%$ & & & \\
\hline $\begin{array}{l}\text { Autorizar entrega } \\
\text { parcelada }\end{array}$ & ECODE & & & $70 \%$ & & & & & & & \\
\hline $\begin{array}{l}\text { Solicitar recolhimento } \\
\text { de medicamentos }\end{array}$ & ECODE & $17 \%$ & $57 \%$ & $16 \%$ & & & $20 \%$ & $3 \%$ & & & \\
\hline $\begin{array}{l}\text { Recebimento dos } \\
\text { comprovantes de } \\
\text { entrega da medicação }\end{array}$ & ECODE & & & & $17 \%$ & & & $2 \%$ & $50 \%$ & & \\
\hline & TOTAL & $77 \%$ & $57 \%$ & $93 \%$ & $100 \%$ & $0 \%$ & $20 \%$ & $100 \%$ & $100 \%$ & $35 \%$ & $0 \%$ \\
\hline
\end{tabular}

Fonte: dados de pesquisa 
A Tabela 22 apresenta o percentual de tempo gasto com as atividades da Equipe de Gestão (EGET) e Protocolo após a adoção do sistema.

Tabela 22- Percentual de tempo gasto por atividades após adoção do sistema - Protocolo e EGET

\begin{tabular}{l|c|c|c|c|c|c|c|c|c}
\hline \multirow{2}{*}{\multicolumn{1}{c|}{ ATIVIDADES }} & \multicolumn{7}{c}{ FUNCIONÁRIOS } \\
\cline { 2 - 11 } & & $\mathbf{2 7}$ & $\mathbf{2 8}$ & $\mathbf{2 9}$ & $\mathbf{3 0}$ & $\mathbf{3 1}$ & $\mathbf{3 2}$ & $\mathbf{3 3}$ & $\mathbf{3 4}$ \\
\hline Coordenação de Equipe (5) & EGET & & & & & & & & $65 \%$ \\
\hline Solicitar depósito judicial & EGET & & & & $1 \%$ & $40 \%$ & $30 \%$ & $15 \%$ & \\
\hline Realizar atendimento telefônico & EGET & & & & $4 \%$ & $40 \%$ & $0 \%$ & & $5 \%$ \\
\hline Realizar atendimento via e-mail & EGET & & & & $5 \%$ & $20 \%$ & $60 \%$ & $80 \%$ & $10 \%$ \\
\hline $\begin{array}{l}\text { Elaboração de respostas aos órgãos } \\
\text { de controle e demais stakeholders } \\
\text { do processo de compra }\end{array}$ & EGET & & & & $90 \%$ & $0 \%$ & $10 \%$ & $5 \%$ & $20 \%$ \\
\cline { 2 - 12 } & TOTAL & $\mathbf{0 \%}$ & $\mathbf{0 \%}$ & $\mathbf{0 \%}$ & $\mathbf{1 0 0 \%}$ & $\mathbf{1 0 0 \%}$ & $\mathbf{1 0 0 \%}$ & $\mathbf{1 0 0 \%}$ & $\mathbf{1 0 0 \%}$ \\
\hline
\end{tabular}

Fonte: dados de pesquisa

Cabe ressaltar que como as atividades de protocolo foram informatizadas e as novas atividades atribuídas com a adoção do Sistema não serão desempenhadas pelos colaboradores 27, 28 e 29, os percentuais do uso da força de trabalho é $0 \%$, ou seja, eles podem ser redirecionados para outros setores.

A Tabela 23 apresenta o percentual de tempo gasto com as atividades do Serviço de Armazenamento e Distribuição de Medicamentos (SADM) e Coordenação de Execução Orçamentária e Financeira (CEOF) após a adoção do Sistema. 
Tabela 23 - Percentual de tempo gasto por atividades após adoção do sistema - SADM e CEOF

\begin{tabular}{|c|c|c|c|c|c|c|c|c|c|c|c|c|}
\hline \multirow{2}{*}{ ATIVIDADES } & \multicolumn{12}{|c|}{ FUNCIONÁRIOS } \\
\hline & & 35 & 36 & 37 & 38 & 39 & 40 & 41 & 42 & 43 & 44 & 45 \\
\hline Emissão da Guia de Remessa & SADM & $5 \%$ & $75 \%$ & & $70 \%$ & & $40 \%$ & & & & & \\
\hline $\begin{array}{l}\text { Solicitação de coleta de } \\
\text { medicamentos no aeroporto }\end{array}$ & SADM & & & & $20 \%$ & & $20 \%$ & & & & & \\
\hline $\begin{array}{l}\text { Solicitação de recolhimento de } \\
\text { medicamentos }\end{array}$ & SADM & & $15 \%$ & $90 \%$ & $3 \%$ & & & & & & & \\
\hline Recebimento de Medicamento & SADM & & & $5 \%$ & $4 \%$ & $50 \%$ & & $60 \%$ & & & & \\
\hline $\begin{array}{l}\text { Preparo dos medicamentos } \\
\text { para envio }\end{array}$ & SADM & & & $5 \%$ & $3 \%$ & $20 \%$ & & $30 \%$ & & & & \\
\hline $\begin{array}{l}\text { Resolução de pendências de } \\
\text { entrega }\end{array}$ & SADM & $25 \%$ & $5 \%$ & & & & & & & & & \\
\hline $\begin{array}{llll}\begin{array}{l}\text { Controle } \\
\text { estoque }\end{array} & \text { e supervisão } & \text { do } \\
\end{array}$ & SADM & & & & & $30 \%$ & & $10 \%$ & & & & \\
\hline $\begin{array}{l}\text { Envio de nota fiscal para } \\
\text { pagamento }\end{array}$ & SADM & & & & & & $40 \%$ & & & & & \\
\hline Disponibilidade orçamentária & CEOF & & & & & & & & & $25 \%$ & & \\
\hline Empenho & CEOF & & & & & & & & & $75 \%$ & & \\
\hline Solicitação de abertura da LI & CEOF & & & & & & & & & & $20 \%$ & $20 \%$ \\
\hline Autorização da ANVISA & CEOF & & & & & & & & & & $20 \%$ & $10 \%$ \\
\hline Pagamento & CEOF & & & & & & & & $100 \%$ & & $40 \%$ & $70 \%$ \\
\hline \multirow[t]{2}{*}{ Solicitação de Embarque } & CEOF & & & & & & & & & & $10 \%$ & \\
\hline & TOTAL & $25 \%$ & $95 \%$ & $100 \%$ & $100 \%$ & $100 \%$ & $100 \%$ & $100 \%$ & $100 \%$ & $100 \%$ & $90 \%$ & $100 \%$ \\
\hline
\end{tabular}

Fonte: dados de pesquisa

As Tabelas apresentadas demonstram que, após a implementação do Sistema, diversos funcionários estão ociosos, uma vez que grande parte da utilização da mão de obra está inferior a $100 \%$ (corresponde ao pleno uso), possibilitando aos gestores a incorporação de novas atribuições e atividades ou a realocação dos colaboradores em outras áreas do Ministério da Saúde.

Com as novas atividades, foi realizada nova apropriação de custos de salários, transporte, aluguel, licença de importação, publicação e material de expediente. Cabe ressaltar que os custos que tiveram maior redução foram referentes aos salários e ao material de expediente. A nova apropriação de custo está demonstrada no Tabela 24. Os valores apresentados são em reais. 
Tabela 24 - Apuração do custo das atividades mensais após a adoção do sistema - Geral

(Continua)

\begin{tabular}{|c|c|c|c|c|c|c|c|}
\hline ATIVIDADES & $\begin{array}{l}\text { MATERIAL DE } \\
\text { EXPEDIENTE }\end{array}$ & TRANSPORTE & $\begin{array}{c}\text { ALUGUEL DE } \\
\text { ALMOXARIFADO }\end{array}$ & $\begin{array}{l}\text { LICENÇA DE } \\
\text { IMPORTAÇÃO }\end{array}$ & PUBLICAÇÃO & SALÁRIOS & TOTAL \\
\hline Coordenação da Setor & 9,46 & & & & & $11.663,80$ & $11.673,26$ \\
\hline Pendências de Entrega & 9,46 & & & & & $2.127,31$ & $2.136,77$ \\
\hline Coordenação de Equipe (1) & 9,46 & & & & & $3.368,24$ & $3.377,70$ \\
\hline Realizar a análise farmacêutica & 9,46 & & & & & $6.735,86$ & $6.745,32$ \\
\hline $\begin{array}{l}\text { Definição da quantidade a ser } \\
\text { adquirida }\end{array}$ & 9,46 & & & & & $7.287,21$ & $7.296,67$ \\
\hline $\begin{array}{l}\text { Definição da forma de } \\
\text { cumprimento da decisão } \\
\text { judicial }\end{array}$ & 9,46 & & & & & $5.028,32$ & $5.037,78$ \\
\hline $\begin{array}{l}\text { Cadastramento do } \\
\text { medicamento no Sistema de } \\
\text { Ação Judicial }\end{array}$ & 9,46 & & & & & $2.616,15$ & $2.625,61$ \\
\hline $\begin{array}{l}\text { Programação das planilhas de } \\
\text { compra agrupada por } \\
\text { medicamento }\end{array}$ & 9,46 & & & & & $1.929,98$ & $1.939,44$ \\
\hline Coordenação da Equipe (2) & 9,46 & & & & & $1.779,94$ & $1.789,40$ \\
\hline $\begin{array}{l}\text { Realizar o agrupamento das } \\
\text { aquisições por período }\end{array}$ & 9,46 & & & & & $1.800,00$ & $1.809,46$ \\
\hline $\begin{array}{l}\text { Solicitar retificação de proposta } \\
\text { de preço }\end{array}$ & 9,46 & & & & & $2.142,51$ & $2.151,97$ \\
\hline Analisar propostas de preço & 9,46 & & & & & $5.472,67$ & $5.482,13$ \\
\hline $\begin{array}{l}\text { Solicitar a retirada de } \\
\text { medicamentos do estoque }\end{array}$ & 9,46 & & & & & $5.617,84$ & $5.627,30$ \\
\hline $\begin{array}{l}\text { Publicar a compra na Imprensa } \\
\text { Oficial }\end{array}$ & 9,46 & & & & $6.265,41$ & $7.459,88$ & $13.734,75$ \\
\hline Coordenação da Equipe (3) & 9,46 & & & & & $4.431,90$ & $4.441,36$ \\
\hline
\end{tabular}

Fonte: dados de pesquisa 
Tabela 24 - Apuração do custo das atividades mensais após a adoção do sistema - Geral

(Continuação)

\begin{tabular}{|c|c|c|c|c|c|c|c|}
\hline ATIVIDADES & $\begin{array}{l}\text { MATERIAL DE } \\
\text { EXPEDIENTE }\end{array}$ & TRANSPORTE & $\begin{array}{c}\text { ALUGUEL DE } \\
\text { ALMOXARIFADO }\end{array}$ & $\begin{array}{l}\text { LICENÇA DE } \\
\text { IMPORTAÇÃO }\end{array}$ & PUBLICAÇÃO & SALÁRIOS & TOTAL \\
\hline $\begin{array}{l}\text { Cobrar os fornecedores nos } \\
\text { casos de atraso na entrega de } \\
\text { medicamentos }\end{array}$ & 9,46 & & & & & $3.259,36$ & $3.268,82$ \\
\hline Autorizar entrega parcelada & 9,46 & & & & & $3.500,00$ & $3.509,46$ \\
\hline Agendar entrega no SADM & 9,46 & & & & & $2.203,14$ & $2.212,60$ \\
\hline $\begin{array}{l}\text { Conferir a documentação } \\
\text { apresentada pela transportadora }\end{array}$ & 9,46 & & & & & $10.330,31$ & $10.339,77$ \\
\hline $\begin{array}{l}\text { Solicitar recolhimento de } \\
\text { medicamentos }\end{array}$ & 9,46 & & & & & $5.359,76$ & $5.369,22$ \\
\hline $\begin{array}{l}\text { Recebimento dos } \\
\text { comprovantes de entrega da } \\
\text { medicação }\end{array}$ & 9,46 & & & & & $5.439,10$ & $5.448,56$ \\
\hline Coordenação de Equipe (5) & 9,46 & & & & & $5.761,47$ & $5.770,93$ \\
\hline Solicitar depósito judicial & 9,46 & & & & & $3.337,13$ & $3.346,59$ \\
\hline $\begin{array}{l}\text { Realizar atendimento } \\
\text { telefônico }\end{array}$ & 9,46 & & & & & $1.274,12$ & $1.283,58$ \\
\hline $\begin{array}{l}\text { Realizar atendimento via e- } \\
\text { mail }\end{array}$ & 9,46 & & & & & $9.961,59$ & $9.971,05$ \\
\hline $\begin{array}{l}\text { Elaboração de respostas aos } \\
\text { órgãos de controle e demais } \\
\text { stakeholders do processo de } \\
\text { compra }\end{array}$ & 9,46 & & & & & $7.883,83$ & $7.893,29$ \\
\hline Emissão da Guia de Remessa & 9,46 & & $1.908,59$ & & & $8.653,14$ & $10.571,19$ \\
\hline $\begin{array}{l}\text { Solicitação de coleta de } \\
\text { medicamentos no aeroporto }\end{array}$ & 9,46 & $127.310,26$ & $1.908,59$ & & & $1.883,17$ & $131.111,48$ \\
\hline $\begin{array}{l}\text { Solicitação de recolhimento de } \\
\text { medicamentos }\end{array}$ & 9,46 & $127.310,26$ & $1.908,59$ & & & $5.444,87$ & $134.673,18$ \\
\hline
\end{tabular}

Fonte: dados de pesquisa 
Tabela 24 - Apuração do custo das atividades mensais após a adoção do sistema - Geral

(Conclusão)

\begin{tabular}{|c|c|c|c|c|c|c|c|}
\hline ATIVIDADES & $\begin{array}{l}\text { MATERIAL DE } \\
\text { EXPEDIENTE }\end{array}$ & TRANSPORTE & $\begin{array}{c}\text { ALUGUEL DE } \\
\text { ALMOXARIFADO }\end{array}$ & $\begin{array}{l}\text { LICENÇA DE } \\
\text { IMPORTAÇÃO }\end{array}$ & PUBLICAÇÃO & SALÁRIOS & TOTAL \\
\hline Recebimento de Medicamentos & 9,46 & $127.310,26$ & $1.908,59$ & & & $6.709,95$ & $135.938,26$ \\
\hline $\begin{array}{l}\text { Preparo dos medicamentos para } \\
\text { envio }\end{array}$ & 9,46 & & $1.908,59$ & & & $3.279,49$ & $5.197,54$ \\
\hline $\begin{array}{l}\text { Resolução de pendências de } \\
\text { entrega }\end{array}$ & 9,46 & & $1.908,59$ & & & $1.500,80$ & $3.418,85$ \\
\hline $\begin{array}{l}\text { Controle e supervisão do } \\
\text { estoque }\end{array}$ & 9,46 & & $1.908,59$ & & & $2.127,37$ & $4.045,42$ \\
\hline $\begin{array}{l}\text { Envio de nota fiscal para } \\
\text { pagamento }\end{array}$ & 9,46 & & $1.908,59$ & & & $2.000,00$ & $3.918,05$ \\
\hline Disponibilidade orçamentária & 9,46 & & & & & $1.410,72$ & $1.420,18$ \\
\hline Empenho & 9,46 & & & & & $4.232,17$ & $4.241,63$ \\
\hline Solicitação de abertura da LI & 9,46 & & & $14.945,56$ & & $2.571,75$ & $17.526,77$ \\
\hline Autorização da ANVISA & 9,46 & & & & & $1.685,37$ & $1.694,83$ \\
\hline Pagamento & 9,46 & & & & & $13.445,53$ & $13.454,99$ \\
\hline Solicitação de Embarque & 9,46 & & & & & 399,49 & 408,95 \\
\hline
\end{tabular}

Fonte: dados de pesquisa 
Após a consolidação das informações contidas no Tabela 17 e 24, finalmente é possível conhecer quais os custos totais de cada atividade desenvolvida pela CDJU e as demais áreas do Ministério da Saúde na compra e entrega de medicamentos após a adoção do sistema PECJUDICIAL.

As atividades de maior custo permaneceram aquelas relacionadas à entrega e à coleta de medicamentos, pois os custos do contrato de transporte do Ministério com a empresa de operação logística não foram impactados com a adoção do Sistema.

A Tabela 25 apresenta a análise comparativa por equipe/divisão após a adoção do Sistema e o percentual total correspondente aos custos para cumprimento de determinação judicial no âmbito do DLOG.

Tabela 25 - Análise comparativa dos custos das atividades por equipe / divisão

\begin{tabular}{|c|c|c|c|c|c|c|}
\hline \multirow{2}{*}{$\begin{array}{c}\text { EQUIPE } \\
\text { Coordenação } \\
\end{array}$} & \multicolumn{2}{|c|}{$\begin{array}{l}\text { CUSTO TOTAL MENSAL } \\
\text { (SEM A UTILIZAÇÃO DO } \\
\text { PECJUDICIAL) }\end{array}$} & \multicolumn{2}{|c|}{$\begin{array}{c}\text { CUSTO TOTAL MENSAL } \\
\text { (COM A UTILIZAÇÃO DO } \\
\text { PECJUDICIAL) }\end{array}$} & \multirow{2}{*}{$\begin{array}{c}\begin{array}{c}\text { DIFERENÇA } \\
\%\end{array} \\
0 \% \\
\end{array}$} & \multirow{2}{*}{$\begin{array}{c}\text { PERCENTUAL } \\
\text { TOTAL DO } \\
\text { CUSTO }\end{array}$} \\
\hline & $\mathrm{R} \$$ & $11.663,80$ & $\mathrm{R} \$$ & $11.663,80$ & & \\
\hline ECAP & $\mathrm{R} \$$ & $41.617,60$ & $\mathrm{R} \$$ & $29.159,30$ & $30 \%$ & $5 \%$ \\
\hline ECOMP & $\mathrm{R} \$$ & $53.975,98$ & $\mathrm{R} \$$ & $30.595,00$ & $43 \%$ & $5 \%$ \\
\hline ECODE & $\mathrm{R} \$$ & $53.358,05$ & $\mathrm{R} \$$ & $30.148,44$ & $43 \%$ & $5 \%$ \\
\hline Protocolo & $\mathrm{R} \$$ & $19.509,61$ & $\mathrm{R} \$$ & 0,00 & $100 \%$ & $0 \%$ \\
\hline EGET & $\mathrm{R} \$$ & $28.282,52$ & $\mathrm{R} \$$ & $28.265,44$ & $0 \%$ & $5 \%$ \\
\hline SADM & $\mathrm{R} \$$ & $432.647,78$ & $\mathrm{R} \$$ & $428.873,93$ & $1 \%$ & $72 \%$ \\
\hline CEOF & $\mathrm{R} \$$ & $39.180,30$ & $\mathrm{R} \$$ & $38.747,35$ & $1 \%$ & $6 \%$ \\
\hline TOTAL & $\mathrm{R} \$$ & $680.235,64$ & $\mathrm{R} \$$ & $597.453,25$ & $12 \%$ & $100 \%$ \\
\hline
\end{tabular}

Fonte: dados de pesquisa

Pode-se verificar que, após a implementação do Sistema, houve uma redução total de $12 \%$ no custo total processual. As atividades desenvolvidas pelo Protocolo foram as mais afetadas com a implementação do Sistema, pois com o fim dos processos físicos as atividades desenvolvidas pela equipe também acabaram. 
Realizando a análise comparativa do custo total da Coordenação de Compra por Determinação Judicial (CDJU), correspondendo às equipes ECAP, ECOMP, ECODE, EGET e Coordenação, observa-se que com a adoção do Sistema ocorreu a redução média de aproximadamente $38 \%$ do custo total da Coordenação.

O impacto no custo das atividades desenvolvidas pelo SADM não foi relevante devido aos elevados custos de armazenagem e transporte, pois os direcionadores de custos envolvidos nestas atividades não são afetados pela informatização das atividades.

A Coordenação de Execução Orçamentária e Financeira (CEOF) teve a redução somente de $1 \%$ do custo total de suas atividades, devido à diminuição dos custos com material de expediente e à informatização de apenas uma atividade de pouca relevância.

Após a adoção do sistema PECJUDICIAL pode-se verificar uma redução relevante nos custos consumidos com o pagamento de salários e gratificações. À medida que novas versões for desenvolvidas e novas atividades incorporadas ao Sistema deve-se realizar um novo levantamento de custo, a fim de identificar os resultados atingidos com as melhorias. 


\section{DISCUSSÃO}

A discussão dos resultados, segue a mesma organização dos objetivos específicos e da seção anterior. Primeiramente, são discutidos os resultados referentes às barreiras e aos facilitadores à implantação do PECJUDICIAL. Em segundo lugar, são discutidos os resultados referentes à avaliação do PECJUDICIAL pelos usuários internos. Por fim, são discutidos os resultados referentes aos custos antes e depois da adoção do PECJUDICAL.

\subsection{BARREIRAS E FACILITADORES À IMPLEMENTAÇÃO DO SISTEMA PECJUDICIAL}

Sobre as barreiras à implementação do Sistema, aquelas de natureza humana foram as mais recorrentes, representando $34 \%$ do total. Os fatores humanos abordam a comunicação entre os envolvidos no projeto, o relacionamento interpessoal, os interesses pessoais e as atividades que envolvem o trabalho em equipe (PRADO et al, 2010).

Grande parte das barreiras humanas encontradas no presente estudo consiste na resistência às mudanças e a falta de comprometimento dos envolvidos no processo, ou seja, aspectos comportamentais interrelacionados. Diversos estudos apontam que na Administração Pública, a resistência às mudanças por parte dos servidores, especialmente aqueles com mais tempo de serviço, é um grande obstáculo para a implementação das políticas públicas (DE AZEVEDO; LOUREIRO, 2014).

Segundo Schein (1985), a cultura organizacional é formada pelos pressupostos básicos desenvolvidos pelos grupos na medida em que lidam com problemas de adaptação externa e integração interna. Segundo o autor a cultura organizacional é composto por três níveis: símbolos e comportamentos, valores e normas e pressupostos. Os símbolos e comportamentos referem-se a qualquer componente da cultura que seja concreto ou visível por todos os membros de uma organização, como a vestimenta, linguagem e comportamentos. Os valores e normas 
estão relacionados a todos os itens importantes que regem e norteiam uma empresa e a todas as regras de comportamento estabelecidas dentro do meio corporativo. Os pressupostos dizem respeito aos comportamentos inconscientes presentes na mente dos profissionais no ambiente de trabalho, estes componentes são dificilmente reconhecidos dentro do convívio diário entre os colaboradores de uma empresa ou organização.

Schein (1992) afirma que a cultura é um processo em formação, pelo fato de existir uma aprendizagem contínua de como se adaptar ao ambiente externo e de como melhor administrar as questões internas. Segundo o autor o grande responsável pelas mudanças organizacionais é o líder. Para que as organizações sejam eficazes, os gestores têm que efetivamente serem líderes, desempenhando um papel fundamental na formação e na transmissão da cultura organizacional.

Pode-se assumir que a cultura de uma organização mantém a estabilidade e coesão do sistema social, determina padrões e comportamentos considerados adequados a cada contexto e a forma mais adequada de conduzir as atividades e os negócios da organização (BEDANI, 2008). Portanto, é na cultura organizacional que crenças, expectativas e comportamentos diversos se desenvolvem e se mantêm. A resistência a mudanças deve ser compreendida e gerenciada considerando a cultura que perpassa a organização.

Crenças e atitudes dos envolvidos, direta e indiretamente, com as mudanças e inovações adotadas nas organizações estão entre os elementos mais centrais para o sucesso ou fracasso do processo de implementação (NEIVA; PAZ, 2002). Portanto, diagnosticar a presença de resistência permite aos gestores planejar ações que minimizem qualquer impacto negativo na implementação e consolidação das mudanças e inovações desenvolvidas.

Na perspectiva de Prado et al (2010), os fatores humanos estão estreitamente ligados aos conceitos clássicos de cultura organizacional. Entretanto, para fins de classificação, de fatores que compõem barreiras, o referido autor define fator cultural como as diferenças 
culturais que surgem pelo convívio de equipes multidisciplinares e pela participação de colaboradores terceirizados, que trazem consigo outra cultura organizacional, ou seja, outros padrões de valores, crenças e comportamentos (PRADO; TAKAOKA, 2007). No presente estudo, não foram verificadas barreiras associadas a diferenças culturais entre equipes e grupos distintos, e sim fatores humanos associados a resistências que podem ser compreendidos a partir de um olhar sobre a cultura da organização estudada e do próprio setor em que ela está inserida.

Segundo Neiva e Paz (2002), qualquer processo de mudança organizacional, seja ela mais profunda ou pontual, deve considerar a participação dos envolvidos direta e indiretamente no processo, investindo-se em divulgação de informações, canais de comunicação e participação nas discussões e tomadas de decisão

As barreiras de natureza técnicas também tiveram uma importante influência para a implementação do Sistema, uma vez que $26 \%$ do total de barreiras levantadas foram classificadas nesta categoria. Segundo Prado e Takaoka (2007), as barreiras técnicas referemse a todas as características e recursos técnicos disponíveis no projeto. É representado pelas habilidades e capacidades dos colaboradores, bem como pelas técnicas utilizadas para o levantamento dos requisitos, ferramentas aplicadas e métodos. Goguen e Linde (1993) destacam a importância da utilização de métodos participativos na implementação do sistema, pois quanto maior a participação dos usuários na construção do sistema menor serão as barreiras na sua implementação. Novamente, participação e envolvimento ganham papel de destaque no processo de implementação estudado.

Apesar do maior número de barreiras serem classificadas como humanas e técnicas, na implementação, $83 \%$ dos entrevistados apontaram a importância de barreiras políticas como fator mais importante. As barreiras políticas envolvem a importância que se atribui ao projeto, a rotatividade do alto escalão, mudanças de objetivos, estratégias da organização e as disputas internas de poder (PRADO et al 2010). 
A rotatividade dos gestores do Ministério da Saúde foi considerada a principal barreira para implementação. O software PECJUDICIAL foi desenvolvido abrangendo todas as áreas envolvidas no cumprimento da determinação judicial, portanto, devido à transversalidade do software, as mudanças dos gestores do MS impactaram drasticamente a implementação do Sistema. De uma forma geral, observa-se no setor público que a alta rotatividade nos cargos, a existência de disputas internas na alta administração e no corpo gerencial da organização afetam diretamente a implementação das tecnologias da informação e comunicação (ALBERTIN, 2001; PRADO et al 2010). Tal resultado, portanto, não é exclusivo do contexto investigado, mas reforça achados anteriores. Gestores envolvidos com adoção de novas ferramentas de gestão e tecnologias devem estar preparados para lidar com esse tipo de barreira e prever alternativas para transpô-la.

Os entrevistados apresentaram somente 12 facilitadores para a implementação do Sistema, sendo classificados em recursos, humanos, gerenciamento e políticos. Cabe destaque para os facilitadores políticos e recursos, pois ambos representaram $33 \%$ do total de facilitadores mensurados. Os facilitadores de recursos referem-se a todos os recursos materiais utilizados no projeto, trata dos investimentos e recursos financeiros, bem como o software, o hardware e a infraestrutura de tecnologia da informação (GOGUEN; LINDE, 1993; PRADO; TAKAOKA, 2007).

Destaca-se que apesar da rotatividade do alto escalão ter sido considerada a principal barreira, em contraponto os entrevistados indicam que a manutenção da equipe técnica em todo o projeto foi um facilitador para a sua implementação. Portanto, a permanência dos envolvidos no processo é fundamental para o sucesso da solução utilizada. Fatores políticos, em função da configuração que assumem, podem ser tanto importantes barreiras como importantes facilitadores. 
Devem ser empreendidas ações no sentido de formalização da ferramenta em instituições públicas, a fim de minimizar os impactos das barreiras políticas. Para tal, deve ser publicada portaria estabelecendo o sistema como ferramenta institucional. A formalização da ferramenta através de portaria diminui as influências políticas geradas pela rotatividade e fortalece o gestor para a realização da implementação.

Para a elaboração do planejamento estratégico referente a implementação do sistema, é fundamental a descrição e a classificação de suas barreiras e facilitadores. Sem a mensuração dos fatores que impactam positivamente (facilitadores) e pontos que impactam negativamente (barreiras) a tarefa de implementação torna-se sobremaneira demorada e penosa, podendo em muitos casos inviabilizar a utilização do sistema.

O modelo de classificação de barreiras e facilitadores de implementação do sistema é conceitual. As principais limitações encontradas no modelo utilizado foram: dificuldade categorização das barreiras e facilitadores em uma única classe, classificação utilizada pelos autores diferem dos conceitos clássicos apresentados pela literatura e a sobreposição de conceitos devido a abrangência das categorias.

\subsection{AVALIAÇÃO PRELIMINAR DO SISTEMA PECJUDICIAL NA PERSPECTIVA DOS USUÁRIOS INTERNOS}

Os gestores públicos precisam rever constantemente as entregas realizadas pelo Estado e aperfeiçoá-las para que, cada vez mais, sejam entregues serviços e produtos com mais qualidade, economicidade, eficiência e rapidez (PEREIRA, 2015).

A avaliação de produtos de software tem como principal objetivo a melhoria da sua qualidade. Para que tal processo seja mais efetivo, é importante utilizar um modelo validado que seja capaz de mesurar a qualidade do software para atingir os objetivos da organização (OLIVIERA, 2012). 
O presente estudo procurou realizar a avaliação inicial do software PECJUDICIAL na perspectiva dos usuários internos, a fim de verificar quais são os pontos de melhoria do software e, consequentemente, prover o DLOG de informações gerencias para melhor atender à crescente demanda por insumos para saúde no atendimento de determinação judicial. O sistema PECJUDICIAL foi avaliado pelos seus usuários internos com base em cinco características: adequação funcional, confiabilidade, usabilidade, eficiência de desempenho e compatibilidade.

Todas as características foram avaliadas positivamente pelos entrevistados uma vez que todas superaram o percentual de $70 \%$ para as respostas afirmativas. Apesar de $81 \%$ dos usuários concordarem que o sistema PECJUDCIAL possui a característica da usabilidade, esta característica foi aquela avaliada mais negativamente pelos usuários, correspondendo a $47 \%$ do total das respostas em desacordo.

A usabilidade representa facilidade de uso de um produto para desempenhar tarefas prescritas, refere-se à complexidade de uso da ferramenta. Este constructo está ligado ao grau de dificuldade na utilização do sistema, a percepção dos usuários em relação à interface, acessibilidade e operabilidade (OLIVEIRA, 2012). Ainda sobre a usabilidade, para a subcaracterística reconhecimento de adequação, $11 \%$ dos respondentes não sabiam da existência de manual do sistema. A utilização dos manuais afeta diretamente na avaliação desta característica.

Na avaliação da usabilidade é preciso considerar os diversos fatores que afetam a sua performance, especialmente o grau de maturidade do sistema. O grau de maturidade do sistema está relacionado ao seu tempo de uso e consequentemente à familiaridade dos usuários com a ferramenta (ALBERTIN, 2001). O sistema foi recém implementado no Ministério da Saúde e, desta forma, é natural que os usuários estejam se adaptando ao uso da ferramenta e estejam resistentes às mudanças por ele trazidas. 
Uma forma de incrementar melhorias associadas a essa caraterística é a disponibilização de treinamentos para os usuários que apresentaram dificuldade na utilização da ferramenta e a ampla divulgação dos manuais para que em caso de dúvidas os usuários tenham fácil acesso ás soluções. Os próprios membros da equipe que acompanharam o desenvolvimento do sistema podem ser multiplicadores e base para ações informais e cotidianas de aprendizagem dos demais usuários internos.

A característica segurança foi a mais bem avaliada, $92 \%$ das respostas válidas obtidas apontam que o sistema PECJUDICIAL possui a caraterística de segurança. A avaliação da característica segurança envolve o grau em que um produto ou sistema protege informações e dados e controla o nível de acesso de pessoas, produtos ou sistemas de acordo com os tipos e níveis de autorização. Este nível de qualidade é alcançado quando o software protege suas informações e dados de acordo com níveis de autorização (OLIVEIRA, 2012).

Destaca-se que as subcaracterísticas apresentadas no grupo segurança são eminentemente técnicas. Portanto, o elevado número de usuários que não souberam responder às perguntas está dentro do esperado, tendo em vista que a maioria dos usuários entrevistados não possui conhecimento específico na área de sistemas.

A característica segurança é fundamental para o Departamento de Logística em Saúde DLOG, pois todas as atividades do processo de aquisição de insumos para atendimento de determinação judicial são realizadas no ambiente do software, desde do recebimento das propostas de preço até a escolha do vencedor do certame. Segundo dados obtidos na Coordenação de Compra por Determinação Judicial - CDJU, as aquisições para atendimento de determinação judicial ultrapassaram 1,03 bilhões de reais em 2015. Assim, um sistema seguro é fundamental para a manutenção da lisura dos certames bem como fomentar a capacidade de auditoria dos órgãos de controle. 
Não obstante o sistema ter sido avaliado pelos respondentes como seguro, é fundamental que os gestores continuem investindo neste quesito, pois em se tratando de aquisições públicas o quesito segurança e lisura são primordiais. Qualquer falha nesta característica inviabiliza a utilização da ferramenta.

Outra característica fundamental para os gestores do PECJUDICIAL é a compatibilidade. A avaliação da caraterística compatibilidade engloba o nível de troca de informações entre um produto, sistema ou componente com outros produtos, sistemas ou componentes, e/ou realizar suas funções imperativas, enquanto dividem o mesmo ambiente de hardware ou software. Este nível de qualidade é alcançado quando o software consegue trocar informações com outros sistemas no mesmo ambiente operacional (OLIVIERA, 2012).

Após análise do questionário conclui-se que $88 \%$ das respostas válidas obtidas apontam que o sistema PECJUDICIAL possui a caraterística de compatibilidade. Das respostas negativas a característica compatibilidade possui a menor incidência, representando somente $5 \%$ do total de respostas negativas. A característica compatibilidade é fundamental pois, além da informatização das atividades administrativas e o fornecimento de dados gerencias, uma das principais funcionalidades esperadas do sistema é a integração dos dados gerados pelo Ministério da Saúde com os dados disponíveis no SAPIENS, sistema nacional de gerenciamento de documentos da AGU.

A avaliação do sistema proporciona ao gestor oportunidades de identificação de gargalos e melhorias, sendo desta forma um forte input para o aperfeiçoando do seu desempenho e consequentemente possibilitará a oferta de melhores serviços e produtos para o cidadão.

Após a avaliação preliminar realizada sugere-se que o gestor deve empregar esforços para o aperfeiçoamento da melhoria do sistema nas áreas de usabilidade, adequação funcional 
e eficiência de desempenho, pois foram os requisitos que tiveram pior desempenho na perspectiva dos usuários internos.

Cabe ressaltar que a avaliação realizada é preliminar, uma vez que o sistema foi recém implementado no Ministério da Saúde e ainda não houve a total informatização dos processos físicos. A medida que os usuários vão se familiarizando com o sistema, novas funcionalidades vão ser exigidas e novas avaliações devem ser feitas.

O modelo de norma de qualidade para avaliação de software ISO/IEC 25010 mostrou ser adequada ferramenta de gestão, pois proporciona a possibilidade de realização da avaliação de software de forma transversal, fornecendo informações valiosas para o aperfeiçoamento e incremento de desempenho.

Constata-se que não há implementado, em todo Ministério da Saúde, qualquer modelo de avaliação para software, e assim sugere-se que o presente modelo seja utilizado para a avaliação dos softwares desenvolvidos pelo DATASUS.

\subsection{AVALIAÇÃO DOS CUSTOS POR ATIVIDADES ANTES E APÓS IMPLEMENTAÇÃO DO SISTEMA}

As informações de custos são fatores críticos para o sucesso do planejamento, orçamento, controle operacional e da tomada de decisões estratégicas, sendo de fundamental importância para a melhoria da eficiência da gestão pública (BECKETT, 2002). A gestão com foco em resultados enfatiza o uso racional dos recursos, como informação, mão de obra e matérias-primas, por meio de políticas de planejamento e orçamento, logística e compras, gestão de pessoas, contabilidade de custos, sistemas de informação e estruturas organizacionais. Portanto, é necessário o constante monitoramento e a avaliação do efeito dos serviços e políticas públicas, visando o aumento da eficiência, da efetividade e da economicidade da gestão pública (GOMES, 2009). 
A eficiência administrativa consiste na utilização do mínimo necessário de recursos a fim de entregar a maior quantidade possível de um produto ou serviço, sem a redução da qualidade. A economicidade pressupõe a obtenção e a utilização exata de recursos nas quantidades necessárias e suficientes e no momento adequado, sem desperdícios e observando as alternativas mais econômicas no mercado (CRUZ, 1997).

Neste contexto, o software PECJUDICIAL foi desenvolvido. Seu principal objetivo é informatização das tarefas operacionais, a disponibilização de informações gerenciais e a melhoria da performance do Ministério da Saúde no atendimento ao cidadão que necessita de medicamentos demandados pela via judicial. Para mensurar o ganho de performance é necessário inicialmente o levantamento dos custos envolvidos no processo de aquisição de medicamentos oriundos de decisão judicial sem a implementação do Sistema.

A fim de realizar a identificação das atividades relevantes, foram realizadas entrevistas com todos os envolvidos no processo de aquisição e entrega de medicamentos para atendimento de determinação judicial no âmbito do Departamento de Logística em Saúde antes da utilização do sistema PECJUDICIAL. Através das entrevistas foram levantadas 54 atividades relevantes no ciclo logístico.

Após a identificação das atividades relevantes, foram identificados os direcionadores de recursos por atividade. Os principais recursos consumidos pelo DLOG são: salários e gratificações $(38,3 \%$ dos recursos), materiais de expediente $(0,2 \%$ dos recursos), contrato de logística $(56,2 \%$ dos recursos), licença de importação $(2,1 \%$ dos recursos), aluguel do almoxarifado (2,2\% dos recursos) e publicação na imprensa oficial ( $1 \%$ dos recursos).

Após a identificação dos direcionadores de recursos, foram atribuídos os custos às atividades desenvolvidas no DLOG. As atividades que consomem mais recursos são as atividades que envolvem o transporte das mercadorias, pois como apontado no parágrafo anterior o contrato de logística envolve 56,2\% dos custos operacionais, e somente 3 atividades 
relevantes envolvem o custo de logística. As atividades que mais consomem recursos são: solicitação de coleta de medicamentos no aeroporto, solicitação de recolhimento de medicamentos e recebimento de medicamentos.

Levando em consideração somente o direcionador de recursos de salários e gratificações, as atividades que mais consomem recursos são: emissão da guia de remessa (3,3\% dos recursos dos gastos com salários e gratificações), realizar atendimento via e-mail $(3,8 \%)$, coordenação da CDJU $(4,4 \%)$, fazer despacho de devolução $(4,9 \%)$ e pagamento $(5,1 \%)$.

Para a realização da análise comparativa dos custos envolvidos no cumprimento das determinações judiciais no âmbito do DLOG, foi realizada nova rodada de levantamento de atividades após a implementação do Sistema. Foi constatado que, com a implementação do Sistema, foram informatizadas 17 atividades e incorporadas somente 3 novas atividades.

Após a identificação das atividades, foi realizada novamente o levantamento dos direcionadores de recursos. Como diversas atividades foram informatizadas houve uma redução substancial no direcionador de custo salários e gratificações. Além da redução dos custos com mão de obra, houve a redução do custo com o material administrativo.

As atividades de maior custo permaneceram sendo as atividades relacionadas à entrega e à coleta de medicamentos, pois os custos do contrato de transporte com a empresa de operação logística não foram impactados com a implementação do Sistema.

A utilização do PECJUDICIAL proporcionou uma economia total de $12 \%$ dos recursos consumidos para o cumprimento de determinação judicial no âmbito do DLOG. Considerando somente o direcionador de recurso salários e gratificações com a implementação do sistema, o Ministério da Saúde teve a economia de $29,8 \%$ dos recursos gastos neste direcionador, possibilitando aos gestores a incorporação de novas atribuições e atividades ou a realocação dos colaboradores em outras áreas do Ministério da Saúde. 
Após a implementação do Sistema, as atividades que mais consomem recursos, se considerado somente o direcionador salários e gratificações, são: emissão da guia de remessa (4,7\% dos recursos gastos com salários e gratificações), realizar atendimento via e-mail $(5,4 \%)$, conferir a documentação apresentada pela transportadora $(5,6 \%)$, coordenação da CDJU $(6,3 \%)$ e pagamento $(7,3 \%)$. As atividades que consomem mais recursos devem ser o foco do gestor, a fim de que as novas versões do sistema sejam contempladas com melhorias ou ainda outras ferramentas e processos de trabalho sejam pensados e propostos.

O sistema parece, portanto, ser útil para atender as novas exigências dos modelos de gestão com foco nos resultados, pois, além de contribuir com a informatização das atividades, provocando maior celeridade no cumprimento da determinação judicial, gerou economia para os cofres públicos, pois com a sua implementação os custos com os colaboradores reduziram em $29,8 \%$ e o custo geral do cumprimento das determinações judiciais reduziu $12 \%$.

Os resultados obtidos são compatíveis com o preconizado com apela Nova Gestão Pública, nova gestão pública, movimento que enfatiza o aumento da eficiência, os resultados e o acesso e utilização dos serviços. No nível gerencial, as práticas organizacionais devem estar voltadas aos resultados estratégicos pretendidos, visando a otimização do desempenho organizacional e a economia dos recursos públicos (ANDREWS; KOUZMIN, 1998; PEREIRA, 2015).

No setor público brasileiro, muito tem se discutido sobre o desafio de transformar estruturas burocráticas, hierarquizadas, autorreferidas e pouco orientadas ao atendimento do cidadão em organizações flexíveis, empreendedoras e voltadas para a satisfação dos anseios dos cidadãos (PEREIRA, 2015). As tecnologias de informação podem ser um caminho e sua implementação e avaliação devem ser acompanhadas, divulgadas e discutidas para potencializar futuras melhorias esperadas por gestores, pesquisadores e sociedade. 
O modelo de custeio $\mathrm{ABC}$ mostrou ser uma adequada ferramenta de gestão, avaliação e acompanhamento de resultados de novos modelos e tecnologias adotados em organizações públicas, pois permitiu a identificação dos custos por atividade, proporcionando ao gestor a identificação das atividades que mais consomem recursos no alcance dos objetivos organizacionais. Esta ferramenta provisiona o gestor de informações gerenciais para a criação de estratégias que otimizem a utilização dos recursos e aumentem o desempenho da instituição (CAMPIGLIA; CAMPIGLIA, 1994).

Além das informações fornecidas pelo modelo de custeio, a metodologia foi fundamental para a realização da análise comparativa dos custos antes e após a implementação do Sistema. Os resultados preliminares são otimistas para que haja uma divulgação e solidificação da utilização do modelo de custeio ABC como ferramenta de apoio à gestão, podendo ser implementado em diversos outros setores do Ministério da Saúde e da Administração Pública. 


\section{CONSIDERAÇÕES FINAIS}

O presente estudo procurou analisar, empiricamente, a implementação do sistema PECJUDICIAL no atendimento das determinações judiciais em que a União é obrigada a fornecer insumos para saúde. Observa-se que, diante dos resultados apresentados, foi possível cumprir esse intento. De igual forma, cumpriram-se os objetivos específicos de identificar as barreiras e facilitadores que influenciaram a implementação do Sistema, realizar a avaliação dos resultados preliminares da utilização do sistema PECJUDICIAL na perspectiva dos usuários internos e realizar a análise comparativa dos resultados iniciais dos custos por atividade envolvidos no atendimento da determinação judicial pré e pós adoção do PECJUDICIAL.

A identificação das barreiras e facilitadores foi realizada de acordo com a literatura especializada e permitiu traçar um quadro dos principais problemas encontrados e dos facilitadores existentes. Tais informações são importantes para a consolidação da ferramenta e para planejamento de adoção de ferramentas futuras. O foco nos resultados, atualmente presente no setor brasileiro, exige a adoção de inovações, as quais devem ser bem planejadas e monitoradas para que alcancem sucesso. Barreiras de natureza política, por exemplo, precisam ser discutidas no Ministério da Saúde e, por parte dos gestores, pensadas como parte inerente dos processos de inovação.

A avaliação dos resultados preliminares do sistema na perspectiva dos usuários internos foi realizada através do modelo de avaliação ISO/IEC 25000 - Software Quality Requirements and Evaluation (SQuaRE), que demostrou ser um instrumento avaliativo eficiente, proporcionando ao gestor a categorização das principais características desejáveis do sistema e a respectiva avaliação. Além disso, tais resultados podem ser futuramente comparados com estudos conduzidos em outras organizações do setor público sobre avaliação de sistemas 
(OLIVEIRA, 2012). A principal característica que deve ser aperfeiçoada no sistema PECJUDICIAL é a usabilidade, seguidas da adequação funcional e a eficiência de desempenho.

A análise comparativa dos resultados iniciais dos custos por atividade envolvidos no atendimento da determinação judicial pré e pós adoção do PECJUDICIAL foi realizada através do modelo de custeio Active Based Cost - ABC que demonstrou ser uma relevante ferramenta para a gestão por resultados, permitindo o levantamento preciso dos custos por atividade. Com o uso deste modelo de custeio foi possível a identificar que, com a adoção do sistema PECJUDICIAL, o Ministério da Saúde teve a economia de $12 \%$ do total dos custos envolvidos no processo de cumprimento de determinação judicial. Os resultados iniciais, portanto, são animadores e devem ser monitorados longitudinalmente, no sentido de acompanhar alterações ao longo do tempo levantar possíveis variáveis intervenientes.

Sob a perspectiva acadêmica, o trabalho corroborou com os estudos prévios, os quais sugeriram a utilização de modelo de avaliação ISO/IEC 25000 como ferramenta para avaliação de software em instituições públicas (OLIVEIRA, 2012) e com a utilização do modelo de custeio ABC como ferramenta de melhoria de gestão em instituições públicas (BACEN, 2004). Além da validação das ferramentas utilizadas, o trabalho contribuiu para a identificação das melhorias em gestão proporcionada pela utilização da Tecnologia da Informação e Comunicação na Administração Pública e o seu papel fundamental para a melhoria dos serviços prestados ao cidadão (HUGHES, 2012; DAMODARAN et al., 2005; ESCRIVÃO; VEIGA; 2002).

Diante desse estudo, o Ministério da Saúde poderá tomar decisões e estabelecer rotinas de avaliação dos softwares desenvolvidos pelo DATASUS, baseando-se no modelo de avaliação ISO/IEC 25000, e realizar o levantamento dos custos por atividade, alicerçado ao modelo de custeio $\mathrm{ABC}$, nas áreas estratégicas de cada secretaria e fornecer soluções de TI para 
as atividades que mais consomem recursos, visando à redução de gastos e ao aumento da eficiência administrativa.

É necessário apontar algumas limitações deste estudo. A primeira refere-se à amostra de entrevistados para o levantamento das barreiras e facilitadores. Devido à alta rotatividade dos membros do Ministério da Saúde, apenas seis servidores permaneceram do início ao fim da implementação do PEC e, portanto, foram esses os participantes. Outra limitação refere-se ao próprio instrumento utilizado para a avaliação do sistema, que é exclusivamente quantitativo e adota escala de resposta de três pontos independentes. Se por um lado, trata-se de uma ferramenta recomendada pelo ISO/IEC 25000 e permite a sistematização e comparação dos achados com resultados de outras pesquisas, limita a magnitude de avaliação do respondente e não explora aspectos específicos de um ou outro sistema.

Outro aspecto a ser ressaltado diz respeito à maturidade do PECJUDICIAL, pois o sistema foi recém implementado no Ministério da Saúde e os dados gerados são resultados iniciais. Não foi possível conduzir uma avaliação de impacto do sistema e a adoção de outros indicadores, como a análise comparativa do tempo de cumprimento da determinação judicial.

Face aos resultados obtidos, às contribuições e limitações deste estudo, propõe-se a seguinte agenda de pesquisa:

- Realização de avaliação de Sistema utilizando o modelo ISO/IEC 25000 em instituições públicas com critérios quantitativos e qualitativos. Sugere-se que sejam agregadas questões qualitativas no intuito de verificar a opinião dos respondentes de forma aberta, principalmente nas questões relativas às sugestões de melhorias;

- Realização de avaliação de Sistema utilizando o modelo ISO/IEC 25000, como o uso da escala LIKERT, a fim de proporcionar maior riqueza de dados e incrementar as informações gerenciais; 
- Realização de avaliação de Sistema com mais maturidade de uso utilizando o modelo ISSO/IEC 2500 em instituições públicas, a fim de verificar a aderência da ferramenta às características da Administração Pública;

- Realização de estudo sobre barreiras e facilitadores de implementação de sistema em outras instituições do Poder Executivo Federal, a fim de proporcionar a análise comparativa;

- Levantamento dos custos utilizando a metodologia Active Based Cost em instituições públicas a fim de validar a metodologia como ferramenta de auxílio à gestão em instituições públicas;

- Após a realização das melhorias sugeridas no sistema PECJUDICIAL, realizar nova avaliação utilizando a mesma metodologia utilizada neste projeto, a fim de proporcionar uma avaliação longitudinal dos cumprimentos das determinações judiciais;

- Realizar a avaliação dos cumprimentos das determinações judiciais com o foco no impacto gerado pela adoção do sistema no tempo de cumprimento das determinações judiciais; - Conduzir um estudo longitudinal e de impacto do PECJUDICIAL no MS.

Espera-se que o presente estudo possa colaborar com a análise de implementação de sistemas de informação na Administração Pública, incentivando a realização de trabalhos por outros pesquisadores para o avanço do tema e a ampliação da discussão no campo. 


\section{REFERÊNCIAS}

ABRAMSON, M. A.; MEANS, G. E-government. 2001.

ADAM, F.; O'DOHERTY, P. Lessons from enterprise resource planning implementations in Ireland-towards smaller and shorter ERP projects. Journal of Information Technology, v. 15 , n. 4, p. 305-16, 2000.

ALBERTIN, A. L. Valor estratégico dos projetos de tecnologia de informação. Revista de Administração de Empresas, v. 41, n. 3, p. 42-50, 2001.

ALMEIDA, J. T. S. de. Indicadores de desenvolvimento do Governo Eletrônico Brasileiro. 2015. 183f. Tese (Doutorado em Ciências Sociais). Pontifícia Universidade Católica de São Paulo, 2015.

ANDREWS, C. W.; KOUZMIN, A. O discurso da nova Administração Pública. Lua Nova, v. 45, p. 97-130, 1998.

ARAGÃO, C. V. Burocracia, eficiência e modelos de gestão pública: um ensaio. Revista do Serviço Público, a. 48, n. 3, p. 104-32, 1997.

AUCOIN, P. Administrative reform in public management: paradigms, principles, paradoxes and pendulums. Governance, v. 3, n. 2, p. 115-37, 1990. Disponível em: $<$ http://onlinelibrary.wiley.com/doi/10.1111/j.1468-0491.1990.tb00111.x/abstract $>$. Acesso em: 02 out. 2015.

AZEVEDO, C. B; LOUREIRO, M. R. Carreiras públicas em uma ordem democrática: entre os modelos burocrático e gerencial. Revista do Serviço Público, v. 54, n. 1, p. 47-61, 2014.

BANCO CENTRAL DO BRASIL (BACEN). Diretoria de Administração. Departamento de Orçamento e Planejamento. O Banco Central do Brasil e a Gestão Estratégica. BACEN. 2002.

BANCO MUNDIAL. A definition of e-government. 2015. Disponível em: <http://www1.worldbank.org/publicsector/egov/definition.htm>. Acesso em: 02 out. 2015.

BARDIN, L. Análise de Conteúdo. São Paulo: Edições 70, 2011.

BECKETT, J. Toward a better understanding of politics: Linking costs, cultures, and institutional rules to budgets. Public Administration Review, Washington, v. 62. n. 1. p. 112-15, 2002. Disponível em: <http://onlinelibrary.wiley.com/doi/10.1111/15406210.00160/abstract >. Acesso em: 02 out. 2015.

BEDANI, M. Valores, práticas e criatividade organizacionais: estudo do perfil cultural de uma instituição bancária. 2008. 352f. Tese (Doutorado em Psicologia Social, do Trabalho e das Organizações). Universidade de Brasília, Brasília, 2008.

BINGI, P; SHARMA, M. K.; GODLA, J. K. Critical issues affecting an ERP implementation. IS Management, v. 16, n. 3, p. 7-14, 1999. 
BONACIM, C. A. G; ARAÚJO, A. M. P. Gestão de custos aplicada a hospitais universitários públicos: a experiência do Hospital das Clínicas da Faculdade de Medicina de Ribeirão Preto da USP. Revista de Administração Pública, v. 44, n. 4, p. 903-31, 2010.

BRASIL. Acesso à informação. Brasília, 2015. Disponível em: <http://www.acessoainformacao.gov.br/>. Acesso em: 02 out. 2015.

Ministério da Administração Federal e Reforma do Estado. Câmara da Reforma do Estado. Plano Diretor da Reforma do Aparelho do Estado. Brasília, 1995. Disponível em: $<$ http://www.bresserpereira.org.br/Documents/MARE/PlanoDiretor/planodiretor.pdf $>$. Acesso em: 02 out. 2015.

CAMPIGLIA, A. O.; CAMPIGLIA, O. R. P. Controles de gestão: controladoria financeira das empresas. São Paulo: Atlas, 1994.

CASTELLS, M.; GERHARDT, K. B. A sociedade em rede. São Paulo: Paz e Terra, 2000.

CATALÀ, J. P. De la burocracia al "management", del "management" a la gobernanza: las transformaciones de las administraciones públicas de nuestro tiempo. Ministerio de Administraciones Públicas, 2005.

CARMO, L. P. F; SILVA, L. M. Custeio baseado em atividades (ABC) aplicado ao setor público: estudo de caso no Colégio Militar do Rio de Janeiro (CMRJ). Revista Uniabeu, v. 4, n. 6, p. 161-81, 2011.

CHRISTIANSEN, J. C.; MELLICK, M. S. A 'new' program management information system. Transactions of AACE International. 1993.

COELHO, E. M. Governo Eletrônico e seus impactos na estrutura e na força de trabalho das organizações públicas. Revista do Serviço Público, Brasília, a. 52, n. 2, p. 111-38, abr./jun. 2001.

CORRÊA, R. C. Custos em empresas prestadoras de serviços de informática: aplicação do ABC. 2002. 92f. Dissertação (Mestrado em Engenharia de Produção). Programa de PósGraduação em Engenharia de Produção, Universidade Federal de Santa Catarina, Florianópolis, 2002.

CRUZ, F. O método de custeamento ABC adaptado ao controle substantivo da despesa orçamentária ao setor público. Contabilidade Vista \& Revista, Belo Horizonte, v. 8, n. 1, p. 33-42, jun. 1997.

CUNHA, M. A.; ANNENBERG, D.; AGUNE, R. M. Prestação de serviços públicos eletrônicos ao cidadão e-Desenvolvimento no Brasil e no mundo: subsídios e Programa eBrasil. São Caetano do Sul, SP: Yendis Editora, 2007.

CUNHA, R. M. R.; BRAZ, S. G.; DUTRA, P. O.; CHAMON, E. M. Q. O. Os recursos tecnológicos como potencializadores da interdisciplinaridade no espaço escolar. Revista Ciências Humanas, v. 5, n. 1-2 esp., p. 87-108, 2012.

DAMIAN, I. P. M.; MERLO, E. M. Uma análise dos sites de governos eletrônicos no Brasil sob a ótica dos usuários dos serviços e sua satisfação. Rev. Adm. Pública, Rio de Janeiro, v. 47, n. 4, p. 877-99, 2013. 
DAMODARAN, L.; NICHOLLS, J.; HENNEY, A.; LAND, F.; FARBEY, B. The contribution of sociotechnical systems thinking to the effective adoption of e-government and the enhancement of democracy. The Electronic Journal of E-Government, v. 3, n. 1, p. 1$12,2005$.

DANZIGER, J. N.; ANDERSEN, K. V. The impacts of information technology on public administration: an analysis of empirical research from the "Golden Age" of transformation. International Journal of Public Administration, v. 25, n. 5, p. 591-627, 2002. Disponível em: <http://www.tandfonline.com/doi/abs/10.1081/PAD-120003292>. Acesso em: 02 out. 2015.

DIEHL, C. A.; SOUZA, M. A. Publicações sobre o Custeio Baseado em Atividades (ABC) em Congressos Brasileiros de Custos no Período de 1997 a 2006. Revista Contabilidade Vista e Revista, Belo Horizonte, v. 19, n. 4, p. 39-57, 2009. Disponível em: <http://revistas.face.ufmg.br/index.php/contabilidadevistaerevista/article/view/367/366 >. Acesso em: 02 out. 2015.

DIETRICH, E. Por quê é tão difícil desenvolver e implantar sistemas de informação eficazes nas empresas? 2007. Disponível em:

$<$ http://eltondietrich.blogspot.com.br/2007/08/por-qu-to-difcil-desenvolver-e.html >. Acesso em: 15 out 2015 .

DINIZ, E. H; BARBOSA, A. F; JUNQUEIRA, A.R.B; PRADO, O. O Governo Eletrônico no Brasil: perspectiva histórica a partir de um modelo estruturado de análise. Revista de Administração Pública, v. 43, n. 1, p. 23-48, 2009.

ESCRIVÃO, E. F.; VEIGA, J. M. Sistemas integrados de gestão ERP em pequenas empresas: um confronto entre o referencial teórico e a prática empresarial. Revista Gestão \& Produção, São Carlos, v. 9, n. 3, p. 227-296, dez. 2002.

EVANS, P. O Estado como problema e solução. Lua Nova: Revista de Cultura e Política, São Paulo, n. 28-29, p. 107-57, 1993.

FAORO, R. Os donos do poder-formação do patronato político brasileiro. São Paulo: Globo Livro, 2013.

FERNANDES, A. G.; AFONSO, J. R. R. E-Governo no Brasil: experiências e perspectivas. Revista do BNDES, Rio de Janeiro, v. 8, n. 15, p. 21-64, jun. 2001.

FONSECA, D. R.; MENESES, P. P. M.; SILVA FILHO, A. I.; CAMPOS, N. G. Autonomia para gestão estratégica de pessoas no setor público federal: perspectivas de análise e agenda de pesquisa. Revista de Administração Pública, Rio de Janeiro, v. 47, n. 6, p. 1451-75, 2013.

FRANZESE, C.; ABRUCIO, F. L. A combinação entre federalismo e políticas públicas no Brasil pós-1988: os resultados nas áreas de saúde, assistência social e educação. In: ROCHA, M.C.G. (Org.). Reflexões para Ibero-América: avaliação de programas sociais. Brasília: ENAP, 2009.

GOMES, E. G. M. Gestão por Resultados e eficiência na Administração Pública: uma análise à luz da experiência de Minas Gerais. 2009. 187f. Tese (Doutorado em Administração 
Pública e Governo). Escola de Administração de Empresas de São Paulo, Fundação Getúlio Vargas, São Paulo, 2009.

GONÇALVES, A. O.; ANTUNES, M. C.; ISIDRO FILHO, A.; OLIVEIRA, A. B.

Maturidade do alinhamento estratégico entre o Plano Plurianual do Governo Federal e os órgãos de controle no Brasil. Contabilidade, Gestão e Governança, Brasília, v. 16, n. 2, p. 31-45, 2013.

GONÇALVES, J. E. L. Os impactos das novas tecnologias nas empresas prestadoras de serviços. Revista de Administração de Empresas, v. 34, n. 1, p. 63-81, 1994.

GOGUEN, J. A.; LINDE, C. Techniques for Requirements Elicitation Proceedings IEEE International Symposium on Requirements Engineering. 1993.

GUIMARÃES, T. A. A nova Administração Pública e a abordagem da competência. RAP Revista de Administração Pública, Rio de Janeiro, v. 34, n. 3, p. 125-40, 2000.

GRÖNLUND, A.; HORAN, T. A. Introducing E-GOV: history, definitions, and issues. Communications of the Association for Information Systems, v. 15, n. 1, p. 39, 2004. Disponível em: 〈http://aisel.aisnet.org/cgi/viewcontent.cgi?article=3161\&context=cais $>$. Acesso em: 24 jul. 2014.

HEADY, F. Administración Pública: una perspectiva comparada. México: Fondo de Cultura Economica, 1996.

HUGHES, O. E. Public management and administration. 4. ed. Palgrave Macmillan, 2012.

JAMBEIRO, O.; SOBREIRA, R.; RABEIRO, P. TICs e gestão pública em planos diretores de cidades brasileiras. Revista Eptic, v. XI, n. 3, 2011. Disponível em:

<http://www.seer.ufs.br/index.php/eptic/article/view/104/78>. Acesso em: 02 out. 2015.

LAIA, M. M.; CUNHA, M. A.; NOGUEIRA, A. R. R.; MAZZON, J. A. Políticas de Governo Eletrônico no Brasil: contexto, gestão de TIC e resultados. RAE - Revista de Administração de Empresas, v. 51, n. 1, p. 43-57, 2011.

LAUDON, K. C. Computers and bureaucratic reform: the political function of urban information systems. Wiley-Interscience Publications, v. 37, p. 1080, 1975. Disponível em: $<$ http://journals.cambridge.org/action/displayAbstract?fromPage $=$ online\&aid $=6276048 \&$ fileI $\mathrm{d}=\mathrm{S} 0022381600072285>$. Acesso em: 02 out. 2015.

KAPLAN, R. S.; COOPER, R. Custo e desempenho. São Paulo: Futura, 1998.

KLUMB, R.; AZEVEDO, B. M. A percepção dos gestores operacionais sobre os impactos gerados nos processos de trabalho após a implementação das melhores práticas de governança de TI no TRE/SC. Revista de Administração Pública, Rio de Janeiro, v. 48, n. 4, p. 961-82, 2014.

KOOIMAN, J. (Ed.). Modern governance: new government-society interactions. Sage, 1993.

KUMAR, K. Da sociedade pós-industrial à pós-moderna: novas teorias sobre o mundo contemporâneo. Rio de Janeiro: Jorge Zahar, 1997. 
MEDEIROS, P. H. R.; GUIMARÃES, T. A. Contribuições do Governo Eletrônico para a reforma administrativa e a governança no Brasil. Revista do Serviço Público, Brasília, v. 56, n. 4, p. 449-64, 2005.

MENDES, A. M; ABRAHÃO, J. I. A influência da organização do trabalho nas vivências de prazer- sofrimento do trabalhador: uma abordagem psicodinâmica. Revista Psicologia:

Teoria e Pesquisa, 26(2), 179-184, 1996.

MERTON, R. K. Social theory and social structure: toward the codification of theory and research. Glencoe: Free Press, 1949.

MORAIS, R. M; COSTA, A. L. Um modelo para avaliação de sistemas de informação do SUS de abrangência nacional: o processo de seleção e estruturação de indicadores. Revista de Administração Pública, v. 48, n. 3, p. 767-94, 2014.

MORGAN, G. Imagens da organização. 2. ed. São Paulo: Editora Atlas, 2002.

MOTTA, F. C. P. Introdução à organização burocrática. Cengage Learning Editores, 2004.

MUNARETTO, L. F. Uma contribuição ao estudo dos custos de universidades comunitárias com o uso do ABC-Activity Based Costing: o caso da URI/RS. 2000. 112f. Dissertação (Mestrado em Administração). Universidade Federal de Santa Catarina, 2000.

NAKAGAWA, M. ABC custeio baseado em atividades. São Paulo: Atlas, 1994.

NABATCHI, T. Putting the "public" back in public values research: Designing participation to identify and respond to values. Public Administration Review, v. 72, n. 5, p. 699-708, 2012.

NEGRI, J. A.; SALERNO, M. S.; CASTRO, A. B. Inovações, padrões tecnológicos e desempenho das firmas industriais brasileiras. Brasília: IPEA, 2005.

NEIVA, E. R.; PAZ, M. G. Percepção de Mudança Individual e Organizacional: o Papel das Atitudes, dos Valores, do Poder e da Capacidade Organizacional. Revista de Administração, São Paulo, v. 47, n.1, p. 22-37, 2012.

OLIVEIRA, N. B. Avaliação de qualidade do registro eletrônico do processo de Enfermagem. 2012. 158 f. Tese (Doutorado em Enfermagem). Programa de Pós-Graduação em Gerenciamento em Enfermagem, Escola de Enfermagem, Universidade de São Paulo, São Paulo, 2012.

ORDACGY, A. S. A tutela de saúde como um direito fundamental ao cidadão. Revista da Defensoria Pública da União, Brasília, n. 1, 2009.

PADOVEZE, C. L. O papel da contabilidade gerencial no processo empresarial de criação de valor. Caderno de Estudos, São Paulo, n. 21, p. 1-16, 1999.

PECI, A.; PIERANTI, O. P.; RODRIGUES, S. Governança e New Public Management: convergências e contradições no contexto brasileiro. Revista O\&S, v. 15, n. 46, p. 39-55, 2008. 
PEREIRA, L. C. B. A reforma do Estado dos anos 90: lógica e mecanismos de controle. Brasília: Ministério da Administração Federal e Reforma do Estado, 1997.

Uma reforma gerencial da Administração Pública no Brasil. Revista do Serviço Público, v. 49, n. 1, p. 5-42, 1998. Disponível em: <http://www.bresserpereira.org.br/papers/1997/97.Reforma_gerencial-RSP.pdf >. Acesso em: 02 out. 2015.

Do Estado patrimonial ao gerencial. Letras, v. 222, p. 259, 2001. Disponível em: <http://www.bresserpereira.org.br/papers/2000/00-73estadopatrimonial-gerencial.pdf $>$. Acesso em: 02 out. 2015.

. O surgimento do Estado republicano. Lua Nova, v. 62, p. 131-50, 2004.

. O novo desenvolvimentismo e a ortodoxia convencional. São Paulo em Perspectiva, v. 20, n. 3, p. 5-24, 2006. Disponível em:

$<$ http://produtos.seade.gov.br/produtos/spp/v20n03/v20n03_01.pdf $>$. Acesso em: 02 out. 2015.

Da Administração Pública burocrática à gerencial. Revista do Serviço Público, v. 47, n. 1, p. 7-40, 2015.

PETERS, B. G. The politics of bureaucracy. New York: Longman, 1984.

POLLITT, C.; BOUCKAERT, G. Avaliando reformas da gestão pública: uma perspectiva internacional. Revista do Serviço Público, v. 53, n. 3, p. 7-31, 2002.

PORPINO, G.; STEFANI, E. O caso do PAC Embrapa: requisitos de uma gestão orientada para resultados no setor público. Revista de Administração Pública, Rio de Janeiro, v. 48, n. 2, p. 343-66, 2014.

PRADO, E. P. V; TAKAOKA, H. Terceirização de Serviços de TI: Um modelo para avaliação de relações de causa e efeito. Rio de Janeiro, v. 22, 2007.

; CASTRO, R. P. C; ALBUQUERQUE, J. P. Barreiras na implantação de sistemas de informação de uma instituição de saúde: A importância dos fatores humanos e de gerenciamento. Revista de Administração, Contabilidade e Economia da Fundace, v. 1, n. $1,2010$.

PRESSMAN, R. S. Engenharia de software. McGraw Hill Brasil, 2011.

RAMOS, A. G. A Nova ciência das organizações* uma reconceituação da riqueza das nações. Fundação Getúlio Vargas, 1981.

REIS, A. F.; DACORSO, A. L. R.; TENÓRIO, F. A. G. Influência do uso de Tecnologias de Informação e Comunicação na prestação de contas públicas municipais: um estudo de caso no Tribunal de Contas dos Municípios do Estado da Bahia. Revista de Administração Pública, Rio de Janeiro, v. 49, n. 1, p. 231-51, 2015.

REIS, V. Votação eletrônica no Brasil: tecnologia a serviço da democracia. Crescimento do egovernment e expansão dos projetos de inclusão digital. In: FERRER, F.; SANTOS, P. (Orgs.). E-government: o Governo Eletrônico no Brasil. São Paulo: Saraiva, 2004. 
REITELL, C. Direct costing opens the door to profit planning. National Association of Accountants. NAA Bulletin, v. 39, n. 8, p. 5-15, 1958.

RIBEIRO FILHO, J. F. Modelo gerencial para a eficácia de hospitais públicos: análise do âmbito de uma entidade de ensino e assistência. 2002. 288f. Tese (Doutorado em Ciências Contábeis). Faculdade de Economia, Administração e Contabilidade, Universidade de São Paulo, 2002.

RICCIO, E. L.; GOUVEIA, J. J. F. A. O sistema de custos baseado em atividades (ABC) aplicado a bancos. Revista Brasileira de Contabilidade, São Paulo, n. 94, 1995.

SANTOS, R. J. L.; HONORÍFICA, M. Governo Eletrônico: o que se deve e o que não se deve fazer. In: XVI Concurso de Ensayos y Monografías del CLAD sobre Reforma del Estado y Modernización de la Administración Pública "Gobierno Electrónico", Caracas, 2002.

SECCHI, L. Modelos organizacionais e reformas da Administração Pública. Revista de Administração Pública - RAP, Rio de Janeiro, v. 43, n. 2, p. 347-69, 2009.

SCHEIN, E. H. Defining organizational culture. Classics of organization theory, v. 3, p. 490-502, 1985.

SCHEIN, Edgar H. et al. How can organizations learn faster?: the problem of entering the Green Room. San Francisco: Jossey-Bass Publishers. 1992.

SELDIN, R.; RAINHO, M. A. F.; CAULLIRAUX, H. M. O papel da cultura organizacional na implantação de sistemas integrados de gestão: uma abordagem sobre resistência a mudanças. Simpósio da Administração da Produção, Logística e Operações Internacionais, São Paulo, 2003.

SERVA, M. A racionalidade substantiva demonstrada na prática administrativa. Revista de Administração de Empresas, v. 37, n. 2, p. 18-30, 1997.

SERVA, M; CAITANO, D; SANTOS, L; SIQUEIRA, G. A análise da racionalidade nas organizações-um balanço do desenvolvimento de um campo de estudos nos Brasil. Cad. EBAPE.BR, v. 13, nº 3, Artigo 1, Rio de Janeiro, 2015.

SERVIÇO BRASILEIRO DE APOIO ÀS MICRO E PEQUENAS EMPRESAS (SEBRAE). SEBRAE Informática: solução para a pequena empresa. Brasília: SEBRAE, 2014.

SEVERINO, A. J. Metodologia do trabalho científico. Cortez editora, 2014.

STONER, J. A. F. Administração. 5. ed. Rio de Janeiro: LTC, 1999.

TEIXEIRA, A. O uso das novas Tecnologias de Informação e Comunicação (TIC) e a transparência na gestão pública municipal no Ceará. Fortaleza: Fundação Konrad Adenauer, 2004.

TREASURY, Her Majesty's. Better Accounting for Taxpayers Money: Resource Accounting and Budgeting in Government. A Con-sultation Paper, 1994. 
TROSA, S. Gestão pública por resultados: quando o Estado se compromete. Rio de Janeiro: Revan; Brasília: ENAP, 2001.

TRY, D.; RADNOR, Z. Developing an understanding of results-based management through public value theory. International Journal of Public Sector Management, v. 20, n. 7, p. 655-73, 2007. Disponível em:

<http://www.emeraldinsight.com/doi/abs/10.1108/09513550710823542>. Acesso em: 02 out. 2015.

WEST, D. M. E-government and the transformation of service delivery and citizen attitudes. Public Administration Review, v. 64, n. 1, p. 15-27, fev. 2004. Disponível em:

<http://onlinelibrary.wiley.com/doi/10.1111/j.1540-6210.2004.00343.x/abstract $>$. Acesso em: 02 out. 2015.

YONG, C. S. Tecnologia de informação. Revista de Administração de Empresas, São Paulo, v. 32, n. 1, p. 78-87, 1992. Disponível em:

<http://rae.fgv.br/sites/rae.fgv.br/files/artigos/10.1590_S0034-75901992000100009.pdf>. Acesso em: 02 out. 2015.

ZUBOFF, S. Automatizar/informatizar: as duas faces da tecnologia inteligente. Revista de Administração de Empresas, São Paulo, v. 34, n. 6, p. 80-91, 1994. 


\section{APÊNDICES \\ APÊNDICE A - PERGUNTAS SEMIESTRUTURADAS}

Perguntas semiestruturadas (Objetivo 1)

\begin{tabular}{|c|l|}
\hline 01 & $\begin{array}{l}\text { NO ÂMBITO DO MINISTÉRIO DA SAÚDE, QUAIS FORAM AS PRINCIPAIS DIFICULDADES } \\
\text { ENFRENTADAS PARA A IMPLEMENTAÇÃO DO SISTEMA PECJUDICIAL? }\end{array}$ \\
\hline 02 & DAS DIFICULDADE APONTADAS QUAL VOCÊ CONSIDERA MAIS RELEVANTE? \\
\hline 03 & $\begin{array}{l}\text { NO ÂMBITO DO MINISTÉRIO DA SAÚDE, QUAIS FORAM OS PRINCIPAIS FACILITADORES PARA A } \\
\text { IMPLEMENTAÇÃO DO SISTEMA PECJUDICIAL }\end{array}$ \\
\hline
\end{tabular}

Perguntas semiestruturadas (Objetivo 2)

\begin{tabular}{|c|l|}
\hline 01 & $\begin{array}{l}\text { QUAIS SÃO AS PRINCIPAIS ATIVIDADES DESENVILVIDAS POR VOCÊ NO CUMPRIMENTO DAS } \\
\text { DETERMINAÇÕES JUDICIAS NO ÂMBITO DO DEPARTAMENTO DE LOGÍSTICA EM SAÚDE? }\end{array}$ \\
\hline 02 & $\begin{array}{l}\text { QUANTO TEMPO VOCÊ GASTA NA EXECUÇÃO DA TAREFA DIARIAMENTE, CONSIDERANDO UM } \\
\text { JORNADA DE TRABALHO DE } 8 \text { HORAS ? }\end{array}$ \\
\hline
\end{tabular}




\section{APÊNDICE B - QUESTIONÁRIO PARA AVALIAÇÃO DO SISTEMA PELOS USUÁRIOS: OBJETIVO 4}

Questionário para Avaliação do Sistema pelos Usuários (Objetivo 04)

(Continua)

\begin{tabular}{|c|c|c|c|c|c|}
\hline Característica & Subcaracterística & Questão chave para a subcaracterística & Acordo & Desacordo & Não se aplica \\
\hline \multirow{6}{*}{$\begin{array}{l}\text { 1. Adequação } \\
\text { Funcional }\end{array}$} & \multirow{2}{*}{$\begin{array}{l}\text { 1.1 Integridade } \\
\text { Funcional }\end{array}$} & $\begin{array}{l}\text { 1.1.1 O PECJUDICIAL atende as necessidades de sua equipe no } \\
\text { cumprimento das determinações judiciais }\end{array}$ & & & \\
\hline & & $\begin{array}{l}\text { 1.1.2 O PECJUDICIAL dispõe de todas as funções necessárias para } \\
\text { execução de suas atividades? }\end{array}$ & & & \\
\hline & \multirow{3}{*}{$\begin{array}{l}1.2 \text { Correção } \\
\text { Funcional }\end{array}$} & $\begin{array}{l}\text { 1.2.1 O PECJUDICIAL permite o correto cumprimento da } \\
\text { determinação judicial? }\end{array}$ & & & \\
\hline & & $\begin{array}{l}\text { 1.2.2 O PECJUDICIAL é preciso na execução das funções no } \\
\text { cumprimento da determinação judicial? }\end{array}$ & & & \\
\hline & & $\begin{array}{l}\text { 1.2.3 O PECJUDICIAL é preciso nos resultados desejados para o } \\
\text { cumprimento da determinação judicial? }\end{array}$ & & & \\
\hline & $\begin{array}{l}1.3 \text { Aptidão } \\
\text { Funcional }\end{array}$ & $\begin{array}{l}\text { 1.3.1 O PECJUDICIAL facilita o cumprimento da determinação } \\
\text { judicial? }\end{array}$ & & & \\
\hline \multirow{4}{*}{ 2. Confiabilidade } & 2.1 Maturidade & 2.1.1 O PECJUDICIAL não apresenta falhas com frequência? & & & \\
\hline & $\begin{array}{l}\text { 2.2 Tolerância a } \\
\text { falhas }\end{array}$ & $\begin{array}{l}\text { 2.2.1. Quando ocorrem falhas o PECJUDICIAL continua funcionando } \\
\text { conforme o esperado? }\end{array}$ & & & \\
\hline & 2.3 Recuperabilidade & $\begin{array}{l}\text { 2.3.1 O PECJUDICIAL é capaz de recuperar dados afetados por } \\
\text { falhas? }\end{array}$ & & & \\
\hline & 2.4 Disponibilidade & 2.4.1 O PECJUDICIAL fica acessível para uso quando necessário? & & & \\
\hline
\end{tabular}


(Continuação)

\begin{tabular}{|c|c|c|c|c|c|}
\hline Característica & Subcaracterística & Questão chave para a subcaracterística & Acordo & Desacordo & Não se aplica \\
\hline \multirow{6}{*}{ 3. Usabilidade } & \multirow{3}{*}{$\begin{array}{l}\text { 3.1 Reconhecimento } \\
\text { de adequação }\end{array}$} & 3.1.1. É fácil entender o conceito e a aplicação? & & & \\
\hline & & 3.1.2. É fácil executar suas funções? & & & \\
\hline & & 3.1.3 O PECJUDICIAL possui tutorial/ajuda? & & & \\
\hline & \multirow{3}{*}{ 3.2 Apreensibilidade } & 3.2.1. É fácil aprender a usar? & & & \\
\hline & & 3.2.2 O PECJUDICIAL facilita a entrada de dados pelo usuário? & & & \\
\hline & & 3.2.3 O PECJUDICIAL facilita a saída de dados pelo usuário? & & & \\
\hline \multirow{6}{*}{ 3. Usabilidade } & \multirow{2}{*}{3.3 Operabilidade } & $\begin{array}{l}\text { 3.3.1 O PECJUDICIAL possui atributos que torna mais fácil a } \\
\text { realização das atividades? }\end{array}$ & & & \\
\hline & & 3.3.2 O PECJUDICIAL fornece ajuda de forma clara? & & & \\
\hline & 3.4 Acessibilidade & $\begin{array}{l}\text { 3.4.1 O PECJUDICIAL pode ser utilizado por pessoas com } \\
\text { deficiência? }\end{array}$ & & & \\
\hline & $\begin{array}{l}\text { 3.5 Proteção contra } \\
\text { erro }\end{array}$ & $\begin{array}{l}\text { 3.5.1 O PECJUDICIAL informa ao usuário a entrada de dados } \\
\text { inválidos? }\end{array}$ & & & \\
\hline & \multirow{2}{*}{$\begin{array}{c}3.6 \text { Estética de } \\
\text { Interface de usuário }\end{array}$} & 3.6.1 O design gráfico é agradável ao usuário? & & & \\
\hline & & 3.6.2 A cor é agradável? & & & \\
\hline \multirow{5}{*}{$\begin{array}{l}\text { 4. Eficiência de } \\
\text { Desempenho }\end{array}$} & \multirow{2}{*}{ 4.1 Tempo } & 4.1.1 O tempo de resposta do software é adequado? & & & \\
\hline & & 4.1.2 O tempo de execução do software é adequado? & & & \\
\hline & 4.2 Recursos & 4.2.1. Os recursos utilizados pelo software são adequados? & & & \\
\hline & \multirow{2}{*}{ 4.3 Capacidade } & 4.3.1 O PECJUDICIAL permite uma boa navegação? & & & \\
\hline & & 4.3.2 O PECJUDICIAL é rápido? & & & \\
\hline
\end{tabular}


(Conclusão)

\begin{tabular}{|c|c|c|c|c|c|}
\hline Característica & Subcaracterística & Questão chave para a subcaracterística & Acordo & Desacordo & Não se aplica \\
\hline \multirow[b]{2}{*}{ 5. Compatibilidade } & 5.1 Interoperbilidade & $\begin{array}{l}\text { 5.1.1 O PECJUDICIAL tem capacidade para trocar informações com } \\
\text { outros sistemas? }\end{array}$ & & & \\
\hline & 5.2 Coexistência & $\begin{array}{l}\text { 5.2.1 O PECJUDICIAL realiza suas funções com eficiência mesmo } \\
\text { quando os outros sistemas estão em uso, compartilhado a mesma } \\
\text { rede? }\end{array}$ & & & \\
\hline \multirow{7}{*}{ 6. Segurança } & $\begin{array}{c}6.1 \\
\text { Confidencialidade } \\
\end{array}$ & $\begin{array}{l}\text { 6.1.1 O PECJUDICIAL dispõe de segurança de acesso através de } \\
\text { senhas? }\end{array}$ & & & \\
\hline & \multirow{3}{*}{6.2 Integridade } & 6.2.1 O PECJUDICIAL impede o acesso de pessoas não autorizadas? & & & \\
\hline & & $\begin{array}{l}\text { 6.2.2 O PECJUDICIAL impede a modificação de dados por pessoas } \\
\text { não autorizadas? }\end{array}$ & & & \\
\hline & & $\begin{array}{l}\text { 6.2.3 O PECJUDICIAL é capaz de impedir a exclusão ou alteração } \\
\text { das informações armazenadas? }\end{array}$ & & & \\
\hline & 6.3. Não repúdio & $\begin{array}{l}\text { 6.3.1 O PECJUDICIAL é capaz de identificar o autor/data e hora dos } \\
\text { registros? }\end{array}$ & & & \\
\hline & $\begin{array}{c}6.4 \\
\text { Responsabilização }\end{array}$ & $\begin{array}{l}\text { 6.4.2 O PECJUDICIAL é capaz de identificar de maneira confiável e } \\
\text { inequívoca os usuários que registram os dados no sistema? }\end{array}$ & & & \\
\hline & 6.5 Autenticação & $\begin{array}{l}\text { 6.5.1 O PECJUDICIAL utiliza um método de autenticação de forma a } \\
\text { garantir a irretratabilidade da autenticação realizada? }\end{array}$ & & & \\
\hline
\end{tabular}


APÊNDICE C - FLUXOGRAMA DAS ATIVIDADES INFORMATIZADAS PELO PECJUDICIAL NO ATENDIMENTO DE DETERMINAÇÃO JUDICIAL (continuação)

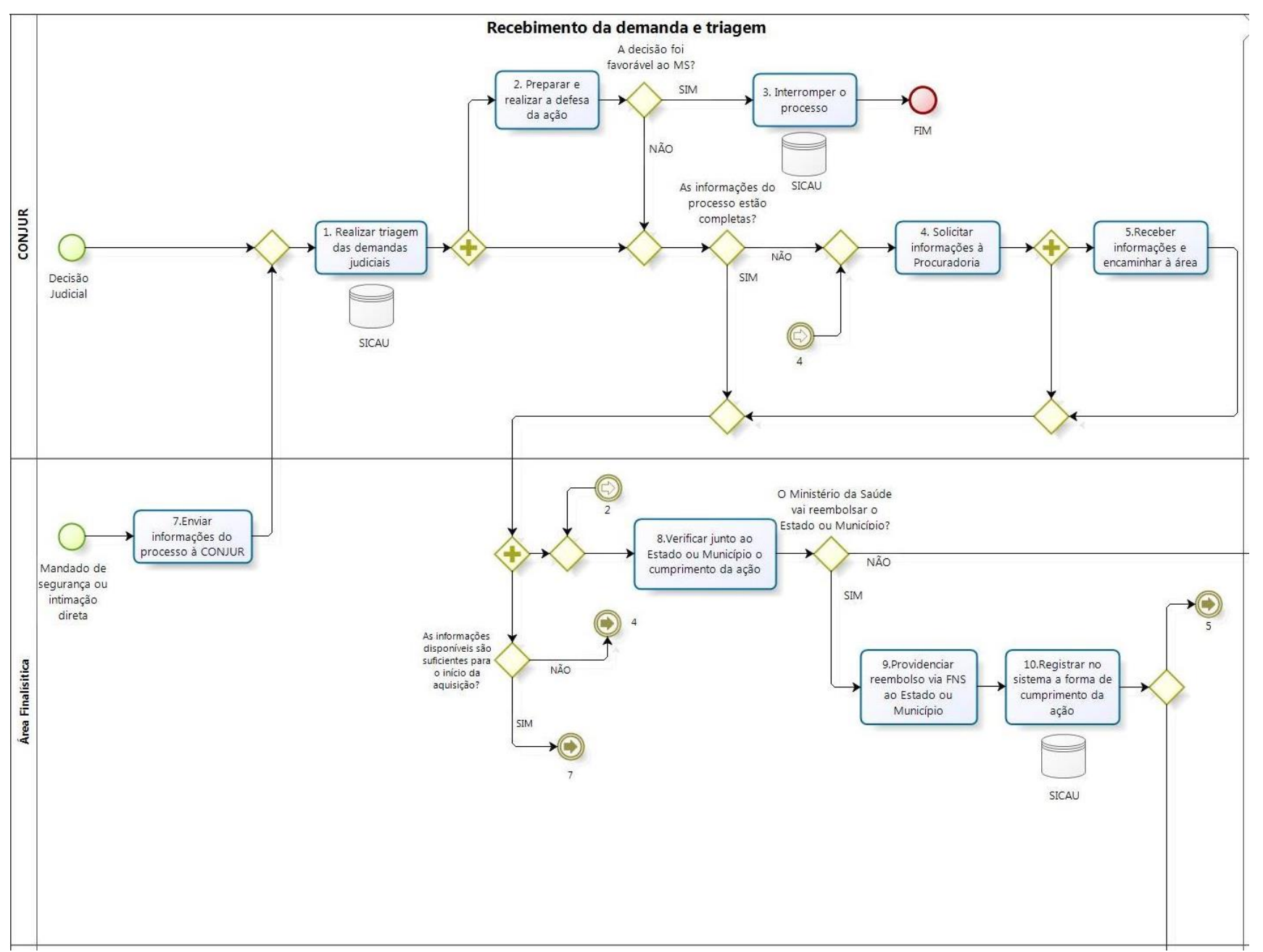


APÊNDICE C - FLUXOGRAMA DAS ATIVIDADES DESENVOLVIDAS PELO MINISTÉRIO DA SAÚDE NO ATENDIMENTO DE DETERMINAÇÃO JUDICIAL (continuação)

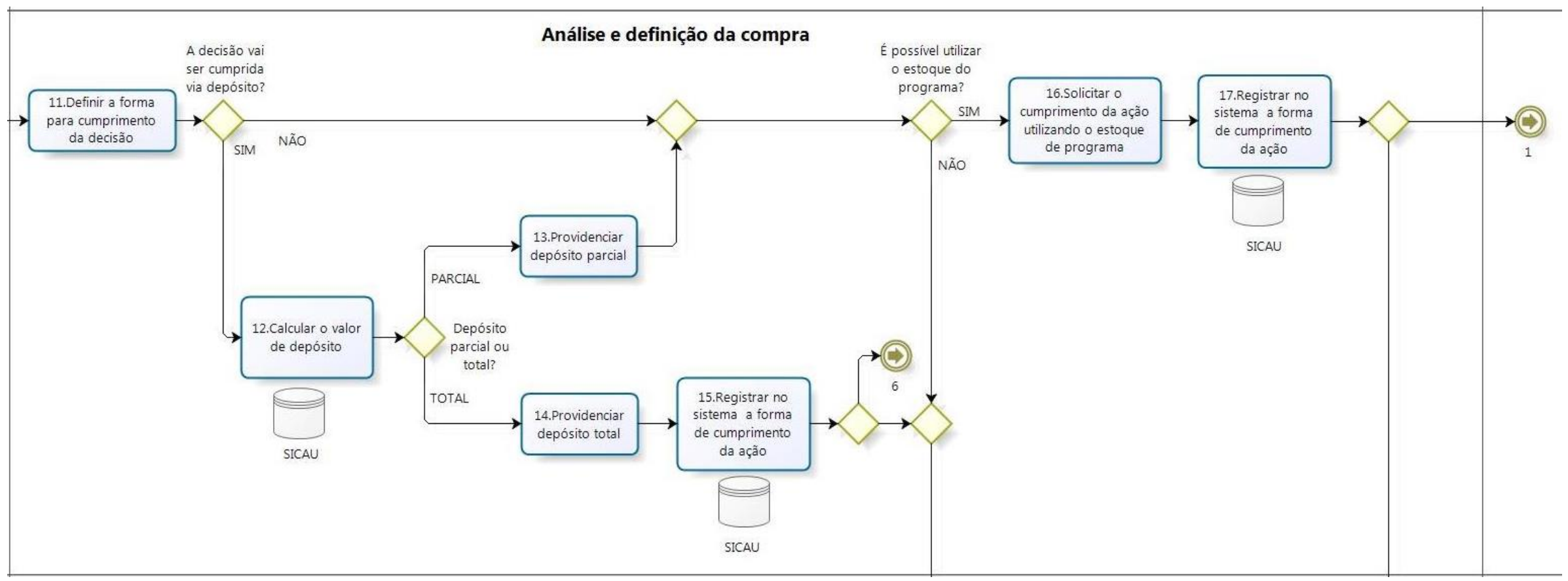


APÊNDICE C - FLUXOGRAMA DAS ATIVIDADES DESENVOLVIDAS PELO MINISTÉRIO DA SAÚDE NO ATENDIMENTO DE DETERMINAÇÃO JUDICIAL (continuação)

Aquisição

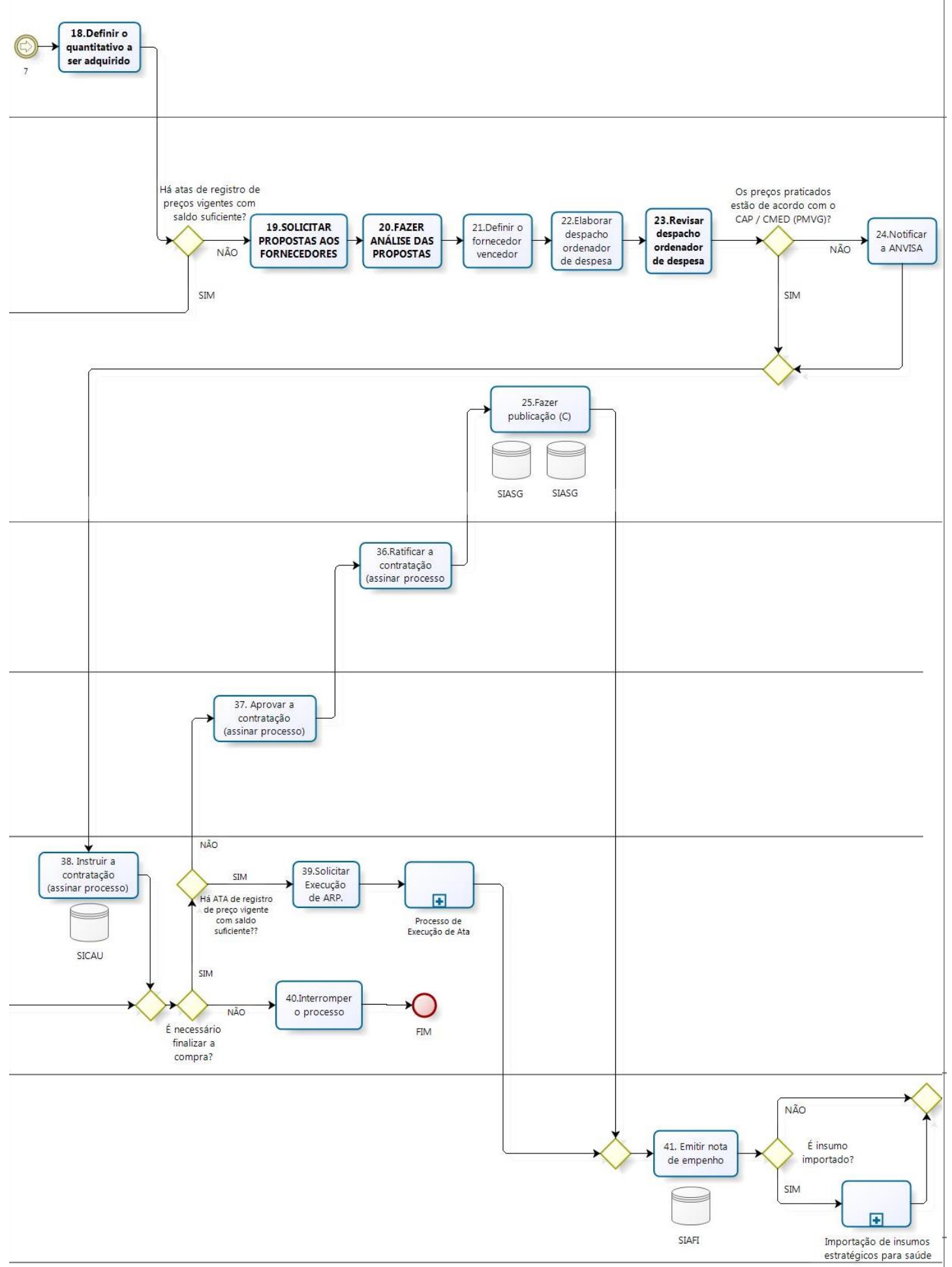


APÊNDICE C - FLUXOGRAMA DAS ATIVIDADES DESENVOLVIDAS PELO MINISTÉRIO DA SAÚDE NO ATENDIMENTO DE DETERMINAÇÃO JUDICIAL (continuação)

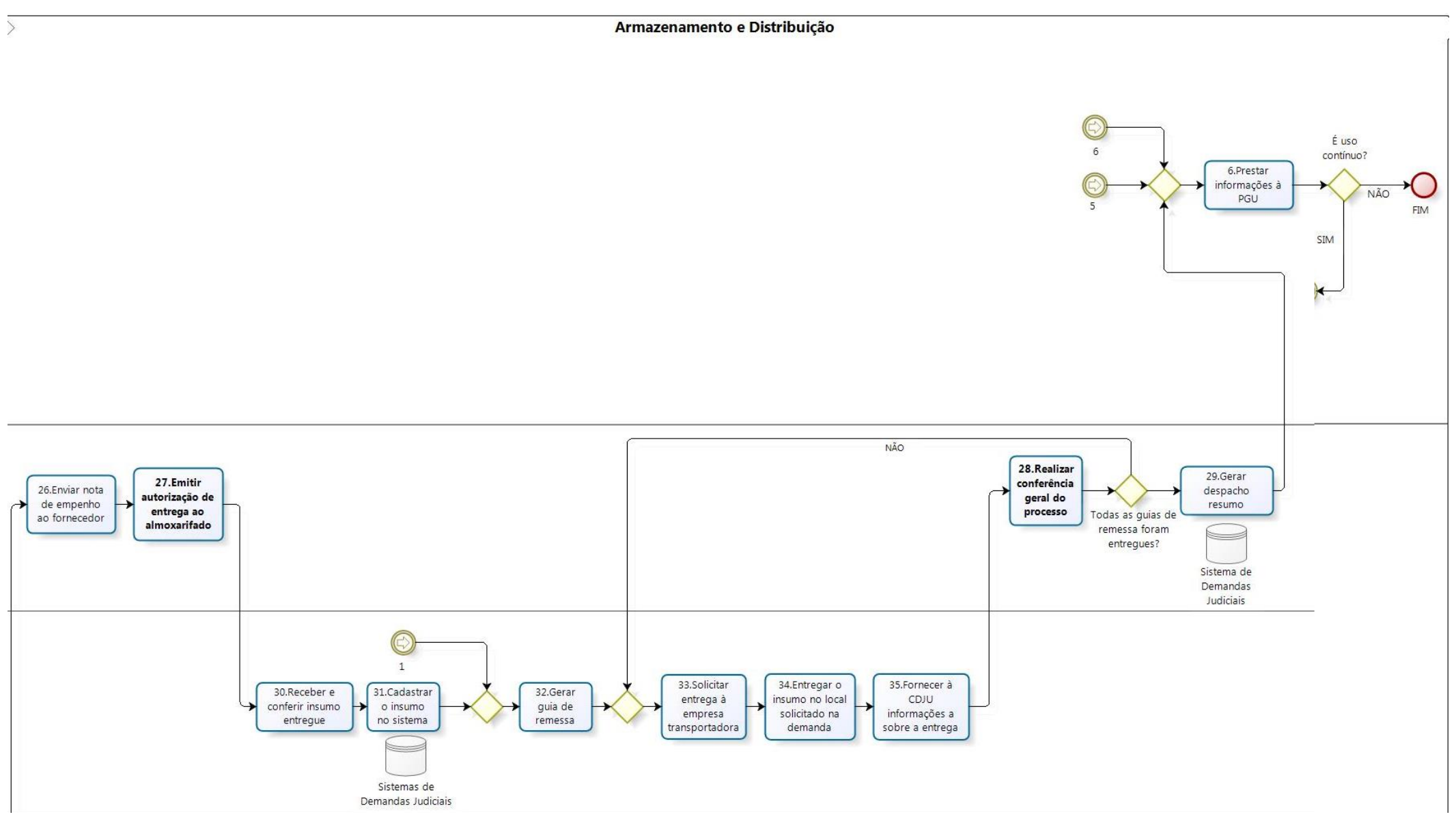

